\title{
Mahshid Moradi
}

\section{Health-related quality of life and disease burden of psoriasis in Iran}




\title{
Department of Health Economics
}

\section{Supervisors:}

\author{
Prof. Márta Péntek, MD, PhD \\ Fanni Rencz, MD, MSc, PhD
}

(C) Mahshid Moradi 


\section{Corvinus University of Budapest}

\section{Doctoral School of Business and Management}

Health-related quality of life and disease burden of psoriasis in Iran

Ph.D. Thesis

Mahshid Moradi

Budapest, 2017 


\section{Table of Contents}

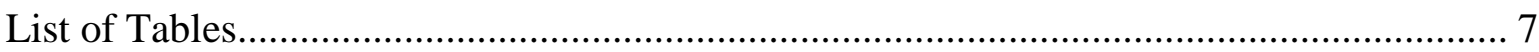

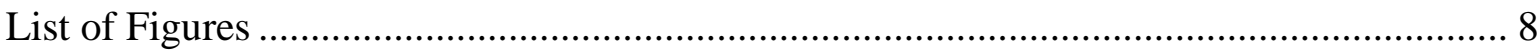

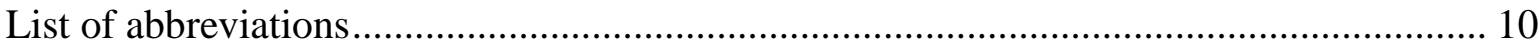

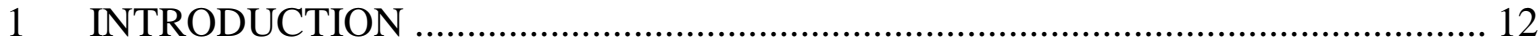

2 KEY TERMS AND DEFINITIONS OF THE THESIS …........................................ 15

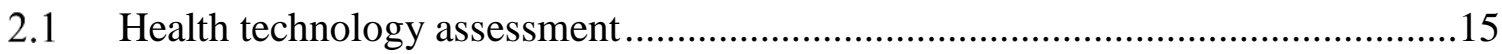

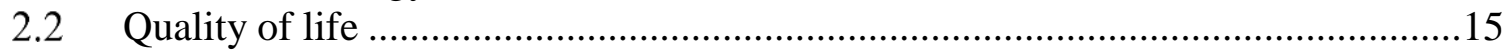

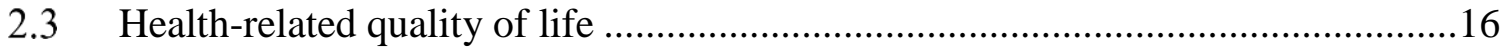

2.3.1 Disease-specific versus global assessment.................................................16

2.3.2 Clinical endpoints versus long-term outcomes .............................................17

2.3.3 Patient ratings versus proxy assessments .......................................................17

2.3.4 Objective versus subjective measures .........................................................17

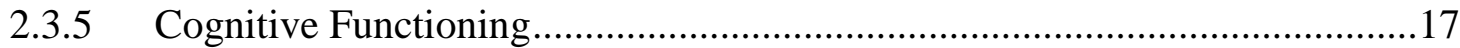

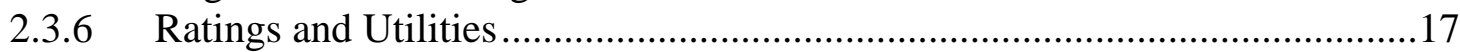

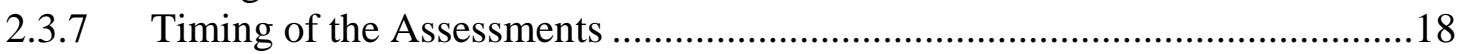

2.4 Quality-adjusted life year ...............................................................................18

2.5 Mapping from disease-specific measures to utilities ..........................................20

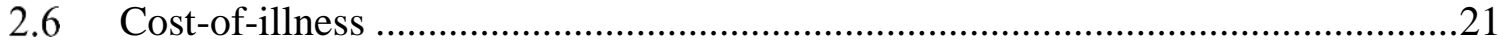

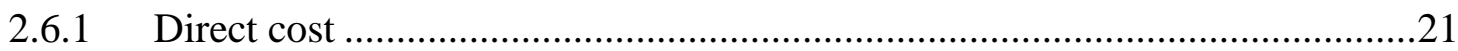

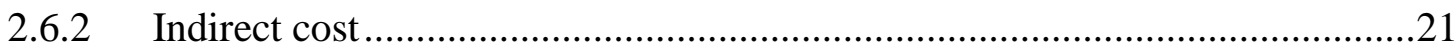

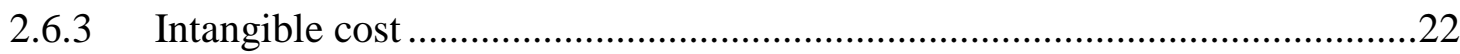

2.6.4 Cost-of-illness studies and their use in decision making ................................22

2.6.5 Costing approach.................................................................................24

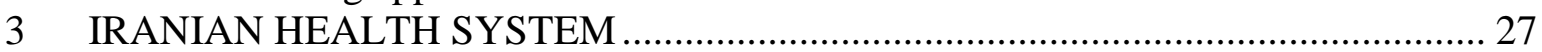

3.1 Demography and health status of the population in Iran.....................................27

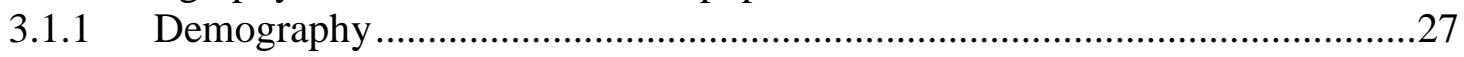

3.1.2 Causes of death and disability ................................................................... 31

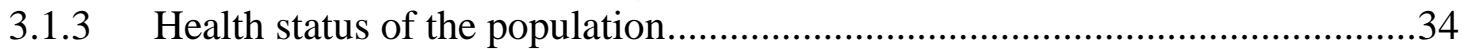

3.1.4 Comparison with countries of the region ......................................................36

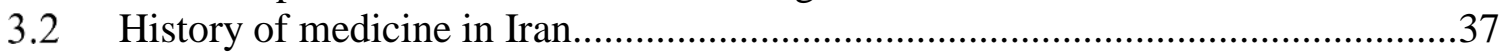

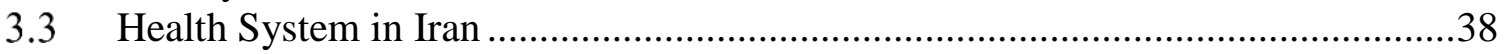

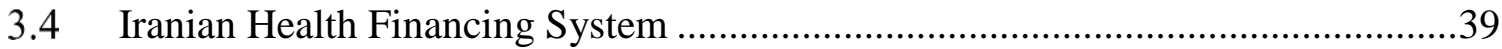

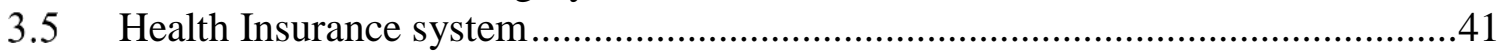

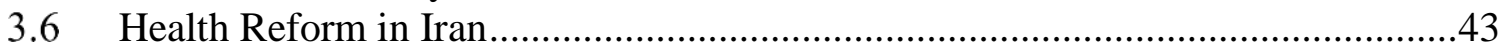

3.7 Health Sector Evolution Plan ...........................................................................

4 HEALTH POLICY AND HEATH TECHNOLOGY ASSESSMENT IN IRAN ....... 46

4.1 Health technology assessment in Iran ................................................................46

4.1.1 Pharmaceutical market and drug reimbursement decisions ............................50

4.1.2 Current pharmaceutical market .............................................................52

4.1.3 Drug reimbursement in Iran .................................................................5

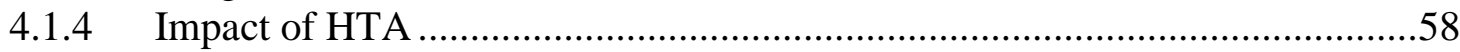


5 AN EMPIRICAL INVESTIGATION INTO THE CONCEPT OF HEALTH ........... 61

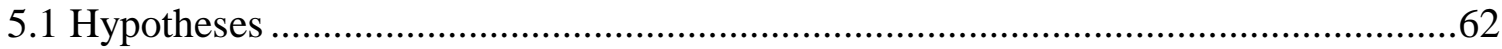

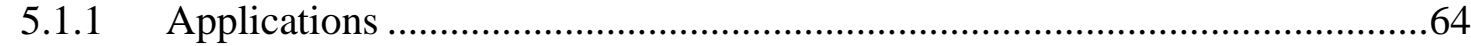

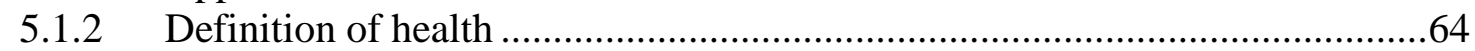

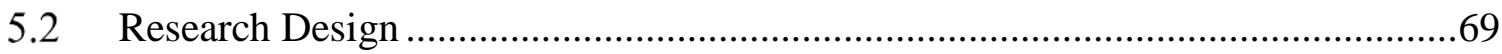

5.2.1 Instructions for scoring each factor ................................................... 70

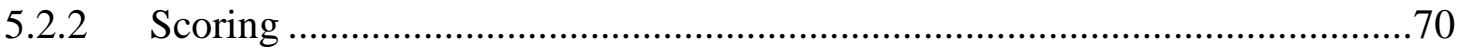

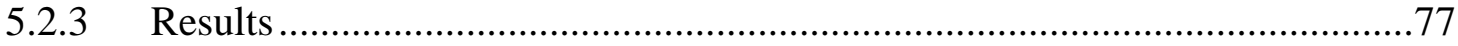

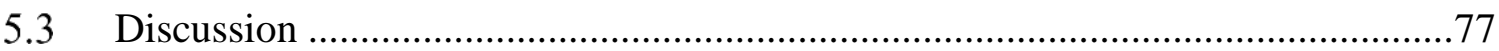

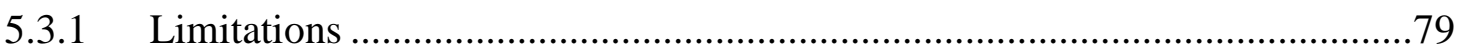

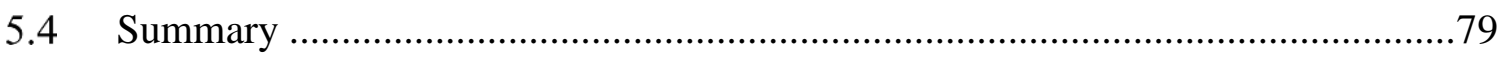

6 HEALTH-RELATED QUALITY OF LIFE AND COST-OF-ILLNESS OF

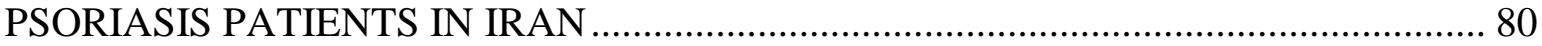

6.1 Description of the discussed health problem - psoriasis.................................. 80

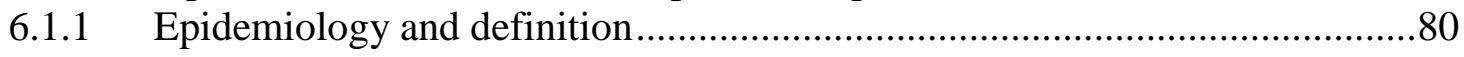

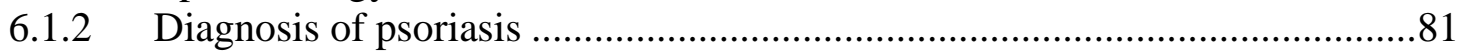

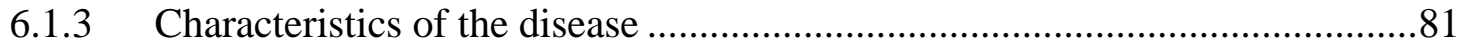

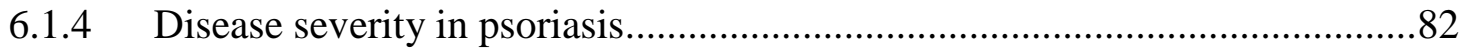

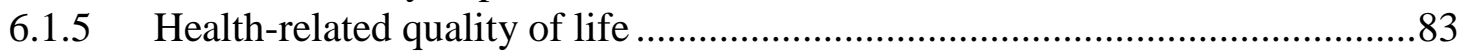

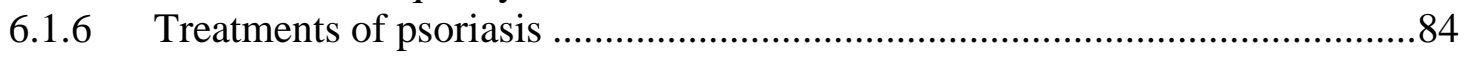

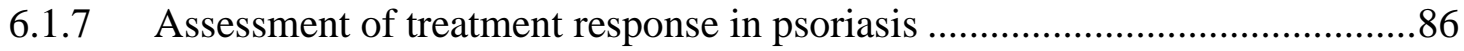

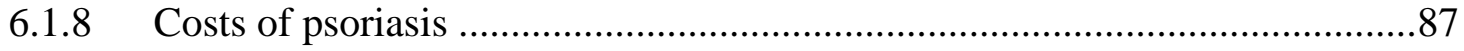

6.1.9 Health-related quality of life and disease burden studies of psoriasis in Middle

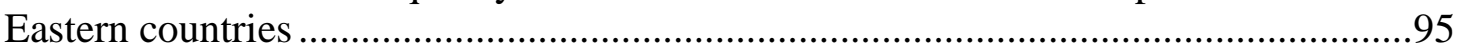

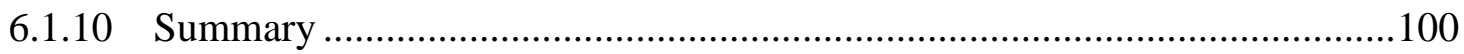

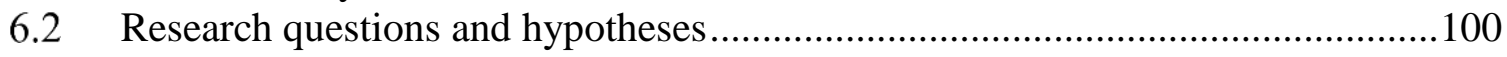

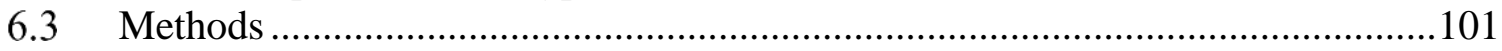

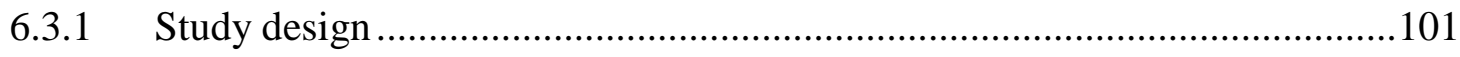

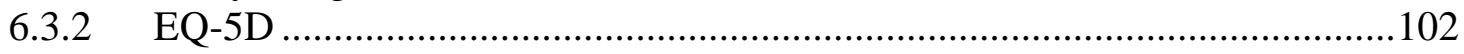

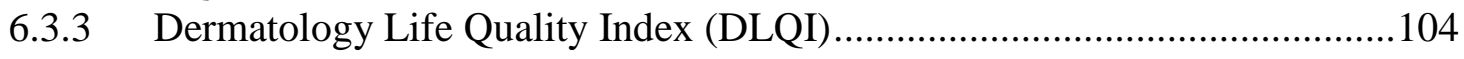

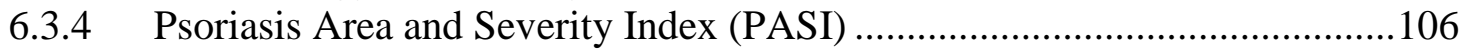

6.3.5 Physician's global assessment visual analogue scale .................................108

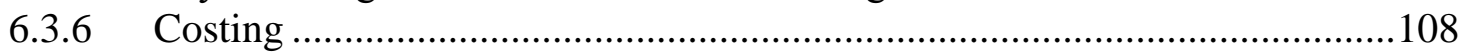

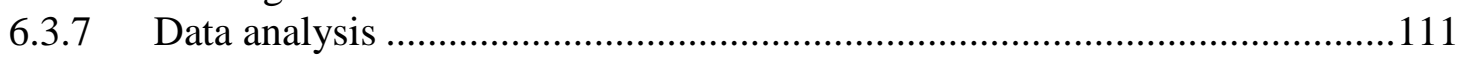

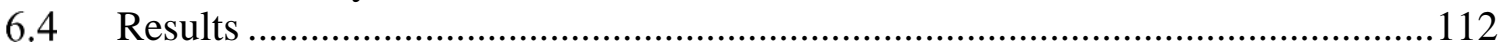

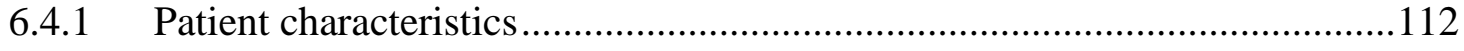

6.4.2 Health-related quality of life and disease severity ...................................114

6.4.3 Comparison of HRQOL in psoriasis patients to the Iranian general

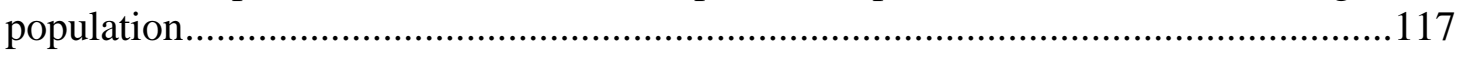

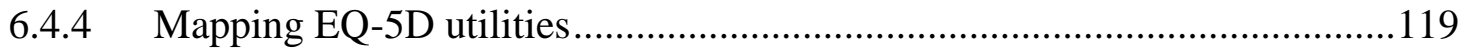

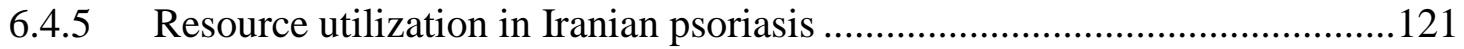

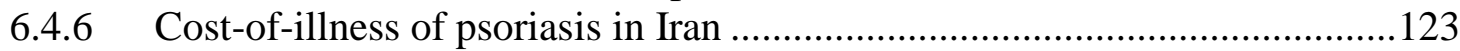

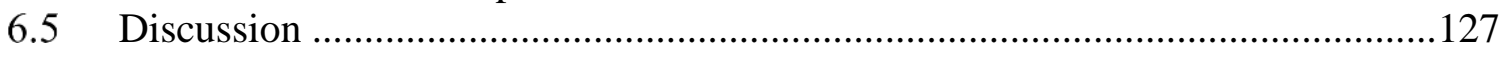

6.5.1 Comparison with previous studies on HRQOL from Iran ..........................127 
6.5.2 Comparison of HRQOL findings between the findings of Iranian and the Hungarian study 129

6.5.3 International comparison of HRQOL results ............................................. 131

6.5.4 Comparison with other EQ-5D studies in Iran..........................................134

6.5.5 Comparison of cost-of-illness in psoriasis patients in Iran and Hungary .....136

6.5.6 Comparison of cost-of illness of psoriasis and other diseases in Iran...........137

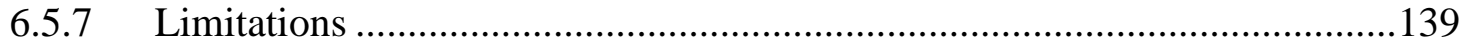

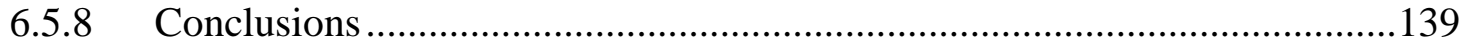

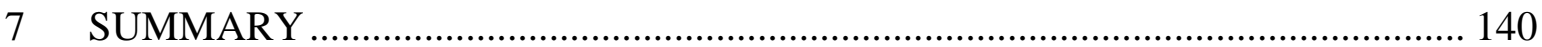

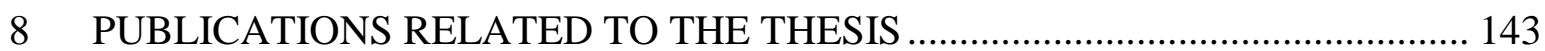

Published papers................................................................................................... 143

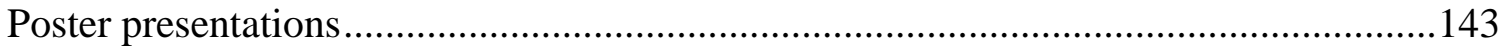

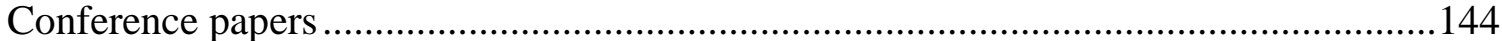

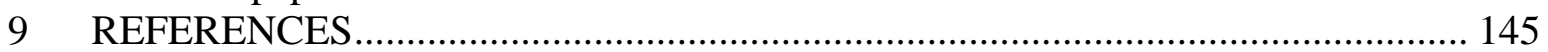

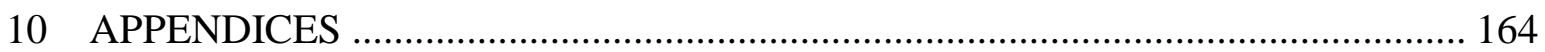

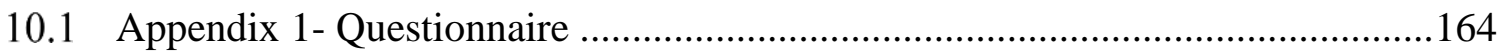

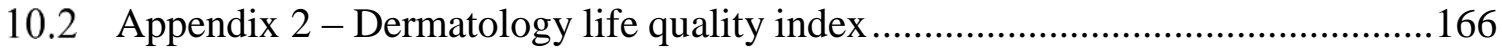

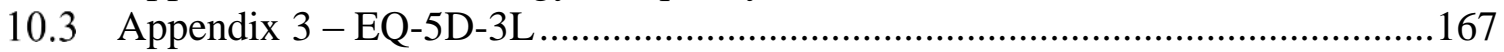




\section{List of Tables}

Table 1 Direct and indirect costs of chronic conditions - some examples ........................22

Table 2 Costs included in cost-of-illness (COI) studies using different perspectives ..........24

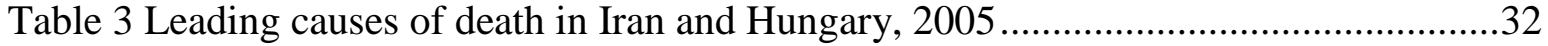

Table 4 Leading causes of death in Iran and Hungary, 2015 ........................................32

Table 5 Leading causes of disability in Iran and in Hungary, 2005 ..................................33

Table 6 Leading causes of disability in Iran and in Hungary, 2015 ..................................34

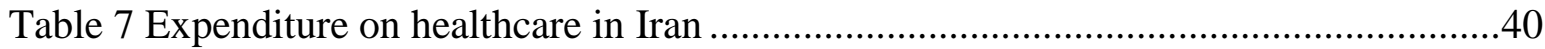

Table 8 Iran Pharmaceutical Industry's SWOT Analysis..........................................54

Table 9 Headline Pharmaceuticals \& Healthcare Forecasts (Iran 2014-2020) ...................55

Table 10 List of factors the authors could choose to ask the participants to find the most relevant to the most irrelevant factor which contribute to health in general......................69

Table 11 Calculation of factors based on the participants' answers $1-9$............................71

Table 12 Calculation of factors based on the participants' answers $10-18 \ldots \ldots \ldots \ldots \ldots \ldots \ldots \ldots . . . . . . . . . .71$

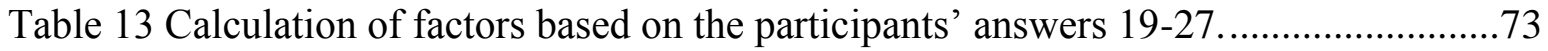

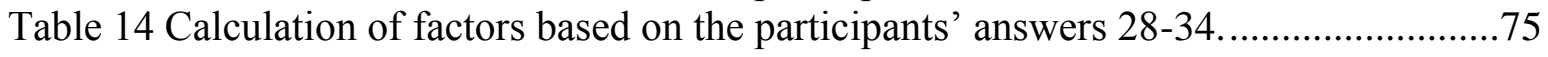

Table 15 Outcome measures suggested to be used in psoriasis by the EMA ....................87

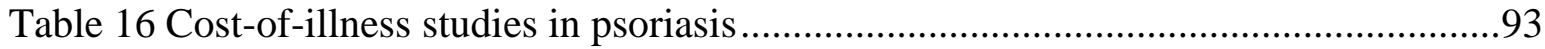

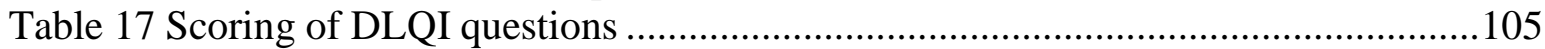

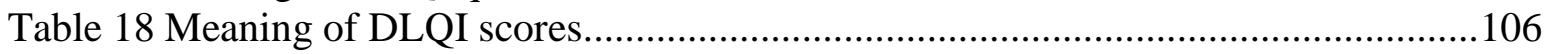

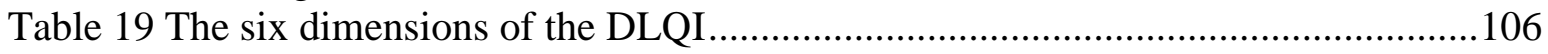

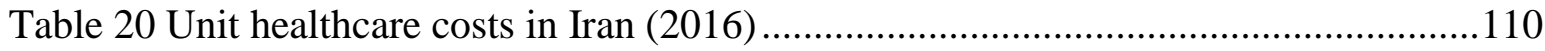

Table 21 Characteristics of the psoriasis patient population $(n=62) \ldots \ldots \ldots \ldots \ldots \ldots \ldots \ldots \ldots \ldots . . . . . . . . . . . . . .113$

Table 22 Quality of life and disease severity of the Iranian psoriasis patients ...................114

Table 23 Subgroup analysis of EQ-5D, EQ VAS, DLQI and PASI scores ......................116

Table 24 Spearman's correlations between the outcome measures ................................117

Table 25 Healthcare resource utilization in psoriasis patients .....................................121

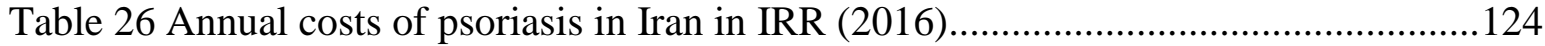

Table 27 Annual costs of psoriasis in Iran in EUR (2016) .......................................... 125

Table 28 Characteristics of the Hungarian and Iranian patients .....................................129

Table 29 Health-related quality of life and disease severity of Hungarian and Iranian patients

Table 30 Spearman's correlations between the outcome measures in Iran and Hungary...131

Table 31 Comparison of the relationship between EQ-5D, DLQI and PASI with previous

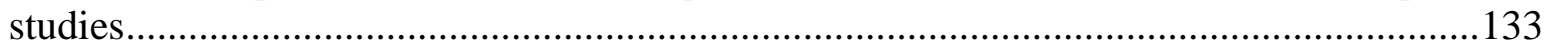

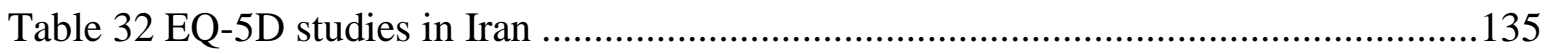

Table 33 Comparison of annual cost in psoriasis in Iran and Hungary ...........................136

Table 34 Recent cost-of-illness studies in Iran ...........................................................138 


\section{List of Figures}

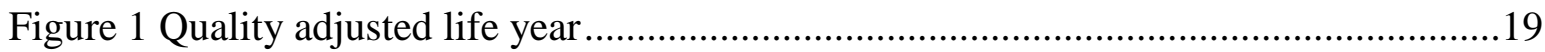

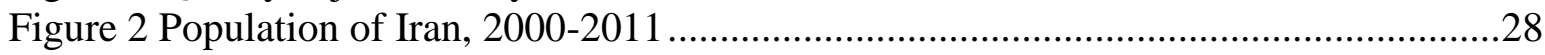

Figure 3 Population of Iran aged less than 15 and 65 and over, 2006-2011 .......................28

Figure 4 Population of Iran: demographic trees 1950-2050 …………………….............29

Figure 5 Male population age structure in Iran and Hungary, 2016 ………………............30

Figure 6 Female population age structure in Iran and Hungary, 2016................................31

Figure 7 Health status of the general population by age-groups in Iran ................................35

Figure 8 Health status of the general population by age-groups in Hungary..........................36

Figure 9 Health-adjusted life-expectancy in 20 countries of the region, 2010 ......................37

Figure 10 Pharmaceutical Market Forecast (2011-2025)...................................................56

Figure 11 The volume market size of pharmaceutical products in Iran.................................57

Figure 12 The volume market size of pharmaceutical products in Iran................................57

Figure 13 Possible degrees of health..............................................................................61

Figure 14 Search strategy used in PubMed for quality of life and cost-of-illness studies in psoriasis in 20 selected countries in the Middle Eastern region ..........................................95

Figure 15 Proportion of the patients reporting problem in EQ-5D domains ......................115 Figure 16 Comparison of the proportion of problems across the five domains of the EQ-5D$3 \mathrm{~L}$ in psoriasis patients and the age-matched general population.....................................118

Figure 17 Scatterplot and a linear relationship between EQ-5D and DLQI .......................120

Figure 18 Scatterplot and a linear relationship between EQ-VAS and DLQI ....................120

Figure 19 Informal care utilization in psoriasis patients (hours/week) ...............................122

Figure 20 Absenteeism in psoriasis patients (hours/week) ...............................................122

Figure 21 Presenteeism in psoriasis patients (hours/week) ..............................................123

Figure 22 Distribution of cost across cost categories in psoriasis in Iran ............................126 


\section{Acknowledgement}

This dissertation could not have been completed without the great support that I have received from many people over the years. I wish to offer my most heartfelt thanks to the following people.

First, I would like to express my special appreciation and thanks to my supervisors Prof. Dr. Márta Péntek and Dr. Fanni Rencz whose expertise, understanding, and patience, added considerably to my graduate experience. Their vast knowledge and their guidance helped me extensively in conducting this research.

Besides my supervisors, my sincere thanks also go to Prof. Dr. László Gulácsi. Without his precious support it would not be possible to conduct this research.

To all of them, I doubt that I will ever be able to convey my appreciation fully, but I owe them my eternal gratitude.

My sincere thanks also go to Prof. Dr. Ágnes Zsóka whose support, encouragement, and advice kept me going through this journey.

I would like to thank Prof. Dr. Sándor Kerekes for all his help and support. You are the one professor who truly made a difference in my life.

I thank Ms. Szilvia Nárai and Ms. Zsuzsa Krista for keeping their office door open and being available all the times.

Additionally, I would like to thank my fellow PhD student, Ms. Zsuzsanna Beretzky.

Finally, and most importantly, I would like to thank my family for the support they provided me through my entire life. My parents, my sisters, my brother, and my husband, Vahid who are the most important people in my world and I dedicate this thesis to them. 


\section{List of abbreviations}

\begin{tabular}{|c|c|}
\hline BDI & Beck Depression Inventory \\
\hline BIA & Budget impact analysis \\
\hline BIS & Body Image Satisfaction Scale \\
\hline BMI & Body mass index \\
\hline BOD & Burden of disease \\
\hline BSA & Body surface area \\
\hline $\mathbf{C B A}$ & Cost-benefit analysis \\
\hline CEA & Cost-effectiveness analysis \\
\hline CD & Crohn's disease \\
\hline CI & Confidence Interval \\
\hline COI & Cost-of-illness \\
\hline CECS & Courtauld Emotional Control Scale \\
\hline DBPRC & Drug Benefit Package Review Committee \\
\hline DLQI & Dermatology Life Quality Index \\
\hline DQOLS & Dermatology Quality of Life Scales \\
\hline EMA & European Medicines Agency \\
\hline HAD & Hamilton Anxiety-Depression Scale \\
\hline HCA & Human capital approach \\
\hline HIC & Higher Insurance Council \\
\hline HIOs & Health Insurance Organizations \\
\hline HRQOL & Health-related quality of life \\
\hline HSEP & Health Sector Evolution Plan \\
\hline HTA & Health technology assessment \\
\hline IFDA & Iran Food and Drug Administration \\
\hline IHME & Institute of Health Metric and Evaluation \\
\hline INN & International Nonproperty Names \\
\hline
\end{tabular}


IML

LSS

MCDM

MoHME

MSIO

MTX

P4P

PASI

PDI

PHC

PGA

PLSI

PQLQ

PsA

PSORIQOL

PUVA

QALY

QOL

RCT

SCoHI

SF-6D

SF-36

STAI I-II

T2DHPS

TSS

VAS

WHO

WHOQOL WPAI
Iran Medicine List

Life Satisfaction Scale

Multiple Criteria Decision Making

Ministry of Health and Medical Education

Medical Services Insurance Organization

Methotrexate

Pay for performance

Psoriasis Area Severity Index

Psoriasis Disability Index

Primary Health Care

Physician's Global Assessment

Psoriasis Life Stress Inventory

Psoriasis Quality of Life Questionnaire

Psoriatic arthritis

Psoriasis index of quality of life

Psoralen and UltraViolet A (photochemotherapy)

Quality-adjusted life year

Quality of life

Randomized Controlled Trial

Supreme Council of Health Insurance

Short form 6 dimensions

Medical Outcomes Study 36-Item Short Form

Spielberger State-Trait Anxiety Scale

Type 2 Diabetes and Health Promotion Scale

Total severity sign score

Visual analogue scale

World Health Organization

World Health Organization Quality of Life Assessment

Work Productivity and Activity Impairment 


\section{INTRODUCTION}

The concept of health has dynamically been changing by rise of new needs and diversity in human preferences. Also by improvement of life expectancy from the beginning of $20^{\text {th }}$ century, the concept of health for the person and the society has evolved. Advancements in science and technology has made this possible and has changed human needs. For example, fear of dying has changed to dedication to survival and living healthier for a longer time.

Longer life expectancy leads to larger population of elderly people with higher chance of chronic health problems. Economic evaluation is vital, to make value for money when utilizing resources and achieve higher efficiency and effectiveness in decision-making. In order to avoid unfeasible and suboptimal decisions, a careful analysis of all aspects including costs and consequences is needed. Decision-making that are based on preferences for health states, along with the economic analysis focused on the patient's and societal perspective, can improve the distribution of finite resources in the face of a growing and increasingly challenging demand.

New innovative health technologies are developed, often very effective but rather costly. The fourth hurdle, i.e., requirement of effectiveness and cost-effectiveness data for drug coverage policy decisions, became highly relevant even in economically developed countries. (Gulacsi et al., 2004).

Health technology assessment (HTA) is now an established input to healthcare decisionmaking and has been introduced in many countries. HTA involves health economic evaluation that requires input data considering local aspects such as characteristics of the health care system, clinical practice, patients' characteristics, individual and societal preferences in a given country.

Transferability of international results is often limited due to differences between countries and regions (costs differ, health states might differ, cultural differences might affect people's preferences), therefore economic evaluation conducted in one setting might not be applicable 
to another and as a consequence, country-specific evaluations are needed that reflect the needs of the decision-makers in that country.

HTA has been introduced in Iran, however country-specific input data both on health-related quality of life (HRQOL) and cost data for health economic evaluation are often missing.

The main aims of the studies of this thesis are the following:

- to explore notions of health among the general public as it may have implications for HRQOL assessments and decision making in healthcare, including both medical and resource allocation decisions

- to investigate HRQOL and cost-of-illness in a specific patient population, namely psoriasis and analyse the inter-country differences.

In the first part of the thesis followed this introduction (Chapter 1 Introduction), the key terms related to the empirical researches are described (Chapter 2 Key terms and definitions of the thesis). Afterwards, a description of the Iranian health care system is provided (Chapter 3 Iranian health system) as well as a policy analysis of the development of the Iranian HTA based on extensive literature review (Chapter 4 Health policy and health technology assessment in Iran).

The focus of the empirical research of this thesis is on HRQOL, i.e. how individuals or a group perceive physical and mental health and social well-being over time. This subjective perception can be influenced by several factors, including their beliefs, subjective expectations, previous experiences, cultural and religious attitudes, personality-related factors. Moreover, it can vary individually or regionally.

The first empirical study of this thesis (Chapter 5: An empirical investigation into the concept of health) aimed to explore people's perception on health, which aspects of health are the most relevant for the individuals. It can have implications on HRQOL research and preference measurement. 
The second empirical study (Chapter 6: Health-related quality of life and cost-of-illness of psoriasis patients in Iran) involved a cross-sectional survey in Iran among patients with a chronic dermatological disease, namely psoriasis. This study was part of a psoriasis research project leaded by researchers at Corvinus University; most of it was conducted in Hungary. Psoriasis is of high interest due to its prevalence, impact on patients' HRQOL and, from the economic point of view, due to the costly biological drugs. Biological drugs have speeded up HRQOL and cost-of-illness (COI) research in psoriasis in many countries - measure health outcomes considering patients' preferences (HRQOL measurement), costeffectiveness, budget impact issues and affordability. The aims of the study were on the one hand, to assess patients HRQOL and to assess the relationship between disease-specific and generic HRQOL measures in order to provide local data for health economic analyses, to compare the results with other countries and thus provide a basis for transferability analyses. On the other hand, and I find it equally important, this experiment can serve also as useful test how brief cross-sectional surveys developed in a European country (namely in Hungary) can be applied in and adapted to Iran in terms of feasibility and applicability in order to obtain comparable data in the context of limited research resources and to strengthen international collaboration.

The results of the thesis clearly show the usefulness and increasing importance of health economics in health policy and financial decision making.

Finally, all the results and policy implications are discussed in the last chapter (Chapter 7 Summary). 


\section{KEY TERMS AND DEFINITIONS OF THE THESIS}

In this section, I provide a brief introduction to the main terms used in the thesis.

\subsection{Health technology assessment}

Health technology assessment (HTA) has been defined as "a form of policy research that systematically examines the short- and long-term consequences, in terms of health and resource use, of the application of a health technology, a set of related technologies or a technology related issue". (Henshall et al., 1997)

The focus of HTA is mostly on the medical, organizational, economic and societal consequences of implementing health technologies or interventions within the health system. Thus, HTA is a multidisciplinary activity. It systematically evaluates the effects of a technology on health. It also evaluates the effects of a technology on the availability and distribution of resources and on other aspects of health system performance such as equity and responsiveness. (Garrido et al., 2008) Goodman (2004) states that the goal of HTA is to notify policymaking for technology in health care, where policymaking is used in the broad sense to include decisions made at various levels. For example, , the individual or patient level, the level of the health care provider or institution, or the regional, national and international are the mentioned levels. (Goodman, 2004)

\subsection{Quality of life}

Quality of Life according to World Health Organization's (WHO) definition is an ["individual's perception of their position in life in the context of the culture and value systems in which they live and in relation to their goals, expectations, standards and concerns"] (1995). Different factors can play a role in quality of life according to personal preferences. These factors are, for instance, financial security, job satisfaction, family life, 
health and safety. When quality of life is considered in the context of health and disease, it is commonly referred to as health-related quality of life (HRQOL) to differentiate it from other aspects of quality of life. (Lipscomb et al., 2004)

\subsection{Health-related quality of life}

Strategies and processes for the effective dissemination and diffusion of research findings on health-related quality of life (HRQOL) into practical applications were explored at a workshop held in Montreal in April, 1994 by Wilson and Cleary. Wilson and Cleary published their seminal conceptual model of HRQOL, which provides a causal pathway linking traditional clinical variables to HRQOL. (Till et al., 1994, Shiu et al., 2014, Wilson\&Cleary, 1995) The Wilson \& Cleary model of HRQOL was further revised by Ferrans et al. in 2005. (Ferrans et al., 2005) A conceptual model for dissemination and diffusion of evidence about HRQOL was used to identify five different target groups: HRQOL assessors, policy makers, planners of clinical trials, developers of clinical practice guidelines, and those at the level of patient-practitioner clinical decision making. (Till et al., 1994) HRQOL is a multidimensional construct covering physical, psychological with social functioning and well-being that includes both negative and positive aspects.

HRQOL has a focus on the effects of illness and specifically on the impact; treatment may have on Quality of life (QOL). QOL is therefore appears to be a broad and idiosyncratic construct affected only moderately by health. (Feldman et al., 2000)

To select measures for evaluating HRQOL, seven issues can be addressed, as follow:

\subsubsection{Disease-specific versus global assessment}

Measures may concentrate on the symptoms, complaints, disabilities, and distributions in life that are specific to the clinical condition under study. The disease-specific approach has been recommended in the study of arthritis, heart disease, and the evaluation of chemotherapy. Instead, global assessment, evaluate the quality of life resulting from the overall consequences of disease and management on the functional capacities and patients' perception of well-being. (Medicine\&Technology, 1989) 


\subsubsection{Clinical endpoints versus long-term outcomes}

Clinical endpoints usually used for evaluating prognoses include evidence of improvement following intervention, remission of disease, and recurrence. Long-term outcomes can be viewed as crucial to patients as they live with their resulting states of health. (Medicine\&Technology, 1989)

\subsubsection{Patient ratings versus proxy assessments}

Preferably quality of life is reported by the patients themselves. When patients are not able to provide information regarding their health status (e.g., children, patients with cognitive problems), proxies (which include close family members or health care professionals) can provide the needed information on behalf of the patient. (Punjabi, 2008)

\subsubsection{Objective versus subjective measures}

Objective measures include indicators of health and living conditions, socio-demographic items and role functioning. (Yamauchi et al., 2008) Objective measures can be observed and recorded by various testing procedures and assessors. Whereas, subjective indicators measure life satisfaction in general and within different life domains. Subjective measures provide opportunities for individuals to express their thoughts, knowledge, attitudes, moods, and feelings. (Yamauchi et al., 2008, Medicine\&Technology, 1989)

\subsubsection{Cognitive Functioning}

Cognitive functions are detected by studying behavior in defined stimulus-response situations. (Daliento et al., 2006)

\subsubsection{Ratings and Utilities}

As Schuessler and Fisher (1985) indicate, quality of life measures provide ratings or rankings of health and life. Some assessments attempt to move from states of health to judgments of 
the worth or value of life with a given state of health. (Schuessler\&Fisher, 1985, Medicine\&Technology, 1989)

Analyzers are designing measures of the utilities of health states, with the typical scores ranging from 0 to 1 ("Death" to "Normal Health"). By multiplying the utility values by the number of years individuals live with a given health state, survival time can be demonstrate in Quality-Adjusted Life Years (QALY). Health economists have used this approach to compare technologies in terms of costs per QALY gained. Utility measures move the measurement of quality of life from rankings to judgments of worth and value. (Medicine\&Technology, 1989)

\subsubsection{Timing of the Assessments}

Measures like the linear analogue self-assessment scales or the Functional Living Index, are designed for repeated use before, during, and immediately after treatment. The purpose of the repeated measures is to evaluate patients' short-term responses during the course of therapy. (Medicine\&Technology, 1989)

\subsection{Quality-adjusted life year}

Three different approaches to measuring quality of life are global scales, multi-attribute utility scales and multidimensional scales. Each of these approaches provides different kinds of information about quality of life and each can be used to provide information to healthcare purchasers concerning the relative value-for-money of health interventions. The value-formoney of health interventions, in terms of quality of life, can be demonstrated in 2 ways: a formula-driven approach based on cost-utility analysis, which uses scales generating the unit of a quality-adjusted life year (QALY); and a non-formula-driven approach, which uses scales generating multidimensional profiles of quality of life. (Hyland, 1997)

The QALY is a widely used measure, which incorporates both quality and quantity of life. It is applicable to all individuals and diseases. (Whitehead\&Shehzad, 2010) QALYs are designed to aggregate in a single summary measure the total health improvement for a group 
of individuals, capturing improvements from impacts on both quantity of life and quality of life - with quality of life broadly defined. (Torrance\&Feeny, 1989)

QALYs are calculated by estimating the years of life remaining for a patient following a particular treatment or intervention and weighting each year with a quality of life score (on a 0 to 1 scale) that reflect the preference for the given health state, the so called utility. (Figure 1)

\section{Figure 1 Quality adjusted life year}

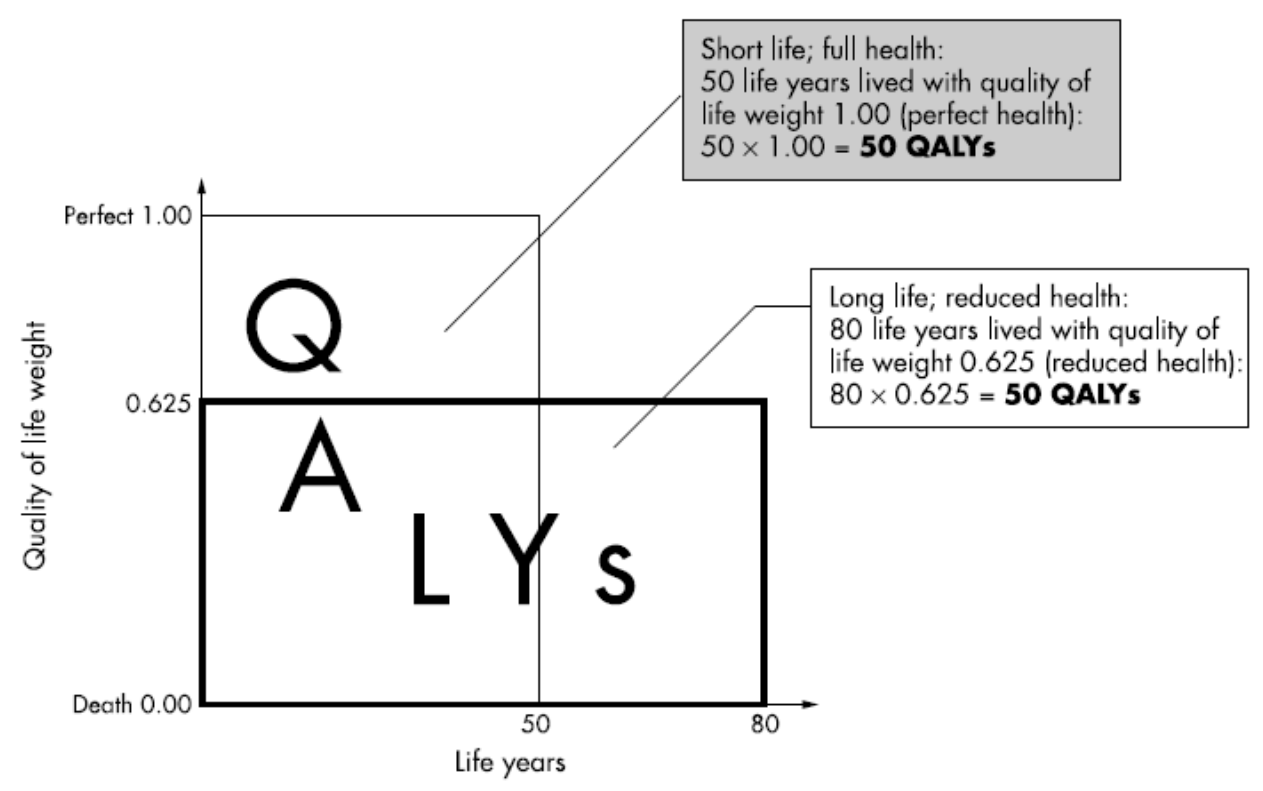

Source: (Arnesen\&Norheim, 2003)

Utilities are measured on a cardinal scale of $0-1$, where 0 indicates death and 1 indicates full health. Using the 'anchors' of 0 and 1, utility measurement is on an interval scale, where the same change means the same irrespective of the part of the scale being considered (e.g. a change in health from 0.2 to 0.3 is equivalent to a change from 0.8 to 0.9 ). States worse than 
death can also be accounted for, with such states taking a negative value. (Whitehead\&Shehzad, 2010)

One form of cost-effectiveness analysis, cost-utility analysis, allows the comparison of different health outcomes (such as prolongation of life, prevention of blindness or relief of suffering) by measuring them all in terms of a single unit — the QALY. (Mcgregor, 2003)

\subsection{Mapping from disease-specific measures to utilities}

The main purpose of mapping is to derive utility scores for non-preference-based measures to be used in economic evaluation. Therefore, to perform a mapping two data sets are necessary: first an estimation data set and second a study data set. The estimation data set includes information about both the target (preference-based) measure and the base (nonpreference-based) measure from the same population. In contrast, the study data set includes only the base measure. (Chuang\&Whitehead, 2012)

Mapping or cross-walking is a methodology used to estimate the relationship between a nonpreference-based measure and a generic preference-based measure (Brazier et al., 2010). In randomized controlled trials (RCTs), data on clinical effectiveness are typically collected on disease-specific measures, as these are more sensitive to changes in outcomes as a results of treatments. (Wiebe et al., 2003) Meanwhile, preference-based methods are rarely applied in RCTs; therefore, utilities for cost-effectiveness analyses are lacking. Mapping provides an alternative to translate scores of disease-specific measures into utility values. (Brazier et al., 2010, Lu et al., 2013)

Mapping process involves the following steps:

1. Regression methods should be use to get a statistical relationship between two measures that we have gathered. Therefore, through regression method we get a formula or algorithm.

2. The algorithm that we got from the regression result, then applied to the base measure in the study data set to obtain the predicted score of the target measure. 
3. Then finally, the predicted utility values are now ready for the study data set to conduct the required cost-utility analysis. (Chuang\&Whitehead, 2012)

\subsection{Cost-of-illness}

Cost-of-illness (COI), also known as burden of disease (BOD), is a definition that encompasses various aspects of the disease impact on the health outcomes in a country, specific regions, communities, and even individuals. (Jo, 2014) The aim of a cost-of-illness study is to identify, and measure all the costs of a particular disease, including the direct, indirect, and intangible dimensions. The output, expressed in monetary terms, is an estimate of the total burden of a particular disease to society. (Byford et al., 2000, Rice, 1994)

The quantifiable costs associated with human disease and illness are usually categorized into two unique components, including direct (medical and non-medical) and indirect costs. (Boccuzzi, 2003)

\subsubsection{Direct cost}

Direct costs consist of healthcare costs and non-healthcare costs (also called direct medical and non-medical costs). Direct health care costs refer to the healthcare expenditures for diagnosis, treatment, and rehabilitation, etc., while direct non-healthcare costs refer to the costs like transportation, household expenditures, relocating, property losses and informal costs of any kinds (Jo, 2014).

\subsubsection{Indirect cost}

Indirect cost in cost-of-illness studies refers to productivity losses due to morbidity and mortality, borne by the individual, family, society, or the employer. (Sherman et al., 2001, Jo, 2014). (Table 1) Indirect costs cannot be traced to a given cost object without resorting to some arbitrary method of assignment. (Cleverley\&Cameron, 2007) 
Table 1 Direct and indirect costs of chronic conditions - some examples

\begin{tabular}{|c|c|c|}
\hline \multicolumn{2}{|l|}{ Direct costs } & \multirow[t]{2}{*}{ Indirect costs } \\
\hline Direct healthcare costs & $\begin{array}{l}\text { Direct non-healthcare } \\
\text { costs }\end{array}$ & \\
\hline Doctor's office visits & $\begin{array}{l}\text { Care provided by nonpaid } \\
\text { caregivers }\end{array}$ & $\begin{array}{l}\text { Absenteeism of } \\
\text { employees who care } \\
\text { for family members }\end{array}$ \\
\hline Diagnostic testing & $\begin{array}{l}\text { Consumer health } \\
\text { education }\end{array}$ & $\begin{array}{l}\text { Loss of productivity at } \\
\text { work }\end{array}$ \\
\hline $\begin{array}{l}\text { Durable and nondurable } \\
\text { medical products }\end{array}$ & $\begin{array}{l}\text { Financial assistance to } \\
\text { persons with chronic } \\
\text { disease }\end{array}$ & Cessation of work \\
\hline $\begin{array}{l}\text { Hospital, nursing home and } \\
\text { home care services }\end{array}$ & $\begin{array}{l}\text { Housekeeping assistance } \\
\text { needed because of disease }\end{array}$ & $\begin{array}{l}\text { Restricted work } \\
\text { activity days }\end{array}$ \\
\hline Medications, immunizations & $\begin{array}{l}\text { Research and } \\
\text { construction of healthcare } \\
\text { facilities }\end{array}$ & \\
\hline $\begin{array}{l}\text { Physicians and other } \\
\text { professionals }\end{array}$ & $\begin{array}{l}\text { Transportation to and } \\
\text { from healthcare visits }\end{array}$ & \\
\hline $\begin{array}{l}\text { Treatment of general medical } \\
\text { conditions attributed to } \\
\text { condition }\end{array}$ & & \\
\hline
\end{tabular}

Source: (Cleverley\&Cameron, 2007)

\subsubsection{Intangible cost}

Intangible costs are usually the costs of pain, grief and suffering and loss of quality of life and these kind of costs cannot be quantified directly in monetary terms. (Jefferson et al., 2000) Intangible costs are often omitted because of the difficulty in accurately quantifying it in monetary terms. In such a case, the study should note that intangible costs have been omitted. (Joel E, 2006, Hodgson\&Meiners, 1982, Cooper\&Rice, 1976)

\subsubsection{Cost-of-illness studies and their use in decision making}

Health economic analyses are becoming increasingly important in healthcare systems due to the scarcity of resources in healthcare systems. Disease burden or cost-of-illness (COI) analysis was the first economic evaluation technique used in the field of health economics. 
The COI study is considered to be an essential evaluation technique in health care. By measuring and comparing the economic burdens of diseases to society, such studies can help health-care decision-makers to set up and prioritize health-care policies and interventions. $($ Jo, 2014)

COI studies serve a different purpose compared to other economic evaluations such as costeffectiveness analysis (CEA), and cost-benefit analysis (CBA) that mainly compare the costs and outcomes of an intervention. COI always presumes the hypothesis that the emerging cost is the expenditure that return as profit in case of a positive result, so it estimates the amount that could be saved if a disease were to be abolished. Additionally, COI findings offer a good basis for further CEA and CBA studies.

The usefulness of cost-of-illness as a decision-making tool has however been questioned since its inception. The main criticism came from welfare economists who rejected COIs because they were not grounded in welfare economics theory. (Tarricone, 2006) Other attacks related to the use of the human capital approach (HCA) to evaluate morbidity and mortality costs since it was said that the HCA had nothing to do with the value people attach to their lives. Finally, objections were made that COI could not be of any help to decision makers and that other forms of economic evaluation (e.g. cost-effectiveness, cost-benefit analysis) would be much more useful to those taking decisions and ranking priorities. Conversely, it is here suggested that COI can be a good economic tool to inform decision makers if it is considered from another perspective. COI is a descriptive study that can provide information to support the political process as well as the management functions at different levels of the healthcare organizations. (Tarricone, 2006) To do that, the design of the study must be innovative, capable of measuring the true cost to society; to estimate the main cost components and their incidence over total costs; to envisage the different subjects who bear the costs; to identify the actual clinical management of illness; and to explain cost variability. In order to reach these goals, COI need to be designed as observational bottomup studies. (Tarricone, 2006) 
Cost-of-illness studies may be conducted from different perspectives, which determine the types of cost included in the analysis. These perspectives may measure costs to society, the health care systems, participants and their families, and third party payers. (Table 2)

Table 2 Costs included in cost-of-illness (COI) studies using different perspectives

\begin{tabular}{|c|c|c|c|c|}
\hline Perspective & Medical cost & $\begin{array}{l}\text { Productivity } \\
\text { (due to } \\
\text { morbidity } \\
\text { and } \\
\text { mortality) } \\
\end{array}$ & $\begin{array}{l}\text { Non-medical } \\
\text { cost (time cost, } \\
\text { informal care, } \\
\text { transportation) }\end{array}$ & $\begin{array}{l}\text { Transfer } \\
\text { payment }\end{array}$ \\
\hline Societal & All & All & All & $\begin{array}{l}\text { Administration } \\
\text { cost and } \\
\text { excess burden } \\
\text { of taxes }\end{array}$ \\
\hline $\begin{array}{l}\text { Health care } \\
\text { system }\end{array}$ & All & - & - & - \\
\hline $\begin{array}{l}\text { Participants } \\
\text { and their } \\
\text { families }\end{array}$ & Out of pocket costs & $\begin{array}{l}\text { Lost wages or } \\
\text { household } \\
\text { production }\end{array}$ & $\begin{array}{l}\text { Out of pocket } \\
\text { costs amount } \\
\text { received }\end{array}$ & $\begin{array}{l}\text { Amount } \\
\text { received }\end{array}$ \\
\hline $\begin{array}{l}\text { Third party } \\
\text { payer }\end{array}$ & Covered cost & Covered cost & - & $\begin{array}{l}\text { Amount paid } \\
\text { by others }+ \\
\text { administration } \\
\text { cost }\end{array}$ \\
\hline
\end{tabular}

Source: (Weinstein et al., 1996, Joel E, 2006, Saha\&Gerdtham, 2013)

\subsubsection{Costing approach}

Cost-of-illness studies can be based on three different combinations of costing approaches: incidence or prevalence-based approaches, top-down or bottom-up approaches and prospective or retrospective approaches. (Tarricone, 2006)

\subsubsection{Incidence or prevalence-based approaches}

Prevalence-based COI analysis includes the total costs of prevalent cases of an illness or disease within a specified time period, in most cases one year, no matter when the disease 
first occurred. In other words, prevalence-based estimates are a cross-sectional view of costs associated with the illness. Prevalence-based estimates do not tell us how much can be saved by prevention. They only look at the annual costs of a disease, rather than costs of a disease over the course of a life.

Incidence studies refer to the new number of cases arising in a predefined period of time. (Tarricone, 2006) Unlike prevalence-based COI analysis, incidence-based COI analysis calculates the value of lifetime costs for new cases of the disease or illness. Incidence-based analyses are essential for calculating the value of prevention.

\subsubsection{Top-down versus bottom-up approaches}

Two approaches that are commonly used for quantifying the resources are the top-down (population-based) and the bottom-up (person-based) approach.

The top-down approach estimates economic costs by using aggregate data on mortality, morbidity, hospital admissions, general practice consultations, disease-related costs, and other health-related indicators. Various sources and types of data are used to calculate the fractions of resources used that can be attributed to each disease. Generally, this information is collected from national health care statistics, patient registers, insurance databases, etc. The bottom-up approach calculates the resources used and productivity loss in individuals with the health problem in question. The mean per-person costs are then extrapolated to the whole population with relevant epidemiological data. In this case, the patient sample size needs to be unbiased and representative of the national population. The bottom-up approach is more comprehensive and enables detection of the variability related to differences in important demographic characteristics between patients. (Tarricone, 2006, Larg\&Moss, 2011, Segel, 2006, Akobundu et al., 2006)

Incidence approach requires that the analysis be performed "from the bottom-up", totaling the lifetime costs of an illness. This, in turn, requires that input data be gathered at a level of detail much greater than that employed in the prevalence approach where, in general, the analysis is performed "from the top-down", allocating portions of a known total expenditure to each of several broad disease category. 


\subsubsection{Prospective versus retrospective COI studies}

In a retrospective approach, all the relevant events have already happened when the study starts, in which we just collect the data that are previously recorded. Conversely, in a prospective approach the relevant events have not already occurred at the beginning of the study, which means that the data collection needs to be done by following-up the patients over time. The prevalence- and incidence-based COI studies can be both performed either in prospective or retrospective way. (Jo, 2014, Tarricone, 2006) 


\section{IRANIAN HEALTH SYSTEM}

\subsection{Demography and health status of the population in Iran}

In this chapter basic characteristics of the population of Iran are presented, with special focus on main health indicators and health status. Some comparisons with Hungary are made in order to offer a background for the empirical research in psoriasis (see Chapter 6) which was conducted in these two countries and involved inter-country comparisons.

\subsubsection{Demography}

The total population of the Islamic Republic of Iran is dynamically growing, as it increased by 10 million between 2000 and 2011 (2017i) and was 79,109,000 in 2015 (WHO, 2017a).

Regarding the age-structure of the population, a dominance of age-group 25-54 years can be observed (0-14 years: 23.65\%; 15-24 years: 16.57\%; 25-54 years: 47.59\%; 55-64 years: $6.79 \%$; 65 years and over: 5.4\%). (Indexmundi, 2017a) The rate of inhabitants aged less than 15 is about 4-5 times higher than the inhabitants aged 65 and older, indicating a typically young population. 
Figure 2 Population of Iran, 2000-2011

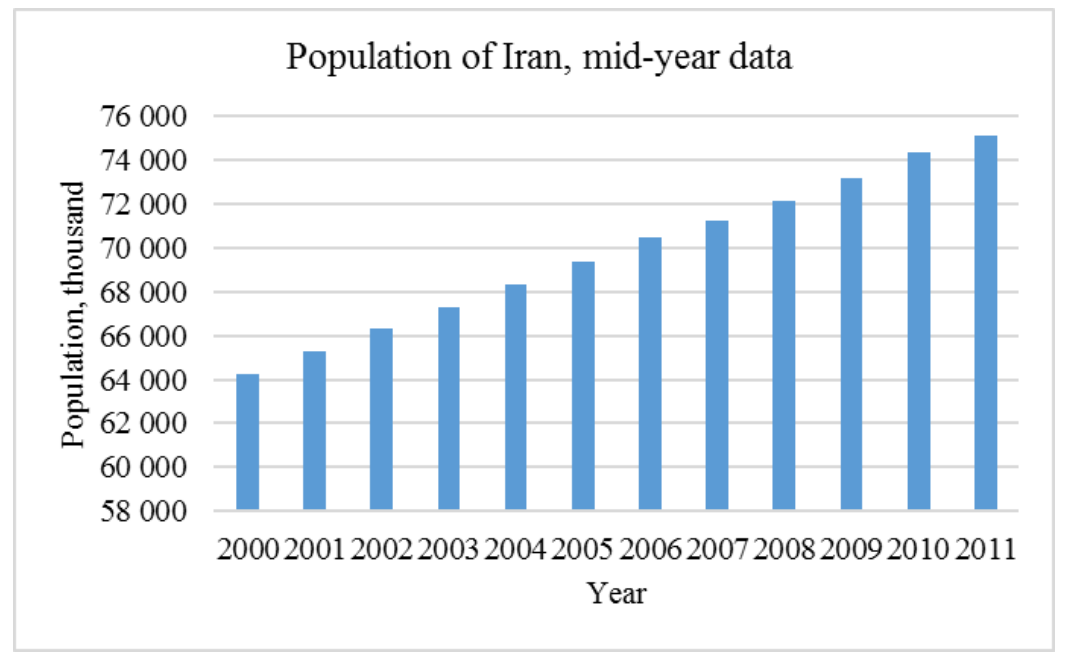

Source: Statistical Center for Iran (2017i)

Figure 3 Population of Iran aged less than 15 and 65 and over, 2006-2011

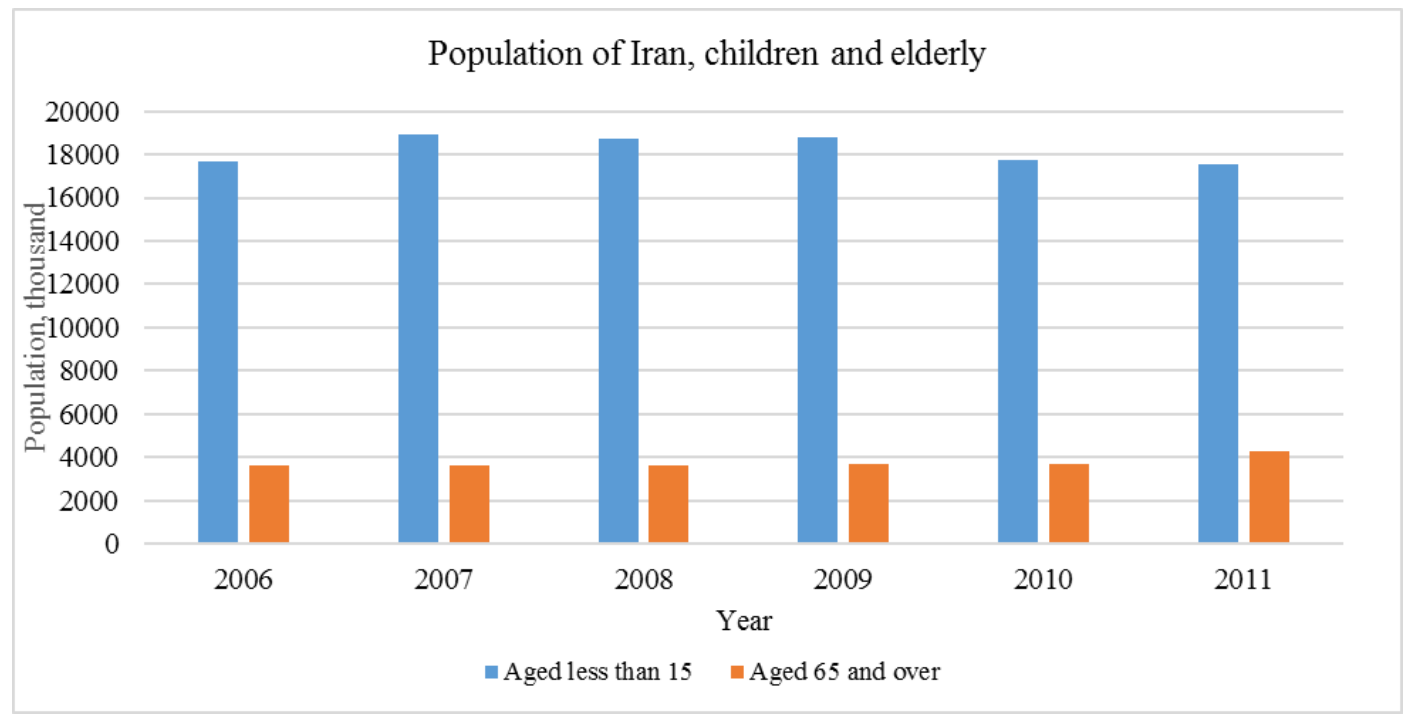

Source: Statistical Center for Iran (2017i) 
However, the population is ageing the projected age tree can be seen in Figure 4.

Figure 4 Population of Iran: demographic trees 1950-2050
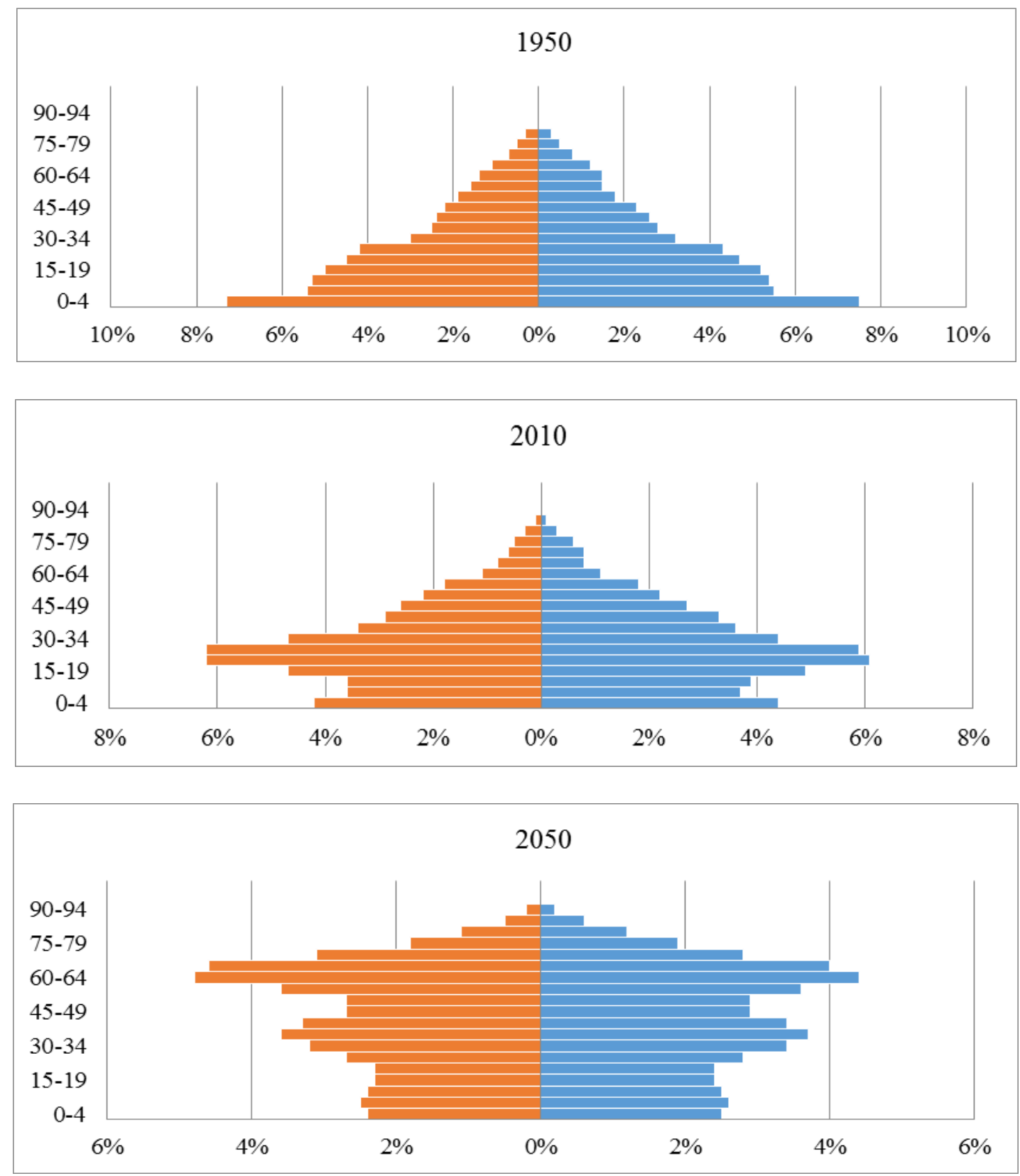

Source: United Nations population prospects data, (Basakha et al., 2014) 
Life expectancy at birth is increasing in Iran (GBD, 2016) and it was 72.1 years for males and 74.6 years for females in 2011. (2017i) The probability of dying between 15 and 60 years per 1000 population is 102 for males and 63 for females; the probability of dying under five per 1000 live birth is $17.53 \%$. Infant mortality rate per 1000 live birth is 13 (year 2015) (Figure 2 and Figure 3). For comparison, the population of Hungary is about eight times smaller than of Iran (9 830485 , year 2016) and it is decreasing. It represents a different age pattern characterized by the dominance of two age-groups (35-40 and 60-65) (Figure 5 and Figure 6).

Life-expectancy at birth in Hungary is rather similar compared to Iran (72.1 and 78.6 years for males and females, respectively) but the infant mortality rate per 1000 live birth is much lower (Hungary: 5, year 2015). (The WorldBank, 2017)

Figure 5 Male population age structure in Iran and Hungary, 2016

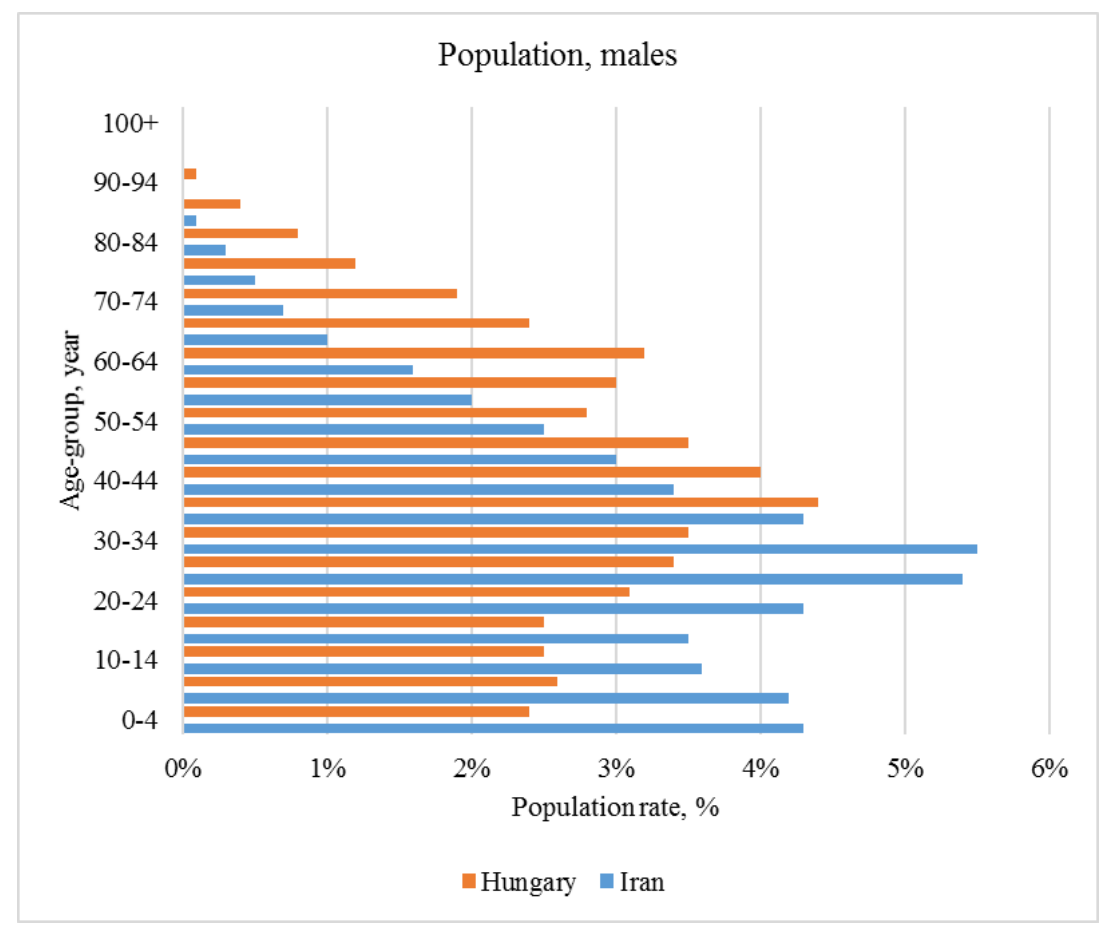

Source: PopulationPyramid.net (2016b, 2016a) 
Figure 6 Female population age structure in Iran and Hungary, 2016

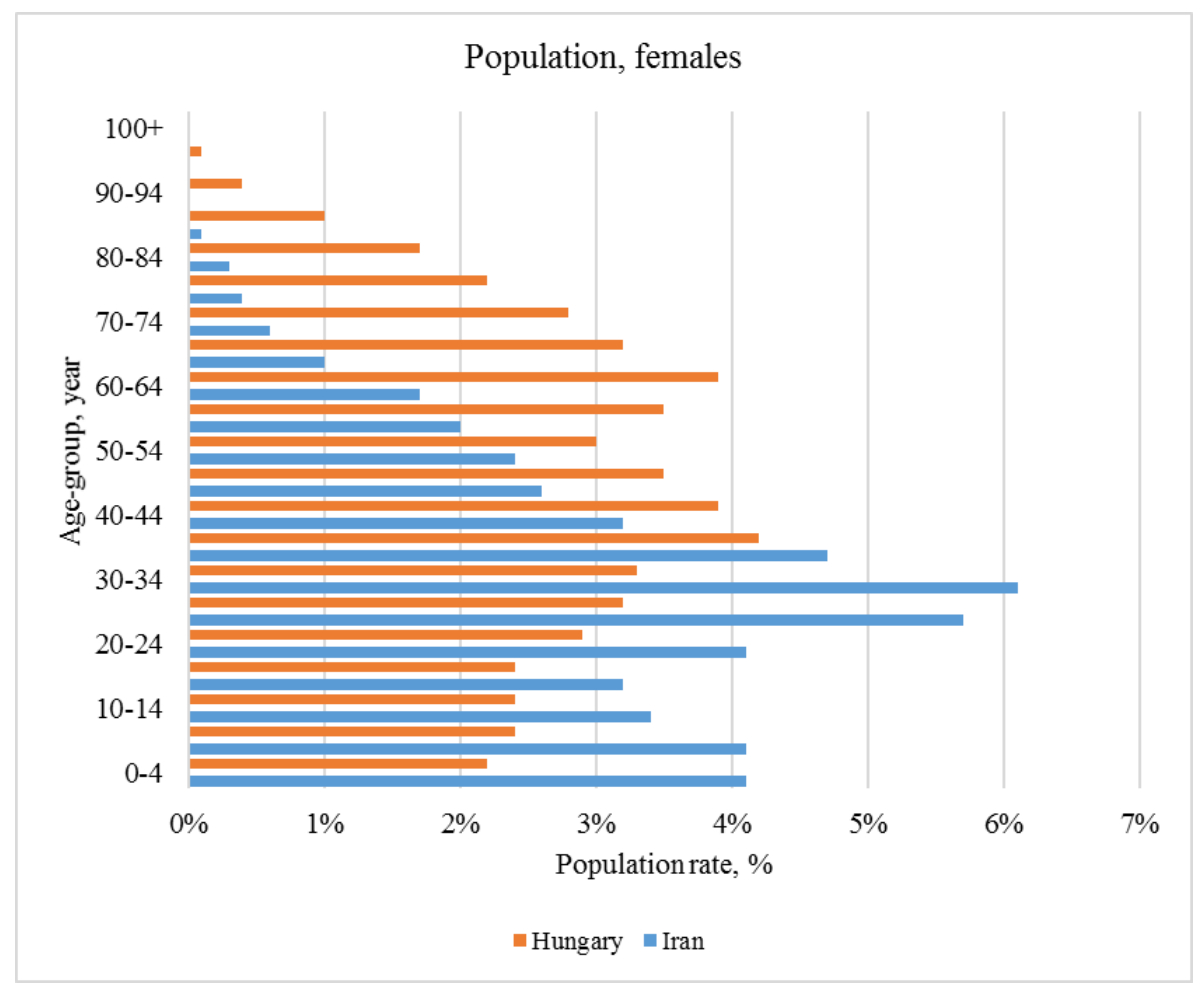

Source: PopulationPyramid.net (2016b, 2016a)

\subsubsection{Causes of death and disability}

The Institute of Health Metric and Evaluation (IHME) provides country reports on disease burden data based on over 80,000 different data sources .

The leading causes of death are non-communicable diseases in Iran, namely ischaemic heart disease and cerebrovascular diseases, the same as in Hungary. (Table 3) However, in Iran road injuries continue to play significant role in deaths in 2015, whilst in Hungary lung and colorectal cancer are in $3^{\text {rd }}$ and $4^{\text {th }}$ place among the causes. Neonatal preterm birth and congenital defects were among the 10 leading causes of death in Iran, however these were ranked lower in 2015, whilst diabetes and stomach cancer came into front. 
Table 3 Leading causes of death in Iran and Hungary, 2005

\begin{tabular}{|l|l|}
\hline IRAN & HUNGARY \\
\hline Ischaemic heart disease & Ischaemic heart disease \\
\hline Cerebrovascular disease & Cerebrovascular disease \\
\hline Road injuries & Lung cancer \\
\hline Hypertensive heart disease & Colorectal cancer \\
\hline Alzheimer disease & COPD \\
\hline Other cardiovascular & Alzheimer disease \\
\hline Neonatal preterm birth & Hypertensive heart disease \\
\hline Congenital defects & Self-harm \\
\hline Lower respiratory infection & Breast cancer \\
\hline COPD & Diabetes \\
\hline
\end{tabular}

Source: Institute for Health Metrics and Evaluation (2017e, 2017d)

Table 4 Leading causes of death in Iran and Hungary, 2015

\begin{tabular}{|l|l|}
\hline IRAN & HUNGARY \\
\hline Ischaemic heart disease & Ischaemic heart disease \\
\hline Cerebrovascular disease & Cerebrovascular disease \\
\hline Road injuries & Lung cancer \\
\hline Hypertensive heart disease & Colorectal cancer \\
\hline Alzheimer disease & COPD \\
\hline Other cardiovascular & Alzheimer disease \\
\hline COPD & Hypertensive heart disease \\
\hline Diabetes & Breast cancer \\
\hline Lower respiratory infection & Self-harm \\
\hline Stomach cancer & Diabetes \\
\hline
\end{tabular}

Source: Institute for Health Metrics and Evaluation (2017e, 2017d)

The most frequent health problems causing disability are very similar in both countries. In 2015, the first four are: low back and neck pain, depressive disorders, sense organ diseases, 
diabetes. Of note, anxiety disorders are in $8^{\text {th }}$ place in both countries and their rate is stable between 2005 and 2015. (Table 4, Table 6)

I find important to note, that skin disorders have similar importance in the ranking $\left(5^{\text {th }}\right.$ and $6^{\text {th }}$ cause in Hungary and Iran, respectively). (Table 5)

According to a study in 2010 which involved all new cases of skin diseases referred to one hospital in Southern Iran over a 3-year period, infectious and parasitic diseases (including infections of the skin and subcutaneous tissues) were found to be the most common skin diseases $(32.1 \%)$, followed by dermatitis and eczema (24.5\%). (Baghestani et al., 2005)

Table 5 Leading causes of disability in Iran and in Hungary, 2005

\begin{tabular}{|l|l|}
\hline IRAN & HUNGARY \\
\hline Low back \& neck pain & Low back \& neck pain \\
\hline Depressive disorders & Sense organ diseases \\
\hline Sense organ diseases & Depressive disorders \\
\hline Skin diseases & Diabetes \\
\hline Migraine & Skin diseases \\
\hline Diabetes & Migraine \\
\hline Other musculoskeletal diseases & Oral disorders \\
\hline Anxiety disorders & Anxiety \\
\hline Drug use disorders & Osteoarthritis \\
\hline Other cardiovascular disorders & Iron-deficiency anemia \\
\hline
\end{tabular}

Source: Institute for Health Metrics and Evaluation (2017e, 2017d) 
Table 6 Leading causes of disability in Iran and in Hungary, 2015

\begin{tabular}{|l|l|}
\hline IRAN & HUNGARY \\
\hline Low back \& neck pain & Low back \& neck pain \\
\hline Depressive disorders & Sense organ diseases \\
\hline Sense organ diseases & Depressive disorders \\
\hline Diabetes & Diabetes \\
\hline Migraine & Skin diseases \\
\hline Skin diseases & Migraine \\
\hline Other musculoskeletal diseases & Oral disorders \\
\hline Anxiety disorders & Anxiety \\
\hline Drug use disorders & Osteoarthritis \\
\hline Other cardiovascular disorders & Iron-deficiency anemia \\
\hline
\end{tabular}

Source: Institute for Health Metrics and Evaluation (2017e, 2017d)

While the major burden of disease is non communicable diseases (NCDs) including cardiovascular disease (CVD), cancer and injuries, the country is still faced with the problem of infectious diseases, for instance Cholera epidemic in 2005 and 2007. (Lankarani et al., 2013)

\subsubsection{Health status of the population}

Health status data of the general population (also called as health status population norm) is available with the Short-Form-36 (SF-36) questionnaire in Iran. This questionnaire has been applied also in Hungary hence it allows inter-country comparisons. (Montazeri et al., 2005)

The SF-36 is a generic health status measure which consist of 36 questions and assesses the health status of the respondent in eight dimensions of health, namely Physical functioning, Role physical, Bodily pain, General health, Vitality, Social functioning, Role emotional, Mental health. A score between 0 and 100 is calculated based on the 36 questions for each dimension, the lower the score the more disability . 
Results of the Iranian population survey confirm that, similarly to other countries, health status of the population worsens with age in Iran. Among the eight health dimensions of the SF-36 survey, Vitality is the most affected in general, but in age-group 65 and over, the highest disability is observed in Role physical dimension.

Direct comparison with the Hungarian data is not feasible as results are available by different age-groups. In general, similar trends and scores can be observed with slightly better scores in the Role emotional dimension in Hungary than in Iran. (Figure 7 and Figure 8)

Figure 7 Health status of the general population by age-groups in Iran

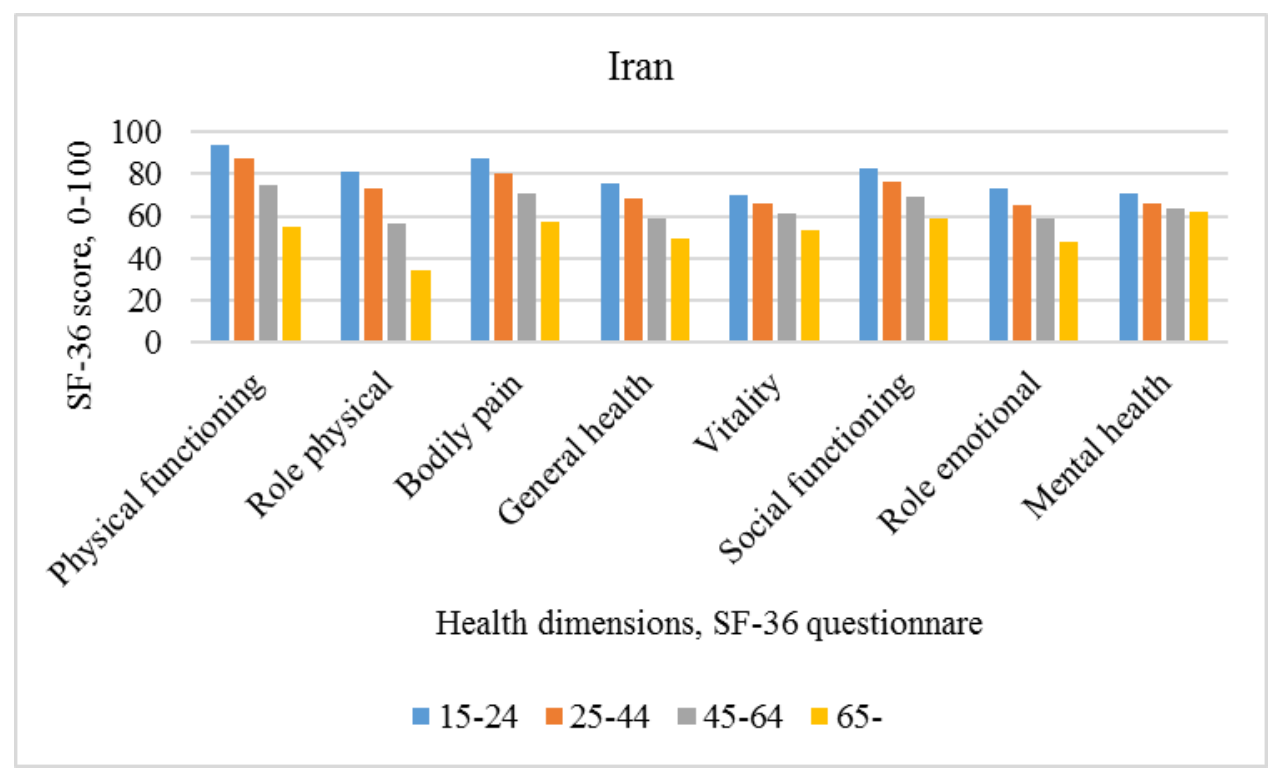

Source: (Montazeri et al., 2005) 
Figure 8 Health status of the general population by age-groups in Hungary

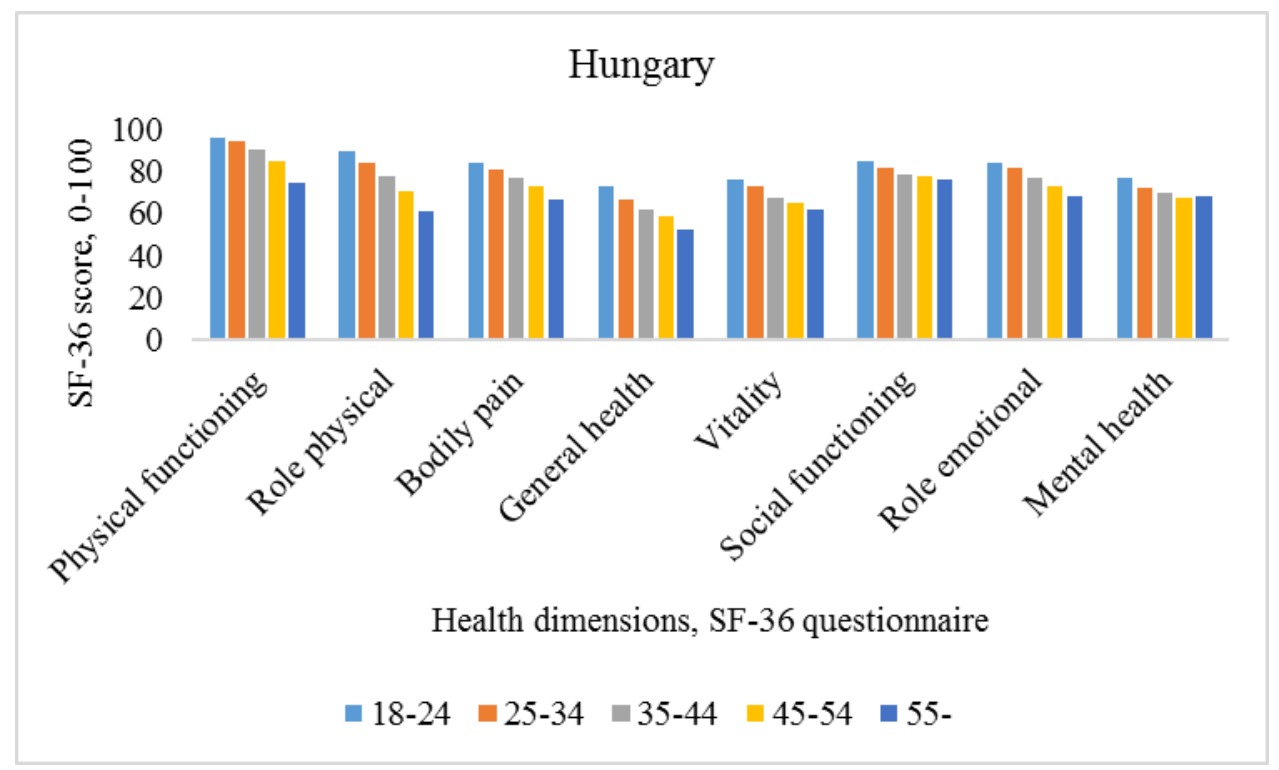

Source: (Czimbalmos et al., 1999)

\subsubsection{Comparison with countries of the region}

The Global Burden of Diseases and Injuries, and Risk Factors Study (GBD) study allows some comparisons between Iran and other countries from the region. (Shahraz et al., 2014) Considering 20 countries (bordering Iran and others: namely Afghanistan, Armenia, Azerbaijan, Bahrain, Egypt, Iran, Iraq, Jordan, Kuwait, Lebanon, Libya, Oman, Pakistan, Qatar, Saudi Arabia, Syria, Tunisia, Turkey, Turkmenistan, United Arab Emirates), with a life-expectancy of 74.4 years $(95 \%$ CI: $73.3-76)$, Iran ranked $14^{\text {th }}$ among the 20 countries in 2010, and 12th by the age-standardized death rates. (Figure 9) 
Figure 9 Health-adjusted life-expectancy in 20 countries of the region, 2010

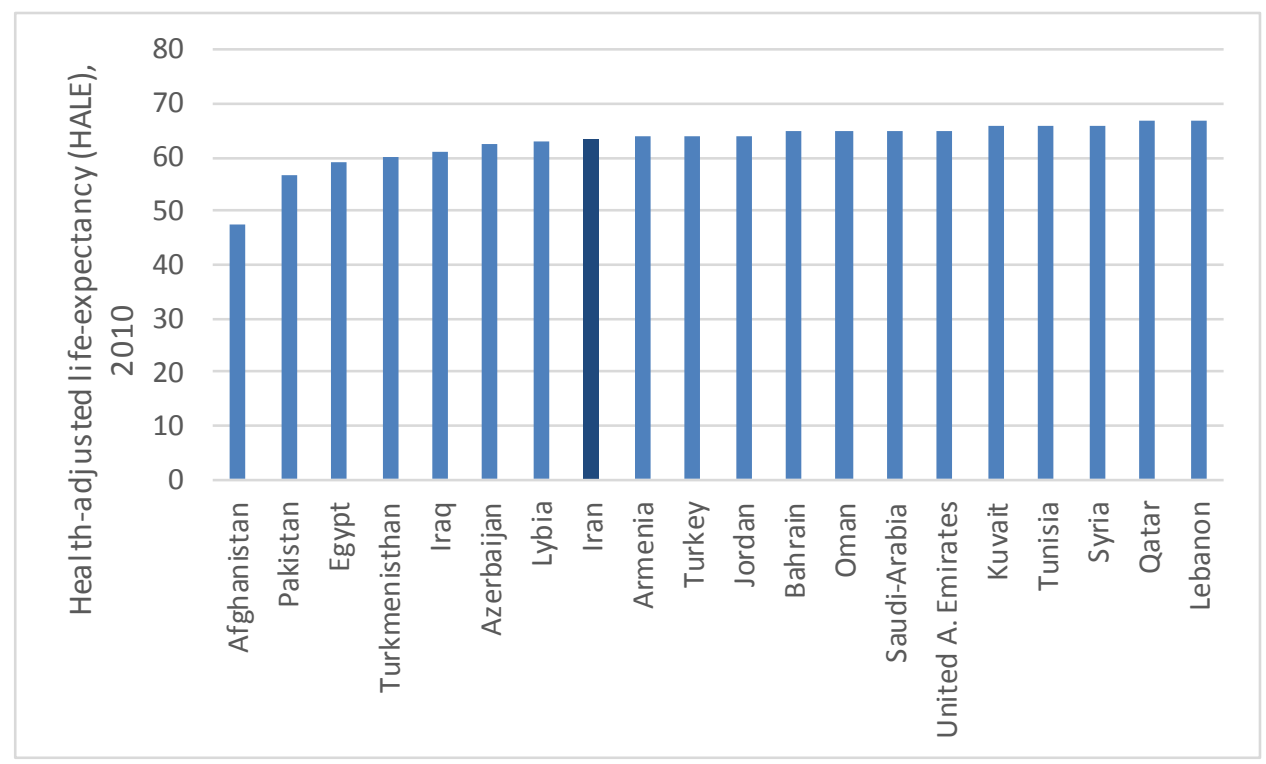

Source: (Shahraz et al., 2014)

\subsection{History of medicine in Iran}

The history of medicine in Iran is as old as and as rich as its civilization. In the pre-Islamic Iran, the history of medicine dates back to four centuries before Christ and the primary principles of Iranian medicine were mentioned in Avesta (the holy Book of Merian - ancient Iranian religion). (Velayati, 1988)

A great center of learning medicine was founded at Jundishapur (Gundeshapur) University in the 4th century AD, which had a large hospital and an academy, and the first international medical congress was held there. (Nikbakht\&Kafi, 2008)

Jundishapur University was a breeding ground for the union among great scientists from different civilizations. These centers successfully followed their predecessors' theories and greatly extended their scientific research through history. (Pourahmad, 2008) Some experts go so far as to claim that: "to a very large extent, the credit for the whole hospital system must be given to Persia". (Pandit, 2009) 
The excellent clinical observations and physical examinations and writings of Iranian scientists such as Rhazes (Al-Razi, 865-925 AD), Haly Abbas (Ali ibn-al Abbas-al Majusi, died 994 AD), Avicenna (Abou Ali Sina, 980-1037) and Jurjan (Osmail ibn al-Husayn alJurjani, 110 AD) influenced all fields of medicine.

The new era of medicine in Iran begins with establishment of Dar-ul-funoon in 1851, which was the only center for modern medical education before the establishment of Tehran University. Following the establishment of the Tehran university school of medicine in 1934 and the return of Iranian graduates from the medical schools in Europe, much progress was made in the development and availability of trained manpower and specialized faculties in medicine. (Pourahmad, 2008)

\subsection{Health System in Iran}

Iran as a developing country is an upper middle-income country located in the southwest of Asia - the Middle East. Based on the latest reports of the World Bank, its population is 79.1 million people (2015), its GDP (current US\$) is 393.7 billion (2015), its Health expenditure, public (percent of total health expenditure) is 41.2 (2014) and its total expenditure on health is 6.9 percent of GDP (2014) (The WorldBank, 2015). Article 29 of the Constitution of the Islamic Republic of Iran emphasizes that every Iranian has the right to enjoy the highest attainable level of health. The Ministry of Health and Medical Education is mandated to fulfill this goal through designing and implementing a national-level health policy (1979). According to the law, government has the responsibility to provide services and financial protection for every individual citizen of the country therefore today the largest health care delivery network is owned and run by the Government through Ministry of Health and Medical Education (MoHME). (The WorldBank, 2008)

Although the Iran health system consists of both public and private sectors, currently all Iranians have access to a government-supported health insurance system. However, due to the lack of sufficient resources in public health sectors and national health insurance schemes, in the past years and up to 2012, out of pocket payments of patients have substantially increased, it was 55\% in 2008 - although the Iranian Development Plan set the goal for out- 
of-pocket payment to as low as $30 \%$ in 2008 - and has topped to over $81.3 \%$ of the costs of medical services. (Davari et al., 2012, Merhdad, 2009)

Health care system in Iran vas compared to a group of high-income countries focusing on the service provider and payment method. In this comparison nine countries including Norway, Australia, United States of America, Germany, Italy, Canada, England, Denmark and Japan were selected. (Khangah et al., 2017) Primary care and hospital care were compared. The author concluded that "the implementation of the process of decentralization of the government in some sections and different levels of health care is the best option for the health care system of Iran".

\subsection{Iranian Health Financing System}

There are several ways of financing healthcare in Iran and the most important types include general revenue financing, social health care insurance, household out-of-pocket payments and also private actuarial health care insurance.

Private actuarial health care insurance mostly gives secondary coverage to the people who have already social insurance. Private insurance market is small in Iran.

Government pay for general revenue financing health care. General revenue financing of health care mostly gives primary health care (PHC) to the people and focus on several secondary care services such as expensive-to-manage diseases. In addition to that, public hospitals' infrastructure mostly paid out of government general revenue. Medicine production benefits from significant government subsidies.

Social health care insurance covers around $90 \%$ of the population and it focused on non-PHC 'treatment' services, which includes most ambulatory, diagnostic and hospital services. The number of services that they provide varies depending on the service and setting, and to some extent on who is the insurer. However, an important share of health care bill is paid by people as out-of-pocket payments at the time of service utilization.

Total health expenditure has increased very rapidly in the past decade. The per capita health expenditure has increased from \$68 in 1995 to \$229 in 2000 to \$351 in 2014 (Table 7) (The 
WorldBank, 2015). World Bank estimated the public health expenditure (\% of government expenditure) 12.7 in 2010 and out-of-pocket expenditure is $81.3 \%$ in 2014.

The Iranian health care financing system organized through a number of public and nonpublic insurance schemes. Access to services and choice of provider is determined largely by the type of insurance coverage.

\section{Table 7 Expenditure on healthcare in Iran}

\begin{tabular}{|l|l|l|l|l|l|}
\hline & $\begin{array}{l}\text { GDP per } \\
\text { capita } \\
\text { (current } \\
\text { US\$) }\end{array}$ & $\begin{array}{l}\text { Total health } \\
\text { expenditure } \\
\text { per capita } \\
\text { (current } \\
\text { US\$) }\end{array}$ & $\begin{array}{l}\text { Total health } \\
\text { expenditure } \\
\text { (\% of GDP) }\end{array}$ & $\begin{array}{l}\text { Public health } \\
\text { expenditure } \\
\text { (\% of GDP) }\end{array}$ & $\begin{array}{l}\text { Private } \\
\text { health } \\
\text { expenditure } \\
\text { (\% of GDP) }\end{array}$ \\
\hline Iran & & & & & \\
$(1995)$ & $1,664.3$ & 68 & 3.7 & 1.7 & 2.1 \\
$(2000)$ & $1,598.5$ & 229 & 4.5 & 1.9 & 2.7 \\
$(2014)$ & $5,442.9$ & 351 & 6.9 & 2.8 & 4.1 \\
\hline
\end{tabular}

Source: The World Bank DataBank (2015)

The Gross Domestic Product per capita in Iran was last recorded at 5757.80 US dollars in 2015. The GDP per Capita in Iran is equivalent to 46 percent of the world's average. (Tradingeconomics, 2017) Gross domestic product based on purchasing-power-parity (PPP) per capita GDP was US\$ 16591.39 in 2013 and 17113.56 US dollars in Iran in 2014. (Indexmundi, 2017b) This figure is similar to the GDP/capita in of the lower income Central and Eastern European countries such as Bulgaria 17709.08 US dollars (2016), and Croatia 21408.55 US dollars (2016). And comparable to other CEE countries for instance Hungary 25381.29 US dollars in 2016 (PPP) and Czech Republic 31071 US dollars. The GDP/capita PPP is comparable to the GDP/capita of the lower income Western European countries such as Portugal 27006 US dollars, Greece 24263.88 US dollars.

These figures show that Iran has a similar health care financing capacity as a group of EU countries and according to our assumption Iran is facing very similar resource allocation decision situation and dilemmas than the group of EU countries with similar or at least comparable GDP/capita. 
Total health expenditure in Islamic Republic of Iran has increased rapidly in the past decade. The per capita health expenditure increased from US\$ 65 in 2000 to US\$ 259 in 2007. In the same period per capita government expenditure increased from US\$ 24 to US\$ 121. However, the share of out-of-pocket expenditure is still over 50\%. (WHO, 2017b)

\subsection{Health Insurance system}

The Iranian health system is primarily an insurance based system which represents an important influence on the Iranian healthcare system (Davari et al., 2012). There are two kinds of health packages, which are funded by the health systems and insurance organizations: basic and supplementary packages. First package is basic health services that governments finance the most part of the costs of this package. The second package includes medical services that are funded by insurance organizations. (Barati Marnani et al., 2012)

There are several insurers each with different benefits package co-payments and referral-and counter-referral systems and $90 \%$ of the population are under the coverage of at least one kind of health insurance market. Different insurance systems provide different levels of service coverage, so enrollment in different plans makes it easier to shop for services at a lower cost. (Mehrdad, 2009)

The main public health insurers are:

1. The Social Security Insurance Organization covers more than 27 million people (36\% of the Iranian population) across the country. (Davari et al., 2012) Almost all of its customers are workers and employees in the private sector where coverage is compulsory by law. (Mehrdad, 2009) The Social Security Insurance Organization owns and runs many out-patient and in-patient settings, mainly in urban areas. Medical services in these out-patient clinics and hospitals are offered either free of charge or at very low payments for the insured individuals.

2. Imdad Imdad (Relief) Committee Health Insurance is a charity-based health insurance for the uninsured poor and destitute. About $20 \%$ of its revenue comes from charitable donations and the government provides the rest. It covers about 4.5 million disadvantage people. (Davari et al., 2012) 
3. The Medical Services Insurance Organization (MSIO) covers governmental employees and all individuals of the community with various socioeconomic levels that were not eligible to be covered by other health insurance organizations. (Davari et al., 2012) The majority of the health care providers accept patients holding this insurance. (Mehrdad, 2009) Patients are paying co-payment at the point of the utilization of the service.

4. The Armed Forces Medical Services Insurance Organization (AFMSIO) covers around 4.5 million people in the armed forces and their families. (Davari et al., 2012)

Health policy, with regard to health insurance is developed by the Higher Insurance Council (HIC) and communicated to all health insurance organizations to implement. The council was established in 1994 to undertake policy planning, coordinating and conducting, monitoring and evaluating the quality and quantity of health insurance services. (Davari et al., 2012)

Each health insurance companies have their own regulation for those who are covering. For example, the regulation provides for those who are covered by Iranian Social Security Law, medical aids shall be rendered by the Social Security Organization or its affiliated physicians, except in the following cases:

1. The Social Security Organization's physician considers that the patient's referral to outside physicians or his treatment outside is mandatory,

2. The patient has had no access to the Social Security Organization's medical services, and

3. If the patient notifies the Social Security Organization within 48 hours of his first referral to an outside physicians or hospitalization.

In $2012,8.04 \%$ of the Iranian population benefited from supplementary medical insurance. Demand for supplementary insurance is growing and peaks in middle-age when savings and income are highest. 
To avoid catastrophic health expenditure ${ }^{1}$ insurance companies should adjust their insurance policy according to clients' needs, household characteristics, and their incomes. (Nouraei Motlagh et al., 2015) Determinants of the health care utilization is an important policy and financing issue. The most important factors affected on utilization were age, income level and deciles, job status, household dimension and insurance coverage. There was a negative relationship between health care utilization and education but it had a positive relationship with private health care utilization. Suffering from chronic disease was the most important variable in health care utilization- (Nouraei Motlagh et al., 2015)

According to the empirical data asymmetric information and moral hazard is an important policy issue in the Iranian insurance market. The presence of such problems can lead to less coverage of health insurance provided by insurers, loss of contracts with health care institutions and service providers, and lower quality of health services. (Lotfi et al., 2015)

\subsection{Health Reform in Iran}

Iran's health system has undergone several reforms in the past three decades with many challenges and successes. The most important reform was the establishment of the National Health Network in 1983, which aimed to reduce inequities and expand coverage and access to health care in deprived areas. (Nasseri et al., 1991) The 11th government, elected in June 2013, launched series of reforms in May 2014 to respond to some of the known issues in the performance of health system. The changes, so-called Health Sector Evolution Plan (HSEP) or Health Transformation Plan, were designed by the Ministry of Health and Medical Education (MoHME) based on the fifth 5-year health development national strategies (20112016) and the new President's manifest in order to achieve the universal and comprehensive

${ }^{1}$ Catastrophic health care expenditure is one of the approaches to assess the financial burden provoked by health expenditure. It refers to cases when out-of-pocket payments exceed a certain threshold share of either total or non-food expenditure of households (Wagstaff\&Eozenou, 2016)

The choice of threshold is somewhat arbitrary, but commonly used thresholds are 10-25\% of total

consumption expenditure or 25-40\% of non-food expenditure (Smith\&Nguyen, 2013) 
health services coverage. (Moradi-Lakeh\&Vosoogh-Moghaddam, 2015) The reforms are driven by concerns about increases in the overall costs of healthcare, the extent of government expenditure on healthcare, decreases in access to healthcare, and the lack of cost effective services. (Bahadori et al., 2015) Rapid population ageing is an important policy issue in Iran, health care reform tries to control the increasing health expenditure. (Basakha et al., 2014)

Equity and sustainability are major concerns during the health care reform. (MoradiLakeh\&Vosoogh-Moghaddam, 2015) In 2013, the MoHME has developed the Health Equity Monitoring System to help formulate evidence based actions and plans to improve equity. (Beheshtian et al., 2015)

As part of the health care reform in Iran the pay for performance (P4P) mechanisms is becoming increasingly popular in the health care sector as a tool for encouraging quality improvement. (Aryankhesal et al., 2013) P4P is a management tool to increase the hospital performance to the national quality standards. The autonomy and financing of the hospitals and other health care institutions including family medicine is an important policy issue nowadays. (Doshmangir et al., 2015, Esmaeili et al., 2014)

\subsection{Health Sector Evolution Plan}

HSEP is a national plan, with two main phases: the first phase relating to improving fair access to healthcare and quality of inpatient and outpatient care in hospitals and the second to the public health care. (Moradi-Lakeh\&Vosoogh-Moghaddam, 2015, Najafi et al., 2016) The reforms resulted in extensive social reaction and different professional feedback. The official monitoring program shows general public satisfaction. However, there are some concerns for sustainability of the programs and equity of financing. (MoradiLakeh\&Vosoogh-Moghaddam, 2015)

One of the important policy issue is the percentage of people with catastrophic health expenditures has been increased from 2.3\% to above 3.1\% between 2003-2010. This tendency clearly shows that the fairness of financial contribution index is decreasing. Cost 
control and fair distribution of the state financed reimbursement is an important public health issue in Iran today. (Fazaeli et al., 2014)

Out-of-pocket expenditures in hospital care with increasing length of stay, lower household wealth index, and admission to a private hospital are major factors contributing to the increase in the probability of catastrophic expenditure. (Hajizadeh\&Nghiem, 2011) Out-ofpocket health expenditure can be an economic shock for household in Shiraz and through spending on health a household may fall into poverty. (Khammarnia et al., 2014) Health inequalities are increasing and reducing inequalities is an important health policy plan. (Zare et al., 2014)

It seems necessary to apply new policies regarding the structure and management of financial resources in order to decrease paying directly from pockets. (Keshavarzian\&Mofidian, 2014) Another health policy issue recently the increasing drug costs in Iran which accounts for about $30 \%$ of the total health care expenditure. The diffusion of the high-cost drugs has been rapidly increasing to the Iranian market, the share of the drug cost within the health care budget is increasing. (Yusefzadeh et al., 2015) 


\section{HEALTH POLICY AND HEATH TECHNOLOGY ASSESSMENT IN IRAN}

\subsection{Health technology assessment in Iran}

Iran has one of the first national Health Technology Assessment (HTA) program, established in 2007, in the Eastern Mediterranean Region. (WHO, 2013)

The main aim of HTA is informing healthcare policymakers, managers and practitioners of the clinical consequences in terms of outcomes, and also the economic, ethical, and other social implications of the diffusion and use of a specific procedure or technique on medical practice. (Fournier, 2012, Facey, 2006)

The mission of HTA office in Iran is: "systematic and rational assessment of health technologies with the purpose of improving the accessibility and productivity of the health system" and "The necessity of applying health technology assessment in health systems has been highlighted by scientific centers and international organizations such as the WHO and World Bank because not only this interdisciplinary knowledge facilitates response the unlimited needs of the population with the limited available resources through systematic assessment of the effects of technology on health, but also affects other aspects of health systems such as equality and responsiveness”. (Doaee et al., 2012)

This assessment is performed by independent experts and evaluates short and long term effects of health technologies. Health technologies include drugs, interventions, medical equipment, drugs, biological substances, medical procedures, and interventions related to the support, organization, and management systems. HTA measures the effectiveness, clinical

This chapter draws upon the following journal article:

MORADI, M., KOVÁCS, Á. (2017): Az egészségügyi forrás allokáció aktuális kérdései Iránban; egészségügyi technológiaelemzés. Köz-gazdaság. [accepted for publication] 
efficiency, safety, cost-effectiveness, social effects like justice in access, and ethical and legal outcomes of these technologies as research projects. (Doaee et al., 2012)

HTA began its activities as a secretariat in the Deputy of Health in 2007 in Iran and it continues as a Health Technology Assessment Office at the Management of Health Technology Assessment, Standardization, and Tariff at the Deputy of curative affairs of Ministry of Health and Medical Education (MoHME) in the beginning of 2010 with structurally enhanced objectives and goals to promote evidence based policy making. (Doaee et al., 2012) Between 2007-2010 altogether 22 HTA evaluations were conducted in Iran, 14 HTAs focused on medical equipments and 8 pharmaceutical drug related HTA were completed (Doaee et al., 2012). These HTA assessments were funded through governmental budgets. Type of equipments and drugs were not specified by the authors.

Priorities have a key importance in the health care sector. Priority setting related to the state reimbursement of technologies in Iran are based on the following key factors:

-prevalence of the disease,

-load of the disease,

-cost and fluctuations in applying technologies,

-political and ethical acceptance, and

application of findings. (Doaee et al., 2012)

According to our interpretation the "load of disease" is a 'disease burden' in health economics term.

Like many developing countries, the process of priority setting and it's criteria in Iran's health care system is not so transparent and explicit. (Dehnavieh et al., 2015) HTA has been established in the healthcare system of Iran but what is needed is a clear political will to push forward the objectives of HTA in Iran. (Doaee et al., 2012)

Mobinizadeh et al. (2016) conducted a questionnaire survey among HTA professionals Iran, the main aim was to create a model for MCDM (Multiple Criteria Decision Making) model 
for priority setting of health technology assessment in Iran. (Mobinizadeh et al., 2016) The following nine priority criteria were identified:

-efficiency/effectiveness,

-safety,

-population size,

-vulnerable population size,

-availability of alternative technologies,

-cost effectiveness in other countries,

-budget impact,

-financial protection, and

-quality of evidence.

Priority setting and stakeholder analysis were conducted by other authors as well. (ArabZozani et al., 2017) Attitude of health technology assessment students were assessed in their given field were conducted at 2015, the needs of the students, professor's attention to motivate and responding to student questions, and anticipated job categories and carriers in the relevant organizations were assessed. (Arab-Zozani et al., 2017)

Ethics and bioethics is an important, country specific issue in HTA this was is also assessed by Iranian authors. (Abbasi, 2012)

Olyaeemanesh et al. (2014) investigated the current challenges of Iran's health technology assessment and provide strategies to establish and institutionalize HTA program. International databases were searched and seven HTA papers were identified from Iran. (Olyaeemanesh et al., 2014) Based on this literature search and analysis twenty-two HTA challenges were identified by the authors. Most of these challenges are policy, governance and management related, such as lack of integration, organization culture related factors, stewardship factors (lack of clear boundaries between private and public sector), lack of HTA institutions and experts, and lack of coordination between the HTA process and the policy- 
making level and insufficient resources. This clearly shows that HTA is an important tool of a well-established, managed and financed health care system with appropriate policy goals.

Olyaeemanesh et al. (2016) stated that between 2010-2015: "More than 50 projects were conducted until the end of 2015; however, no evidence is available on the extent to which these projects have been effective.". (Olyaeemanesh\&Majdzadeh, 2016) Topics like costeffectiveness of the cervical cancer screening (Nahvijou et al., 2016) noninvasive intervention of weight loss (Nojomi et al., 2016) immunization against haemophilus influenzae type B (Moradi-Lakeh et al., 2012) and prosthodontics and restorative dentistry (Mobinizadeh et al., 2014) the whole list of HTAs were not specified by the authors. HTA assessments were ordered by National Institute of Health Research. These HTA assessments were used to inform Health Transformation Plan were mainly implemented in public hospitals since May 2014. Decision making reimbursement medicines and medical equipment by the Ministry of health is done by another Department, not by the HTA office. Reimbursement does not depend on the results of HTA. Increasing knowledge and of the policy makers of HTA results are necessary, but not enough for the effective use of HTA results in Iran for policy and financial decision making. The initiative of the Medical Journal of the Islamic Republic of Iran in publishing HTA results increase the awareness of the providers promote the utilization of HTA.

The next step us establish policy-making process based on the HTA reports, aimed to develop a Decision Support System (DSS) in order to adopt evidence-informed policies regarding health technologies in Iran. (Yazdani\&Jadidfard, 2017) This study was carried out to evaluate the opinions of stakeholders on their roles in health technology assessment (HTA) in Iran and to determine the barriers and facilitators existing in the organizations to help increase their involvement in the HTA program. Therefore, to prevent misunderstanding (inappropriate use and expectations not based by evidences) of stakeholders about HTA, it is essential to create opportunities in which their thoughts and ideas are taken into account. (Yazdizadeh et al., 2016) In Iran the importance of the Evidence Based Medicine is recognized. (Baradaran-Seyed\&Majdzadeh, 2012) 
Several authors are conducting research on how to increase the usefulness and efficacy as well as barriers and solutions of the HTA backed decision making in Iran. (Mohtasham et al., 2016, Yazdani\&Jadidfard, 2017) Competition of health care providers to utilize new technologies and increasing public demand created, and mass media are the key factors that lead to an increase in demand for new health technologies. Uncontrolled rapid diffusion of new health technologies without proper assessment and a full understanding of their side effects decreases public trust toward the health system. (Mohtasham et al., 2016)

The importance of the BIA as practical policy tool was discussed by (Jamshidi et al., 2014). Budget impact analysis (BIA) estimates financial consequences of implementing a new health technology or intervention within a specific health care context. (Mauskopf et al., 2007, Brodszky et al., 2014, Brodszky et al., 2016, Gulácsi et al., 2017, Orlewska\&Gulacsi, 2009) Nowadays, in most of the countries, reimbursement authorities increasingly require BIAs, along with a CEA, as part of reimbursement submissions of the pharmaceutical companies.

\subsubsection{Pharmaceutical market and drug reimbursement decisions}

Abidi was the first Iranian pharmaceutical company in 1946, followed by Tolid Darou and Darou Pakhsh in 1958 and 1963, respectively. (Kebriaeezadeh et al., 2013)

Self-sufficiency and non-reliance became main goals of the government mostly after the Islamic revolution since 38 years ago. After Islamic revolution in 1979, two important motions caused fundamental changes: nationalization of the pharmaceutical industries, and generic scheme. Governmental industry privatization and transition to the semigovernmental sector was one of the major actions taken by the government in the 1988 to 1993 period. (Kebriaeezadeh et al., 2013)

Two years after the revolution Ministry of Health $(\mathrm{MOH})$ adapted a full and compulsory generic medicine policy and based on this policy pharmaceutical companies which were already taken over by the government ask to produce only generic medicines using International Nonproperty Names (INN). In order to promote competition $\mathrm{MOH}$ encouraged 
national pharmaceutical industry to manufacture branded generic medicines since 2011 . (Cheraghali, 2017)

National industry has manufactured copies of biopharmaceuticals in the past few years, but, none of these medicines has had comprehensive evaluation according to Food and Drug Administration (FDA) or European Medicines Agency (EMA) guidelines. The lower cost of these copied biopharmaceuticals could improve the affordability of these clinically important medicines, but authorities need to perform close vigilance of these biopharmaceuticals in order to evaluate their safety and efficacy. (Cheraghali, 2013)

Even after the implementation of national scheme for privatization of the industry we can see that the majority of the local pharmaceutical market is manage by semi-governmental organizations. (Cheraghali, 2017)

All aspects of medicines policy including production, importation and distributions of medicines in Iran are under strict control of Iran Food and Drug Administration (IFDA) (Cheraghali, 2017). IFDA has the mission to regulate all aspects of pharmaceutical market including registration of the new medicines. Iran Drug Selection Committee has the responsibility to maintain and revise Iran Medicine List (IML). The National law has banned production, importation, distribution, and prescription of medicines which they are not included in Iran Medicine List. Although, IFDA policy makers have created a mechanism to provide those medicines that are not included in the medicine list but it might be essential for the treatment of particular patients. (Zargaran et al., 2016)

Entry of any biological product, such as serum and vaccine, and laboratory products, and any pharmaceuticals and pharmaceutical raw materials and pharmaceutical packaging from abroad, by the private or public sector, clearance of customs, and also manufacturing of any kind of medicinal product or biological product and Selling them inside the country or exporting them abroad requires a prior authorization from the Ministry of Health and Medical Education and need licensing (The Law on Medical Pharmaceutical and Food and Drug Affairs Regulations). 
Distributors of various medical and biological products, whether governmental or nongovernmental, and private, must obtain a certificate from the Ministry of Health and Medical Education. By introducing a qualified technical officer whose eligibility is approved by the relevant legal authority (Article 20 of the law), he/she is eligible regarding the distribution of medicines and biological substances throughout the country (The Law on Medical Pharmaceutical and Food and Drug Affairs Regulations). The qualifying terms of the technical authority are: 1) Ph.D. in Pharmacy; 2) no criminal record; 3) no corruption record (The Law on Medical Pharmaceutical and Food and Drug Affairs Regulations).

Iran national pharmaceutical industry is a non-innovative industry which mostly produces generic medicines. Therefore, until recently Iran national pharmaceutical industry never feel to use tools such as pharmacoeconomics in a non-competitive pharmaceutical market of Iran. (Cheraghali, 2006, Cheraghali, 2013) Due to the lack of in the health sectors, in the past years till 2012, out of pocket payments of patients have substantially increased and reached $60 \%$ of the costs of medical services (3). In 2013, the Iran government implemented a national health reform program mostly targeted at reduction of out of pocket payment by the patients. The program was successful to reduce out of pocket spending share in total health care spending to about $20 \%$ and to about $10 \%$ for medicines for inpatient services. In 2014, the Iran pharmaceutical market was valued at about 4.2 billion USD. (Cheraghali, 2016)

\subsubsection{Current pharmaceutical market}

Total expenditure on health is increasing, because private sector expenditure as out-of-pocket payment is significantly high in Iran, whereas the public sector's share is decreasing.

Iranian Pharmaceuticals Industry Analysis Report (2016) conducted that:

- Pharmaceutical spending is close to $20 \%$ of total treatment costs in Iran.

- Ten largest companies hold close to 50\% market share and ten importing drugs companies hold more than $73 \%$ of the importing drug market.

- Antibiotics consumption is nearly a quarter of all drug consumption in Iran, in terms of value. 
- Nearly a third of market sales is linked to sales of brand medicines. The WHO predicted 15 percent increase in the pharmaceutical industry's sales. (Novin, 2016)

SWOT analysis of Iranian pharmaceutical industry was done by Iran Pharmaceuticals \& Healthcare Report Q4 2016 as can be find in the Table 8 (Iran Pharmaceutical and healthcare Report, 2016b). Iran has a large pharmaceutical market in the region and it has a popular destination for medical tourism mostly from the neighboring countries. One of the important threats is the dependency of the industry on the imports of raw materials and government mostly prefer the domestic product rather than imported products and the price of domestic products are much cheaper than the imported ones. However, taxes are low on the foreignmade drugs that are not manufactured locally and expanding public health insurance coverage can boost demand for generic medicines. An exchange rate fluctuation is one of the barriers to attract foreign investment to the country. 
Table 8 Iran Pharmaceutical Industry's SWOT Analysis

\begin{tabular}{|c|c|}
\hline $\begin{array}{l}\text { Strengths: } \\
\text { - Large pharmaceutical market in regional } \\
\text { terms, supported by large population. } \\
\text { - } \quad \text { Popular regional destination for medical } \\
\text { tourism. } \\
\text { - Wide-ranging public healthcare } \\
\text { coverage, including in most rural areas. } \\
\text { - Requirement for registration of drugs } \\
\text { under their brand names. } \\
\text { - Local manufacturing sector output } \\
\text { comprising mostly inexpensive, basic } \\
\text { medicines resulting in a market that is } \\
\text { reliant on imports for hi-tech treatments. } \\
\text { - Acquisition of advanced medicine } \\
\text { production capability. } \\
\text { - Fast-growing alliance of international } \\
\text { trading partners. }\end{array}$ & $\begin{array}{l}\text { Weakness: } \\
\text { - Low per capita spending on } \\
\text { healthcare and pharmaceuticals } \\
\text { results in a focus on basic } \\
\text { treatments. } \\
\text { - International investors are reluctant } \\
\text { to get involved in Iran, especially } \\
\text { given the economic sanctions. } \\
\text { - Relatively poor intellectual } \\
\text { property standards. } \\
\text { - Strict government controls on the } \\
\text { price of pharmaceuticals. } \\
\text { - Strict import regime favoring } \\
\text { domestic companies. } \\
\text { - Around half of raw materials used } \\
\text { by the local industry are imported. } \\
\text { - Government's strategy for self- } \\
\text { sufficiency with regards to } \\
\text { pharmaceutical needs. } \\
\text { - Government corruption and } \\
\text { underinvestment has left healthcare } \\
\text { infrastructure weak. } \\
\text { - Lack of anti-money laundering } \\
\text { legislation and banking regulations. }\end{array}$ \\
\hline $\begin{array}{l}\text { Opportunities: } \\
\text { - Low taxes on foreign-made drugs that are } \\
\text { not manufactured locally. } \\
\text { - } \text { Expanding public health insurance } \\
\text { coverage boosting demand for generic } \\
\text { medicines. } \\
\text { - Improved intellectual property and } \\
\text { regulatory conditions to attract some } \\
\text { investment in local facilities. } \\
\text { - Plans to improve drug registration times. } \\
\text { - Improved international relations may } \\
\text { increase confidence of multinational drug } \\
\text { makers to invest in the market. } \\
\text { - Increased investment in local } \\
\text { pharmaceutical capacities. } \\
\text { - Rising interest in collaborative } \\
\text { agreements with partners in select foreign } \\
\text { markets. } \\
\text { Removal of almost all economic } \\
\text { - Conctions. } \\
\text { Construction of private pharmaceutical } \\
\text { city to house } 100 \text { companies. } \\
\text { Growing swing towards reformist and } \\
\text { moderate political camp. }\end{array}$ & $\begin{array}{l}\text { Threats: } \\
\text { - } \quad \text { Counterfeiting remains a serious } \\
\text { issue. } \\
\text { - Exchange rate fluctuations, rising } \\
\text { energy costs and inflation } \\
\text { negatively impacting on } \\
\text { profitability of drug production and } \\
\text { also on final consumer prices. } \\
\text { - Underperforming economy to have } \\
\text { a negative impact on government } \\
\text { spending. } \\
\text { Potential removal of OTC } \\
\text { medicines from the reimbursement } \\
\text { list. } \\
\text { Trade in parallel imports } \\
\text { threatening companies' } \\
\text { performance. } \\
\text { Regional instability linked to the } \\
\text { proclamation of the Islamic State } \\
\text { creating political and economic } \\
\text { instability. }\end{array}$ \\
\hline
\end{tabular}

Source: Iran Pharmaceuticals \& Healthcare Report Q4 (2016b) 
Iran remains a challenging market for foreign pharmaceutical companies. The difficult political situation will continue to discourage foreign direct investment into the country, in general, while the developed local generic manufacturing industry continues to satisfy most of the domestic demand, because it cost much less than the similar imported one. Truly, governments prefer to increase local manufacturing capacities, and recently they have a great focus on covering biological medicines. High inflation and local currency devaluation are two reasons that might stop the foreign companies to enter the market.

The value of Iran's pharmaceutical market in 2015 was IRR69,545bn (USD1.93bn) and it forecast to increase to a market size of IRR125,142bn (USD2.72bn) by year 2020, corresponding to a local currency compound annual growth rate (CAGR) of $+12.5 \%(7.1 \%$ in US dollar terms, highlighting the severe impact of the depreciating rial). By year 2025, the pharmaceutical market in Iran will be worth IRR202,891bn (USD3.59bn), corresponding to a local currency CAGR of $11.3 \%$ (6.4\% in US dollar terms) (Table 9). (BMI Research, 2016)

Table 9 Headline Pharmaceuticals \& Healthcare Forecasts (Iran 2014-2020)

\begin{tabular}{|l|l|l|l|l|l|l|l|}
\hline & $\mathbf{2 0 1 4}$ & $\mathbf{2 0 1 5}$ & $\mathbf{2 0 1 6 f}$ & $\mathbf{2 0 1 7 f}$ & $\mathbf{2 0 1 8 f}$ & $\mathbf{2 0 1 9 f}$ & $\mathbf{2 0 2 0 f}$ \\
\hline $\begin{array}{l}\text { Pharmaceutical sales, } \\
\text { USDbn }\end{array}$ & 1.910 & 1.930 & 1.990 & 2.360 & 2.460 & 2.680 & 2.910 \\
\hline $\begin{array}{l}\text { Pharmaceutical sales, } \\
\text { \% of GDP }\end{array}$ & 0.45 & 0.44 & 0.60 & 0.59 & 0.58 & 0.57 & 0.57 \\
\hline $\begin{array}{l}\text { Pharmaceutical sales, } \\
\text { of health } \\
\text { expenditure spending, }\end{array}$ & 8.5 & 8.7 & 8.8 & 9.0 & 9.1 & 9.3 & 9.4 \\
\hline $\begin{array}{l}\text { Health } \\
\text { USDbn }\end{array}$ & 22.360 & 22.240 & 22.520 & 26.280 & 27.020 & 28.890 & 30.910 \\
\hline
\end{tabular}

Source: (BMI Pharmaceuticals and Healthcare Report, 2016a) 
BMI highlighted that, after Iran rejoins world economy with sanctions relief on 2016, Iran's economy will herald a new era for the country and we will see pharmaceuticals and healthcare markets benefit from greater multinational interest as foreign drug-makers look to expand their business operations for the long term. However, some issues in the country such as rampant corruption and years of underinvestment may prevent an immediate boom (BMI Report, 2016a)

BMI Research mentioned two examples, in May 2016, Novo Nordisk declared the plans to locally produce Insulin in Iran, and also in May 2016, Iran and India made an agreement to conclude within the year a preferential trade agreement to boost bilateral trade with the aim of lifting sagging exports (Figure 10). The trade pact will be finalized early due to the lifting of international sanctions on Iran and will encompass trade, investment and services for pharmaceuticals as well as auto components, steel and jewelry. (BMI Report, 2016a)

\section{Figure 10 Pharmaceutical Market Forecast (2011-2025)}

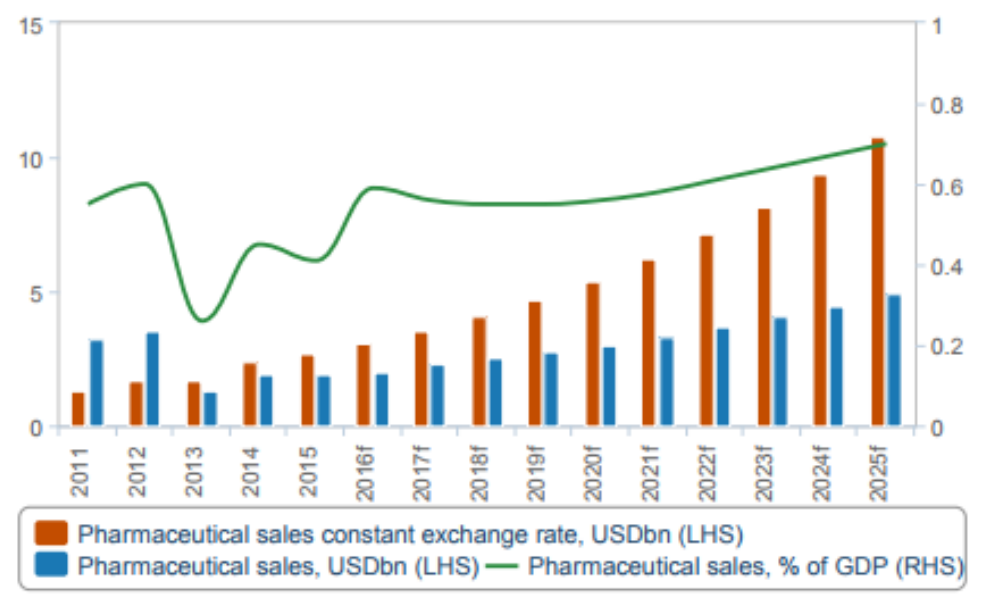

Source: (BMI Pharmaceuticals and Healthcare Report, 2016a)

Dinarvand, indicated that, since 2001 the pharma market, according to Ministry Of Health statistics, has expanded from \$ 690 million to \$ 2250 million in 2008 . The annual growth rate from year 2001 to year 2008 for locally produced items has been $16.6 \%$ while the sale of imported items has annually increased 26.7\% since 2001as can be seen in Figure 12 . However, when the number of items sold in the market is taken into consideration, the total 
sale of pharmaceuticals only shows a moderate $6.8 \%$ annual growth. The sale of locally produced and imported items has annually increased $6.7 \%$ and 9.4\% since 2001. (Figure 11).

Figure 11 The volume market size of pharmaceutical products in Iran

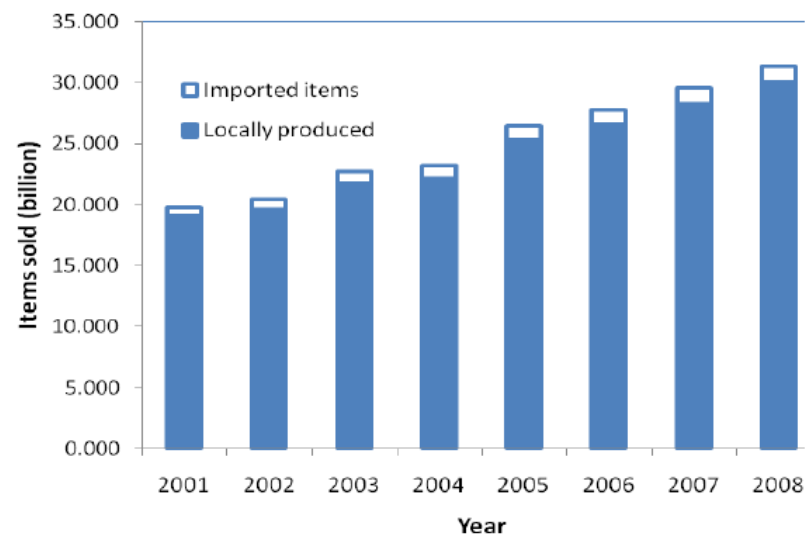

Source: (Dinarvand, 2009)

Figure 12 The volume market size of pharmaceutical products in Iran

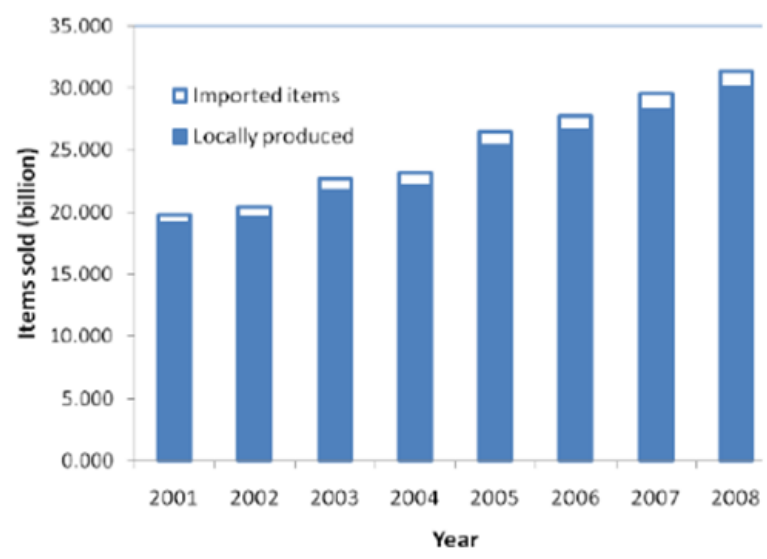

Source: (Dinarvand, 2009) 


\subsubsection{Drug reimbursement in Iran}

Reimbursed drugs account for about $53.5 \%$ of all available drugs and $77.3 \%$ of drug expenditures (Ansaripour et al., 2014). The Supreme Council of Health Insurance (SCoHI) deals with drug reimbursement decisions and the Drug Benefit Package Review Committee (DBPRC) as part of the SCoHI and is responsible for assessment. According to the health law all health technologies and services covered by of Health Insurance Organi11111zations (HIOs) must complete the reimbursement process. Pharmaceutical companies and other health care providers have to submit a dossier to the SCoHI. These documents contain general information about the drug, the proposed price, the cost of the treatment, a list of alternative drug therapies and detailed description of their advantages and disadvantages, and the clinical efficacy, safety, budget impact and cost-effectiveness of the drug. This information contributes to a certain number of points. The maximum possible score is 100 points. If the total score is less than 50 points the application is rejected. If the total score is 50 points or more, the application is send to the DBPRC, and members are asked to comment. If a drug application receives more than 80 points and no significant objections from the DBPRC, it is sent to the SCoHI with a suggestion to reimbursement. If the total score is in between 50 and 80 BBPRC decides whether their vote is positive or negative. Final decision is made by SCoHI. No further information is available about the scoring system and the weights and the process as well as the results of the HTA process in peer reviewed English literature in Medline.

\subsubsection{Impact of HTA}

In Iran HTA activities have been developed and have become internalized in the decision making processes on technologies over the past decade. The most important characteristics of this development are the following:

- formalization and institutionalization (legislation, official institutes with HTA tasks): HTA has been embedded in the law, no national HTA institution has been created yet, 
- standardization (HTA guidelines, standard methodology, national criteria for decisionmaking): no HTA country specific guideline were established yet, however national criteria for decision making has been already established,

- execution (number and types of decisions made): the number of decisions has been published, but information about the types of decisions are not publicly available,

- professionalization (capacity building): Iran has academics who are getting knowledgeable and have been trained in the field of HTA, the overall capacity is still limited.

HTA method and the structure of the HTA report is very similar to other countries, such as: include at least data related to the following topics:

1. Introduction, 2. Medicine characterization, 3. Target population, 4. Perspective, 5. Methods, 6. Comparator, 7. Outcomes (EQ-5D, SF-36), 8. Costs (indirect costs is not being considered), 9. Models: 10. Time horizon: 12. Sensitivity analysis, 13. Threshold: based on current national guidelines, IFDA considers drugs with cost/QALY of less than one national GDP per capita as "cost effective”, 14. Presenting the results. (Cheraghali, 2017)

Cost Utility Analysis is the preferred analytical method. Therefore, the results of the study can be measured and expressed in different units such as quality-adjusted-life-year (QALY), life years gained/saved, disability averted or utility.

A framework of clinical policy making was established and the following three principles of the framework are as follows:

1. The principle of determining the indications: The indications must be specified according to:

effectiveness; cost-effectiveness; complications of the intervention.

2. Principle of explaining the recommendation: developing the guidelines.

3. Principle of evaluation and supervision on the performance: Ultimately, the patients' identification and determining the outcomes and costs are important in monitoring the system performance. (Shirvani et al., 2014) 
Technology Acceptance Model was set, the main aim was to better maintain the technology adoption of the new technologies in Iran. A qualitative study was conducted involving physicians, nurses and managers who work at cardiac specialty hospitals in Tehran. Results showed that more attention must be paid on senior hospital managers they are key professionals of the new technology adoption process. (Safdari et al., 2017) Promoting knowledge level of HTA for all audience groups and raising awareness about the importance of HTA studies is effective tool. (Ghassemi\&Dehnavieh, 2016) 


\section{AN EMPIRICAL INVESTIGATION INTO THE CONCEPT OF HEALTH}

Health and illness were originally concepts of medical science. These concepts are very important. As far as the method of our study is concerned, the specification comes into existence or being by surpassing the limitations of the enormous number of particular definitions. The limitations in our special case can be as follows: positive or negative, wellbeing or freedom from illness, serious or mild sickness, professional definition of health versus laymen's opinions, and so on. (Blaxter, 2010) Let's make a preliminary order among these cases!

Figure 13 Possible degrees of health

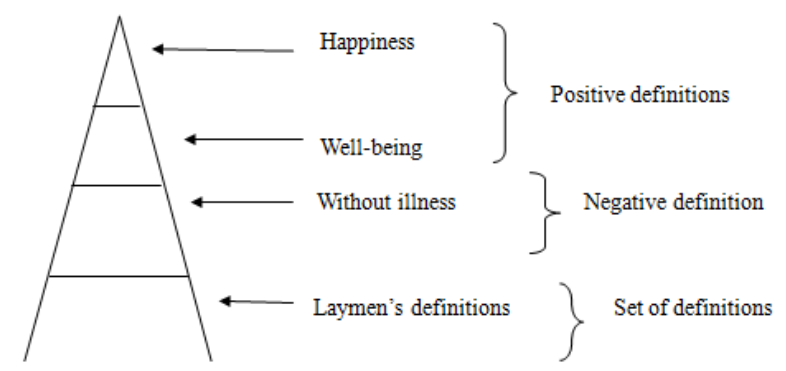

This chapter draws upon:

MAGYARI-BECK I., MORADI M. (2014): An empirical investigation into the concept of health. [Гигиена Культуры.Здоровье культуры - культура здоровья]. Working paper presented at the Russian Conference. Budapest, 2014. 10. 14 - 19. Location: Russian Cultural Centre. 
The figure above shows the possible degrees of health. These concepts can be found in Blaxter's book, but this two-dimensional "pyramid" and its interpretations are ours (Figure 13). (Blaxter, 2010)

The closer to the top a notion is, the narrower both its empirical and logical scope. It would also be not only possible but important as well - via serious empirical and theoretical studies - to construct a bipolar scale having a central "zero" point of indifferent state on the margin of health and illness. However, the conditions of living systems usually are not in a clear, clean and transparent state of health or illness. "The suggestion is, therefore, that "none of us can be categorized as being either healthy or diseased, (instead) we are all located somewhere along a continuum' (Sidell, 2010: 27)". (Blaxter, 2010) Perhaps the best subjective psychological indicator of health - although not totally accurate - can be the lack of subjective symptoms, e.g. the absence of pain. (Illyés, 1976)

\subsection{Hypotheses}

First of all, we immediately have to eliminate a conception widely held in the past and popular among laymen, according to which health is nothing other than a machine-like functioning of living systems. To deal with this mistaken view, we have to define the concept of machine. However, this is now an extremely difficult task. For a long time - thousands of years - a machine was a system of smooth process by an artificial mechanism, which itself could multiply men's efforts mostly in work and art (e.g. musical instruments). This feature was expressed most clearly by the simple machines (Archimedean lever, pulley, and screw) in a transparent way. "Reuleaux's definition of a machine has remained a classic "A machine is a combination of resistant bodies so arranged that by their means the mechanical forces of nature can be compelled to do work accompanied by certain determinant motions." (Mumford\&Winner, 2010) Mumford added to this definition the non-organic nature of classical machine.

However, these sorts of definitions are now outdated. Mumford recognized this: "Instead of simplifying the organic, to make it intelligibly mechanical, as was necessary for the great eotechnic and paleotechnic inventions, we have begun to complicate the mechanical, in order to make it more organic; therefore more effective, more harmonious with our living 
environment." (Mumford\&Winner, 2010) Informatics - as one of the greatest, newest revolutions of mankind - has gone radically beyond the mechanical, non-organic approach concerning machines. Today's machines are very anthropological or humanoid and have little to do with the principle of mere mechanics. Now, what is the difference between mechanical and organic? Our preliminary hypothesis is as follows: the mechanical is a system of linear causalities, whereas the organic is a system of circular causalities.

The problem is that while radically new mechanisms were created, the theory of machines failed to enlarge its basic concepts. The new machines can imitate thinking and - soon - also creating. Moreover, the general notion of machine can rather be as follows. For us machines are the imitations of living systems by engineering using inanimate matter in the service of mankind. The part of the definition "in the service of mankind" is the key point of our approach. Before continuing this train of thought, we must emphasize that the nature of the main determination of human beings is not mechanical. People are determined by their problems: they have a problem structure.

Well. Let us see what health is. It is that kind of self-reproduction by which any living system contributes to the self-reproduction of its meta-systems. The function of the meta system for the living system - is its preservation. There are basically three cases of health. At first: the health of the emerging living systems (young) is: reproduction of itself by exceeding its original "it", and thereby extending and improving its meta-system as well. This is what we call development. This is an offensive way or strategy. Secondly: the health of the living system in its mid-ages is: reproduction of itself and thereby of its meta-system on the same level. This is rather a simple repetition, which can be called sustainability. This is the Midfensive case (I coined this terrible - but useful - notion: I.M.B.). Thirdly: the health of the so-called generation $\mathrm{X}$ - that is the old - is: reproduction of itself by increasing input under the circumstances of lawfully decreasing output. The strategy of the old is defensive. The price of life becomes higher and higher. Death comes when no effort produces the smallest output. The three phases of life are: Development (up), Plateau (horizontal), Decline (descent). It is better to measure people on the basis of their achievements and not on the basis merely of their biological age. And now let us see the applications of these definitions. Without successful applications no valid science can exist. 


\subsubsection{Applications}

Briefly speaking, the health of physiological organs: a semi-mechanical process. The health of the personality: a constructive private drama. The health of the family: mutual physical and psychological support. By the way, we make a distinction between the family and marriage. The family loves, supports, takes care of and develops its members, while marriage is mostly a formal act, which may or may not be good and bad from the point of view of the above. The health of society: some conflicts and balances between horizontal and vertical power. The health of culture: conflicts and balance between contradictory ideas and identification. The health of ethnic groups: balance between intolerance and tolerance. The health of nations: wealth of nations (Smith, 1776) and European concert. (Polanyi, 1944) The health of continents: war and peace. The health of mankind: vertical contra horizontal globalization. Today's Western globalization has the philosophy of phenomenology as its ideology. This sort of philosophy denies the so-called "abstraction ladder" and prefers a picture of the world where there are no differences between the concrete and the abstract. That is, phenomenology is a - mutatis mutandis - Renaissance of a pre-Columbian flat world. Western globalization is not above nations, but instead of them. The above politics and its ideology need considerable improvement in the future.

\subsubsection{Definition of health}

The WHO defined health in its broader sense in 1946 as "a state of complete physical, mental and social well-being and not merely the absence of disease or infirmity". (Grad, 2002)

- Merriam-Webster dictionary gives three definitions of Health (2014b):

1- a: the condition of being sound in body, mind, or spirit; especially: freedom from physical disease or pain

b: the general condition of the body 'in poor health' 'enjoys good health'

2- a: flourishing condition: well-being 'defending the health of the beloved oceans - Peter Wilkinson'

b: general condition or state 'poor economic health 
3- a: a toast to someone's health or prosperity

- The Oxford Dictionary's definition of health is: the state of being free from illness or injury and a person's mental or physical condition (Oxfrod, 2010).

- Medilexicon's medical dictionary has three definitions for health (Medilexicon, 2014a):

1. The state of the organism when it functions optimally without evidence of disease or abnormality.

2. A state of dynamic balance in which an individual's or a group's capacity to cope with all the circumstances of living is at an optimal level.

3. A state characterized by anatomic, physiologic, and psychological integrity, ability to perform personally valued family, work, and community roles; ability to deal with physical, biologic, psychological, and social stress; a feeling of well-being, and freedom from the risk of disease and untimely death.

- Boon How Chew (2011), family physician and lecturer in family medicine defined health as "Health is defined as the ability to adapt and self-manage in the face of social, physical, and emotional challenges.” (Huber et al., 2011)

- Franklin P. Adams defined health as "the thing that makes you feel that now is the best time of year".

- In 1986, the WHO, in the Ottawa Charter for Health Promotion, said that health is "a resource for everyday life, not the objective of living. Health is a positive concept emphasizing social and personal resources, as well as physical capacities.” (WHO, 1986)

- Maloof (1991) argued that a perception of health or mental health is not only defined within the medical context, but it is also defined by the patient within a sociocultural context that includes family and social network as well as a wide selection of potiential providers. Such definitions may vary from one culture to another. Research among ethnic groups in the U.S. demonstrates the complexity in a non-clinical 
definition of health and illness (2017b).

- Earle (2007) mentioned that health has been called "an abstract concept" that people can find difficult to define. (Warwick-Booth et al., 2012)

- Johnson (2007) argued that health is one of those things that most people assume they understand. But if we just stop and consider it for a moment and try to focus on it, it starts to float about in our minds. (Warwick-Booth et al., 2012)

- Tones and Green (2004) refer to health as dichotomous differences in approaches to defining health. On the one hand there are positive approaches to defining health (health as well-being or as an asset) and on the other hand there are more negative definitions of health - those that are illness- or disease-oriented. When health is viewed in a negative way, then definitions will tend to focus on health as absence of disease. When health is viewed in a positive way definitions tend to be broader and take into account concepts such as 'well-being'. (Warwick-Booth et al., 2012)

- Aggleton (1990) argues that health is something that can be bought (by investment in private health care) or sold (through disease or injury). (Warwick-Booth et al., 2012)

- Seedhouse (2001) describes health as the 'foundations for achievement'. Health is a complex and contested concept. Seedhouse views health as the means by which we achieve our potential, both as individuals and as groups. Seedhouse (1986:61) therefore describes a person's optimum state of health as being 'equivalent to the set of conditions that enable a person to work to fulfill her realistic chosen and biological potentials'. (Warwick-Booth et al., 2012)

- Dorland's Medical Dictionary defines health as "a state of optimal physical, mental, and social well-being, not merely the absence of disease. (Ratson, 2003)

- According to a nurse aged fifty-two from Moscow, "Health is both your inner and your outer state - the state of soul - being more optimistic, not giving in to any kind of difficulties, trying to find some kind of compromise.... and also, probably, being needed by society too, however old you are". (Blaxter, 2010) 
- "Complete physical, mental, social and spiritual well-being for individuals and populations.” (Edlund, 2012)

- Health is defined as the ability to adapt and self-manage in the face of social, physical, and emotional challenges. (Godlee, 2011)

- What is health? For most people, it is a state of "perfection", thus excluding most of us; but health is a social right, therefore it should be a possibility for all. This makes us wonder what health really is, and in this aim centering our attention on people with disabilities as a paradigm is really useful. (Bellieni, 2014)

\subsubsection{Classification of the Definitions}

Investigating the short but valuable set of health definitions, we regard it as important to classify them merely on a level of plausibility. This method of classification is an age-old means of reasoning, created by Aristotle. Without it not only the means of definitions is impossible, but the whole rationality, moreover rationalism as well (rationality being an instance of the preconscious, while rationalism being an instance of the conscious). It is true that today's scientific life and the whole intellectual climate prefer such terms and directions as metaphor, phenomenology and postmodern; we will remain old-fashioned, conservative thinkers. Constructive conservatism is not a kind of backwardness. It is rather the preservation of successfully tested results. For us science and intellect are not the tools of omniscience. We accept Kant's view that reason has its limitations. However, what is beyond our actual reason cannot be understood by us at all. In our "philosophy" the only way of understanding reality is the enlargement of reason and not cowardly flight from it. (Gross et al., 1996) The brick of the building of classification is definition, and the building of classification is made of the bricks of definitions. Without classification rational models and constructs cannot be built, or they collapse. However, it is also true that to give here and now a correct and final classification is impossible. So, we tried to arrange the cited classification on appropriate levels of the ladder of abstraction. This would be a door to the second step after the first one of collecting- towards further - but also preliminary - classifications. This venture will be performed by us only in a rudimentary way. 


\subsubsection{On the Ladder of Abstractions}

Working with the above definitions, we identified a number of aspects. Namely: capacities, resources, assets, well-being, absence of disease, physical, psychological, mental, social, state of perfection, social right, ability to adapt, cope with challenges, emotional, selfmanage, relative, spiritual, subjective, longevity, optimism, fitness, compromise, achievement, realism, biological, balance, integrity, identity, coping with stress, freedom, stress, risk. The number of aspects shows the complexity of the notion of health. However, we were also able to reduce this complexity. Counting the number of occurrences of these aspects in these definitions, we found the winner. This was "well-being", a psychological, economic, subjective and so on term. "Well-being" in general got 7 points. Physical wellbeing has 8 points, mental well-being -5 points, social well-being -3 points, spiritual wellbeing -2 points. That is, special cases of well-being have altogether 18 points. If we add the general and special points, which is not an entirely correct method, the result will be 25 points. In second place we find "asset", "absence of disease" and finally "ability to adapt". These aspects scored only 4 points each. All the other aspects lagged far behind the winner.

What can we add to this overall picture? There are wide gaps between the complexity of the phenomenon of health and the simplicity of theoretical considerations in this domain. No wonder that not only laymen but also medical doctors, politicians, sociologists, psychologists, managers, artists, philosophers and scholars are ignorant concerning the issue of health. Just a further remark: health and sickness can be detected in both vertical and horizontal dimensions. As far as the horizontal dimension is concerned, we can speak of the health or illness of every profession, whereas on the vertical dimension it is possible to study

the issue of health and illness on the levels of individuals, family, groups, social layers, cultures and so on. Moreover, the aspects of health and illness on the transcendental level are also absent. Thus, we are far from solving all the problems in this area. Well-being itself was more general in practice and not theoretically. We did not find even the shadow of either a horizontal or a vertical approach to the matter to be studied. Well-being seems to be only one of the stereotypes and remnants of the wealthy society that has already collapsed. 


\subsection{Research Design}

The main aim of our study was to conduct a survey of laymen's opinions concerning the everyday notions of health. The non-professional participants were - as a rule - asked to indicate their sex, age, level of education, profession, and ethnic group. We gathered thirtyfour factors (Table 10) - usually associated with the domain of health according to the literature- and asked the participants to rate the importance of each factor in respect of health in general and also asked them to add factors which they think are important in these respects. In our questionnaire, the degree of importance was measured on a Likert-type scale from 0 to 6 as follows: most irrelevant, irrelevant, not at all relevant, neutral, less relevant, relevant, and most relevant. (Sullivan\&Artino, 2013)

Table 10 List of factors the authors could choose to ask the participants to find the most relevant to the most irrelevant factor which contribute to health in general

\begin{tabular}{|l|l|l|l|l|l|}
\hline 1 & Self-reproduction & 13 & Attractiveness & 25 & Lack of Illness \\
\hline 2 & $\begin{array}{l}\text { Reproduction of } \\
\text { Society }\end{array}$ & 14 & Fitness & 26 & Engagement \\
\hline 3 & Sociability & 15 & Workability & 27 & Inner Freedom \\
\hline 4 & Well-balanced & 16 & $\begin{array}{l}\text { Ability to } \\
\text { Relax }\end{array}$ & 28 & Productivity \\
\hline 5 & Machine-like & 17 & Sport & 29 & Innovativeness \\
\hline 6 & Flow & 18 & $\begin{array}{l}\text { Goals, } \\
\text { Harmony }\end{array}$ & 30 & $\begin{array}{l}\text { Positive } \\
\text { Emotional } \\
\text { Feeling }\end{array}$ \\
\hline 7 & $\begin{array}{l}\text { Constructive Programs } \\
\text { of Personality }\end{array}$ & 19 & $\begin{array}{l}\text { Religiousness } \\
\text { and Belief }\end{array}$ & 31 & $\begin{array}{l}\text { Constructive } \\
\text { Hobby }\end{array}$ \\
\hline 8 & Normal Genes & 20 & Optimism & 32 & Morality \\
\hline 9 & $\begin{array}{l}\text { Identity or Rooted in } \\
\text { one's Culture }\end{array}$ & 21 & Realism & 33 & Love \\
\hline 10 & Creativity & 22 & Maturity & 34 & Responsibility \\
\hline 11 & Longevity & 23 & Playfulness & & \\
\hline 12 & Beauty & 24 & Discipline & & \\
\hline
\end{tabular}




\subsubsection{Instructions for scoring each factor}

We calculated how many participants answered to each degree for each factor. The maximum total score can be 735 and the minimum 7 for each factor. The higher the score, the more important the factor is to the overall health of a person.

\subsubsection{Scoring}

The scoring of each factor is as follows:

0. Most Irrelevant

1. Irrelevant

2. Not at all Relevant

3. Neutral

4. Less Relevant

5. Relevant

6. Most Relevant scored 1

scored 2

scored 3

scored 4

scored 5

scored 6

scored 7

Scoring of each factor is calculated by counting how many times participants answered most irrelevant, irrelevant, not at all relevant, neutral, less relevant, relevant and most relevant to each factor, then the total number of each factor was multiplied by the score we gave to each degree and finally we add up all the numbers. The formula is: (Numbers choosing most irrelevant $\mathrm{x} 1)+($ numbers choosing irrelevant $\mathrm{x} 2)+($ numbers choosing not at all relevant $\mathrm{x}$ $3)+($ numbers choosing neutral $\times 4)+($ numbers choosing less relevant $\times 5)+($ numbers choosing relevant x 6) + (numbers choosing most relevant x 7). For example, 105 participants answered the factor of Ability to relax, the numbers of participants who chose most irrelevant, irrelevant, not at all relevant, neutral, less relevant, relevant, and most relevant, for the factor of ability to relax were $0,0,1,8,14,29,53$, respectively. One participant did not answer for this factor. The total value for the factor of ability to relax was calculated in this way:

$(0 \times 1)+(0 \times 2)+(1 \times 3)+(8 \times 4)+(14 \times 5)+(29 \times 6)+(53 \times 7)=530$ 
Table 11 Calculation of factors based on the participants' answers 1-9.

\begin{tabular}{|c|c|c|c|c|c|c|c|c|c|c|c|c|c|c|c|c|c|c|}
\hline & \multicolumn{2}{|c|}{$\begin{array}{c}1 . \\
\text { Self-report }\end{array}$} & \multicolumn{2}{|c|}{$\begin{array}{c}2 . \\
\text { Report of } \\
\text { society }\end{array}$} & \multicolumn{2}{|c|}{$\begin{array}{c}3 . \\
\text { Sociability }\end{array}$} & \multicolumn{2}{|c|}{$\begin{array}{c}4 . \\
\text { Well- } \\
\text { balanced }\end{array}$} & \multicolumn{2}{|c|}{$\begin{array}{c}5 . \\
\text { Machine- } \\
\text { like }\end{array}$} & \multicolumn{2}{|c|}{$\begin{array}{c}6 . \\
\text { Flow }\end{array}$} & \multicolumn{2}{|c|}{$\begin{array}{c}7 . \\
\text { Constructiv } \\
\text { e } \\
\text { programs } \\
\text { of } \\
\text { personality } \\
\end{array}$} & \multicolumn{2}{|c|}{$\begin{array}{c}\mathbf{8 .} \\
\text { Normal } \\
\text { Genes }\end{array}$} & \multicolumn{2}{|c|}{$\begin{array}{c}9 . \\
\text { Identity } \\
\text { rooted in } \\
\text { one's } \\
\text { culture }\end{array}$} \\
\hline & $\mathrm{F} * \mathrm{~S}$ & $\mathrm{~V}$ & $\mathrm{~F}^{*} \mathrm{~S}$ & $\mathrm{~V}$ & $\mathrm{~F}^{*} \mathrm{~S}$ & $\mathrm{~V}$ & $\mathrm{~F}^{*} \mathrm{~S}$ & $\mathrm{~V}$ & $\mathrm{~F}^{*} \mathrm{~S}$ & $\mathrm{~V}$ & $\mathrm{~F}^{*} \mathrm{~S}$ & $\mathrm{~V}$ & $\mathrm{~F} * \mathrm{~S}$ & $\mathrm{~V}$ & $\mathrm{~F}^{*} \mathrm{~S}$ & $\mathrm{~V}$ & $\mathrm{~F}^{*} \mathrm{~S}$ & $\mathrm{~V}$ \\
\hline I do not know & 3 & - & 3 & - & 1 & & 2 & - & 1 & - & 12 & - & 3 & - & 3 & - & 6 & - \\
\hline Most Irrelevant & $8 * 1$ & 8 & $5 * 1$ & 5 & $1 * 1$ & 1 & $0 * 1$ & 0 & $23 * 1$ & 23 & $3 * 1$ & 3 & $3 * 1$ & 3 & $5 * 1$ & 5 & $6 * 1$ & 6 \\
\hline Irrelevant & $5 * 2$ & 10 & $11 * 2$ & 22 & $0 * 2$ & 0 & $0 * 2$ & 0 & $14 * 2$ & 28 & $4 * 2$ & 8 & $3 * 2$ & 6 & $5 * 2$ & 10 & $7 * 2$ & 14 \\
\hline Not at all & $10 * 3$ & 30 & $8 * 3$ & 24 & $4 * 3$ & 12 & $1 * 3$ & 3 & $23 * 3$ & 69 & $14 * 3$ & 42 & $10 * 3$ & 30 & $8 * 3$ & 24 & $12 * 3$ & 36 \\
\hline Neutral & $18 * 4$ & 72 & $23 * 4$ & 92 & $14 * 4$ & 56 & $12 * 4$ & 48 & $24 * 4$ & 96 & $27 * 4$ & 68 & $16 * 4$ & 64 & $21 * 4$ & 84 & $19 * 4$ & 76 \\
\hline Less Relevant & $26 * 5$ & 130 & $30 * 5$ & 150 & $27 * 5$ & 135 & $15 * 5$ & 75 & $11 * 5$ & 55 & $20 * 5$ & 100 & $22 * 5$ & 110 & $22 * 5$ & $\begin{array}{c}11 \\
0\end{array}$ & $31 * 5$ & 155 \\
\hline Relevant & $21 * 6$ & 126 & $18 * 6$ & 108 & $38 * 6$ & 228 & $37 * 6$ & 222 & $7 * 6$ & 42 & $14 * 6$ & 84 & $32 * 6$ & 192 & $21 * 6$ & $\begin{array}{c}12 \\
6 \\
\end{array}$ & $24 * 6$ & 144 \\
\hline Most Relevant & $14 * 7$ & 98 & $7 * 7$ & 14 & $20 * 7$ & 140 & $38 * 7$ & 266 & $2 * 7$ & 14 & $11 * 7$ & 77 & $16 * 7$ & 112 & $20 * 7$ & $\begin{array}{c}14 \\
0\end{array}$ & $6 * 7$ & 42 \\
\hline Total & \multicolumn{2}{|c|}{474} & \multicolumn{2}{|c|}{415} & \multicolumn{2}{|c|}{572} & \multicolumn{2}{|c|}{614} & \multicolumn{2}{|c|}{327} & \multicolumn{2}{|c|}{382} & \multicolumn{2}{|c|}{517} & \multicolumn{2}{|c|}{499} & \multicolumn{2}{|c|}{473} \\
\hline
\end{tabular}

* Frequency * score of each degree (Most Irrelevant: scored 1, irrelevant: scored 2, not at all relevant: scored 3, neutral: scored 4, less relevant: scored 5, relevant: scored 6, most relevant: scored 7)

$* *$ Value 
Table 12 Calculation of factors based on the participants' answers 10-18.

\begin{tabular}{|c|c|c|c|c|c|c|c|c|c|c|c|c|c|c|c|c|c|c|}
\hline & \multicolumn{2}{|c|}{$\begin{array}{c}10 . \\
\text { Creativity }\end{array}$} & \multicolumn{2}{|c|}{$\begin{array}{c}11 . \\
\text { Longevity }\end{array}$} & \multicolumn{2}{|c|}{$\begin{array}{c}12 . \\
\text { Beauty }\end{array}$} & \multicolumn{2}{|c|}{$\begin{array}{c}13 . \\
\text { Attractiveness }\end{array}$} & \multicolumn{2}{|c|}{$\begin{array}{c}14 . \\
\text { Fitness }\end{array}$} & \multicolumn{2}{|c|}{$\begin{array}{c}15 . \\
\text { Workability }\end{array}$} & \multicolumn{2}{|c|}{$\begin{array}{c}16 . \\
\text { Ability to } \\
\text { relax }\end{array}$} & \multicolumn{2}{|c|}{$\begin{array}{c}17 . \\
\text { Sport }\end{array}$} & \multicolumn{2}{|c|}{$\begin{array}{c}18 . \\
\text { Goals, } \\
\text { Harmony }\end{array}$} \\
\hline & $\mathrm{F} * \mathrm{~S}$ & $\mathrm{~V}$ & F*S & $\mathrm{V}$ & $\mathrm{F}^{*} \mathrm{~S}$ & $\mathrm{~V}$ & $\mathrm{~F}^{*} \mathrm{~S}$ & $\mathrm{~V}$ & $F^{*} \mathrm{~S}$ & $\mathrm{~V}$ & $\mathrm{~F}^{*} \mathrm{~S}$ & $\mathrm{~V}$ & F*S & $\mathrm{V}$ & $F^{*} \mathrm{~S}$ & $\mathrm{~V}$ & $\mathrm{~F}^{*} \mathrm{~S}$ & $\mathrm{~V}$ \\
\hline $\begin{array}{l}\text { I do not } \\
\text { know }\end{array}$ & 0 & - & 4 & - & 0 & - & 0 & - & 0 & - & 1 & - & 0 & - & 0 & - & 0 & - \\
\hline $\begin{array}{lr}0 & \text { Most } \\
\text { Irrelevant }\end{array}$ & $2 * 1$ & 2 & $1 * 1$ & 1 & $5 * 1$ & 5 & $4 * 1$ & 4 & $0 * 1$ & 0 & $0 * 1$ & 0 & $0 * 1$ & 0 & $1 * 1$ & 1 & $0 * 1$ & 0 \\
\hline $\begin{array}{l}1 \\
\text { Irrelevant }\end{array}$ & $3 * 2$ & 6 & $6 * 2$ & 12 & $11 * 2$ & 22 & $7 * 2$ & 14 & $0 * 2$ & 0 & $1 * 2$ & 2 & $0 * 2$ & 0 & $0 * 2$ & 0 & $0 * 2$ & 0 \\
\hline 2 Not at all & $4 * 3$ & 12 & $6 * 3$ & 18 & $13 * 3$ & 39 & $10 * 3$ & 30 & $1 * 3$ & 3 & $3 * 3$ & 9 & $1 * 3$ & 3 & $3 * 3$ & 9 & $1 * 3$ & 3 \\
\hline 3 Neutral & $15 * 4$ & 60 & $24 * 4$ & 96 & $25 * 4$ & 100 & $24 * 4$ & 96 & $5 * 4$ & 20 & $12 * 4$ & 48 & $8 * 4$ & 32 & $14 * 4$ & 56 & $5 * 4$ & 20 \\
\hline $\begin{array}{lc}4 & \text { Less } \\
\text { Relevant }\end{array}$ & $22 * 5$ & 110 & $32 * 5$ & 160 & $34 * 5$ & 170 & $34 * 5$ & 170 & $25 * 5$ & 125 & $38 * 5$ & 190 & $14 * 5$ & 70 & $22 * 5$ & 110 & $25 * 5$ & 125 \\
\hline 5 Relevant & $33 * 6$ & 198 & $23 * 6$ & 138 & $15 * 6$ & 90 & $23 * 6$ & 138 & $36 * 6$ & 216 & $29 * 6$ & 174 & $29 * 6$ & 54 & $43 * 6$ & 258 & $36 * 6$ & 216 \\
\hline $\begin{array}{l}6 \text { Most } \\
\text { Relevant }\end{array}$ & $26 * 7$ & 182 & $9 * 7$ & 63 & $2 * 7$ & 14 & $3 * 7$ & 21 & $38 * 7$ & 266 & $21 * 7$ & 147 & $53 * 7$ & 371 & $22 * 7$ & 154 & $38 * 7$ & 266 \\
\hline Total & \multicolumn{2}{|c|}{570} & \multicolumn{2}{|c|}{488} & \multicolumn{2}{|c|}{$\frac{1}{440}$} & \multicolumn{2}{|c|}{$\frac{1}{473}$} & \multicolumn{2}{|c|}{$\frac{1}{630}$} & \multicolumn{2}{|c|}{570} & \multicolumn{2}{|c|}{530} & \multicolumn{2}{|c|}{$\frac{1}{588}$} & \multicolumn{2}{|c|}{630} \\
\hline
\end{tabular}


Table 13 Calculation of factors based on the participants' answers 19-27.

\begin{tabular}{|c|c|c|c|c|c|c|c|c|c|c|c|c|c|c|c|c|c|c|}
\hline & \multicolumn{2}{|c|}{$\begin{array}{c}19 . \\
\text { Religiousness } \\
\text { \& belief }\end{array}$} & \multicolumn{2}{|c|}{$\begin{array}{c}20 . \\
\text { Optimism }\end{array}$} & \multicolumn{2}{|c|}{$\begin{array}{c}21 . \\
\text { Realism }\end{array}$} & \multicolumn{2}{|c|}{$\begin{array}{c}22 . \\
\text { Maturity }\end{array}$} & \multicolumn{2}{|c|}{$\begin{array}{c}23 . \\
\text { Playfulness }\end{array}$} & \multicolumn{2}{|c|}{$\begin{array}{c}24 . \\
\text { Discipline }\end{array}$} & \multicolumn{2}{|c|}{$\begin{array}{c}25 . \\
\text { Lack of } \\
\text { Illness }\end{array}$} & \multicolumn{2}{|c|}{$\begin{array}{c}26 . \\
\text { Engagement }\end{array}$} & \multicolumn{2}{|c|}{$\begin{array}{c}27 . \\
\text { Inner } \\
\text { Freedom }\end{array}$} \\
\hline & $\mathrm{F}^{*} \mathrm{~S}$ & $\mathrm{~V}$ & $\mathrm{~F}^{*} \mathrm{~S}$ & $\mathrm{~V}$ & $F^{*} S$ & $\mathrm{~V}$ & $\mathrm{~F}^{*} \mathrm{~S}$ & $\mathrm{~V}$ & $\mathrm{~F} * \mathrm{~S}$ & $\mathrm{~V}$ & $\mathrm{~F}^{*} \mathrm{~S}$ & & $\mathrm{~F}^{*} \mathrm{~S}$ & & $\mathrm{~F} * \mathrm{~S}$ & $\mathrm{~V}$ & $\mathrm{~F}^{*} \mathrm{~S}$ & $\mathrm{~V}$ \\
\hline $\begin{array}{l}\text { I do not } \\
\text { know }\end{array}$ & 0 & - & 1 & - & 4 & - & 1 & - & 3 & - & 0 & - & 0 & - & 4 & - & 0 & - \\
\hline $\begin{array}{l}0 \text { Most } \\
\text { Irrelevant }\end{array}$ & $19 * 1$ & 19 & $0 * 1$ & 0 & $1 * 1$ & 1 & $4 * 1$ & 4 & $0 * 1$ & 0 & $0 * 1$ & 0 & $0 * 1$ & 0 & $6 * 1$ & 6 & $0 * 1$ & 0 \\
\hline $\begin{array}{l}1 \\
\text { Irrelevant }\end{array}$ & $16 * 2$ & 32 & $1 * 2$ & 2 & $0 * 2$ & 0 & $1 * 2$ & 2 & $3 * 2$ & 6 & $3 * 2$ & 6 & $2 * 2$ & 4 & $2 * 2$ & 4 & $0 * 2$ & 0 \\
\hline $\begin{array}{l}2 \text { Not at } \\
\text { all }\end{array}$ & $14 * 3$ & 42 & $0 * 3$ & 0 & $3 * 3$ & 9 & $10 * 3$ & 30 & $6 * 3$ & 18 & $4 * 3$ & 12 & $3 * 3$ & 9 & $7 * 3$ & 21 & $4 * 3$ & 12 \\
\hline 3 Neutral & $22 * 4$ & 88 & $5 * 4$ & 20 & $17 * 4$ & 68 & $17 * 4$ & 68 & $18 * 4$ & 72 & $23 * 4$ & 92 & $15 * 4$ & 60 & $25 * 4$ & 100 & $8 * 4$ & 32 \\
\hline $\begin{array}{l}4 \text { Less } \\
\text { Relevant }\end{array}$ & $12 * 5$ & 60 & $16 * 5$ & 80 & $28 * 5$ & 140 & $24 * 5$ & 120 & $16 * 5$ & 80 & $33 * 5$ & 165 & $17 * 5$ & 85 & $25 * 5$ & 125 & $26 * 5$ & 130 \\
\hline $\begin{array}{l}5 \\
\text { Relevant }\end{array}$ & $15 * 6$ & 90 & $43 * 6$ & 258 & $40 * 6$ & 240 & $38 * 6$ & 228 & $33 * 6$ & 98 & $30 * 6$ & 180 & $32 * 6$ & 192 & $27 * 6$ & 162 & $35 * 6$ & 210 \\
\hline $\begin{array}{l}6 \text { Most } \\
\text { Relevant }\end{array}$ & $7 * 7$ & 49 & $39 * 7$ & 273 & $12 * 7$ & 84 & $10 * 7$ & 70 & $26 * 7$ & 182 & $12 * 7$ & 84 & $36 * 7$ & 252 & $9 * 7$ & 63 & $32 * 7$ & 224 \\
\hline Total & \multicolumn{2}{|c|}{380} & \multicolumn{2}{|c|}{633} & \multicolumn{2}{|c|}{542} & \multicolumn{2}{|c|}{522} & \multicolumn{2}{|c|}{456} & \multicolumn{2}{|c|}{539} & \multicolumn{2}{|c|}{602} & \multicolumn{2}{|c|}{481} & \multicolumn{2}{|c|}{608} \\
\hline
\end{tabular}


Table 14 Calculation of factors based on the participants' answers 28-34.

\begin{tabular}{|c|c|c|c|c|c|c|c|c|c|c|c|c|c|c|}
\hline & \multicolumn{2}{|c|}{$\begin{array}{c}28 . \\
\text { Productivity }\end{array}$} & \multicolumn{2}{|c|}{$\begin{array}{c}29 . \\
\text { Innovativeness }\end{array}$} & \multicolumn{2}{|c|}{$\begin{array}{c}30 . \\
\text { Positive emotional } \\
\text { feeling }\end{array}$} & \multicolumn{2}{|c|}{$\begin{array}{c}31 . \\
\text { Constructive } \\
\text { hobby }\end{array}$} & \multicolumn{2}{|c|}{$\begin{array}{c}32 . \\
\text { Morality }\end{array}$} & \multicolumn{2}{|c|}{$\begin{array}{c}33 . \\
\text { Love }\end{array}$} & \multicolumn{2}{|c|}{$\begin{array}{c}34 . \\
\text { Responsibility }\end{array}$} \\
\hline I do not know & 0 & - & 0 & - & 0 & - & 2 & - & 2 & - & 1 & - & 1 & - \\
\hline $\begin{array}{l}0 \quad \text { Most } \\
\text { Irrelevant }\end{array}$ & $1 * 1$ & 1 & $1 * 1$ & 1 & $1 * 1$ & 1 & $1 * 1$ & 1 & $2 * 1$ & 2 & $0 * 1$ & 0 & $1 * 1$ & 1 \\
\hline 3 Neutral & $12 * 4$ & 48 & $18 * 4$ & 72 & $3 * 4$ & 12 & $13 * 4$ & 52 & $21 * 4$ & 84 & $7 * 4$ & 28 & $15 * 4$ & 60 \\
\hline $\begin{array}{ll}4 & \text { Less } \\
\text { Relevant }\end{array}$ & $32 * 5$ & 160 & $37 * 5$ & 185 & $12 * 5$ & 60 & $28 * 5$ & 140 & $30 * 5$ & 150 & $14 * 5$ & 70 & $30 * 5$ & 150 \\
\hline 5 Relevant & $33 * 6$ & 198 & $23 * 6$ & 138 & $33 * 6$ & 198 & $35 * 6$ & 210 & $20 * 6$ & 120 & $32 * 6$ & 192 & $24 * 6$ & 144 \\
\hline $\begin{array}{l}6 \\
\text { Relevant }\end{array}$ & $21 * 7$ & 147 & $14 * 7$ & 98 & $55 * 7$ & 385 & $18 * 7$ & 126 & $15 * 7$ & 105 & $46 * 7$ & 322 & $26 * 7$ & 182 \\
\hline
\end{tabular}


Finally, factors were sorted in descending order in the basis of the sums explained above. We present it in more visible form:

1. Positive emotional feeling 659

2. Optimism 633

3. Fitness or Goal, Harmony 630

4. Love 627

5. Well-balanced 614

6. Inner freedom 608

7. Lack of illness 602

8. Sport 588

9. Productivity or sociability 572

10. Workability or creativity 570

11. Responsibility 560

12. Constructive hobby 553

13. Realism 542

14. Discipline 539

15. Ability to relax 530

16. Innovativeness 527

17. Maturity 522

18. Constructive program of personality 517

19. Morality 503

20. Normal genes 499

21. Longevity 488

22. Engagement 481

23. Self-reproduction 474

24. Identity rooted in one's Culture or Attractiveness 473

25. Playfulness 456

26. Beauty 440

27. Reproduction of society 415

28. Flow 382

29. Religiousness and belief 380

30. Machine-like 327 


\subsubsection{Results}

Survey questionnaires distributed to 105 participants aged 19 to 63 years. The mean age was 31 (SD 9.1), $66.7 \%(\mathrm{n}=70)$ of the participants were female and $33.3 \%(\mathrm{n}=35)$ male. $2 \%$ had completed secondary school, 45.7 \% had a Bachelor's degree, 35.2\% a Master's degree, $13.3 \%$ a $\mathrm{PhD}$ and $3.8 \%$ others.

Table 11, Table 12, Table 13 and Table 14 show the factors from the point of view of evaluation expressed in numbers given by the members of the population studied. The first five most relevant factors are Positive emotional feeling, Optimism, Fitness, Goal and harmony, and Love, respectively, and the five most irrelevant factors are Machine-like, Religiousness and beliefs, Flow, Reproduction of society, and beauty. Some of the most important aspects of health, such as - Discipline, Ability to relax, Innovativeness and Maturity - were placed by participants in the mid part of our rank order. Not to speak of Creativity. It occupies the 10th place in the rank order of aspects of health. Participants were asked to add factors which they thought were important and they were as follows: no stress, patience, security, proper partner relations, education, healthy diet, social responsibility, motivation, loving animals, spiritual well-being, internal and external balance, faithful and reliable friends.

\subsection{Discussion}

The "Positive emotional feeling" is a dubious criterion, especially if we do not know why a person experiences "positive emotional feeling". If, for example, somebody is a sadist, they will have a positive emotional feeling when they torture the victim. A dictator enjoys acting without any moral and/or practical limitation. An idle person is happy even avoiding work that is necessary for him or her. As far as the aspect of "Optimism" is concerned, this is a very important but by no means an omnipotent feature of health. An optimist can also be a heavy drinker who harms himself and the life of his or her family. The same can be said about the drinker's style of life and social relationships. "Fitness or Goal and Harmony" are again, beyond doubt, very important factors of soundness. However, they have to be understood correctly. Fitness in its classical conceptions spoke of a person's good adaptation to the 
conditions of niches of his bio-cultural environment, and not simply to be smart and strong. Similar statements can be made for goal and harmony. Without goals we live in psychophysical entropy, whereas harmony is essential for all animate and inanimate matter. "Love" is again a notion applicable on both the transcendental and worldly levels. The famous Greek philosopher Empedocles applied it to the solar system, while Jesus Christ applied it to human relationships. It was Newton who first coined from it a secular term. What is in fact the concept of "Well-balanced"? This qualification is appropriate for the large systems which can be characterized by three properties, namely: being complex, contradictory and random. These properties are obligatory because both beyond and beneath the human being and including also the latter, we have not found a unique feature of living systems.

Likewise the items in the middle of the scale present very important aspects from the point of view of health. They are as follows: "Discipline", "Ability to relax", "Innovativeness", "Maturity". These features are even more important than the first five winners of this unusual race. All of them contribute much more and better to private and public health than the first five. There are a lot of average people and medical practitioners who have many things to do with public health questions. Now, let's see the most "inferior" aspects of our scale! They are: "Machine-like", "Religiousness and beliefs", "Flow", "Reproduction of society" and "Beauty". To our great surprise these aspects have the most importance as regards human soundness. "Machine-like" - if it is identified with strict and strong determination - is unacceptable. But if the term machine includes new techniques like the Internet, the matter seems different: strict determination immediately evaporates and the notion of human-like becomes acceptable, important and appropriate. Now, "Religiousness and belief" are the most important values in history. Without them no enlightenment and progress are possible. Mutatis mutandis, the same can be said of humanity and health. "Flow" - the term coined by Csíkszentmihályi - is one of the best characteristics of healthy functioning of man and mankind. (Csíkszentmihályi, 1990)

This proto-psychological type of psychological concept expresses the lack of obstacles in living systems' functioning, without which health is impossible. Finally: "Reproduction of society" and "Beauty" mean, on the one hand, sustainability and on the other hand signal a biological, psychological and mental excellence. 


\subsubsection{Limitations}

The first results of our 34 dimensions 7 levels wellbeing score is presented here. The 34 dimensions were derived from the literature, the 7 levels were defined by the researches who conducted this study. Further studies are needed to validate the design, the Like-type scale used and the results.

\subsection{Summary}

In summary our first remark is: that the laymen's concepts of health are usually upside down notions. What is health and soundness for a layman is the opposite of logic and good sense. Can we illuminate the background of these approaches? We all know that our historical age is the age of liberalism. But what is liberalism? Is it a possibility or is it a necessity? For us liberalism is first all a necessity. Why? Because we, in the Euro-Atlantic culture, have developed our culture to such an extent that it is impossible for the average man to keep up with the changes. The balance between the general and particular values vanishes to the benefit of particularities. As a result, poor man confronts a huge amount of problems in his mental helplessness. Under these circumstances freedom is not a gift, it is a compulsion. Busy with solving their particular problems, people's minds are occupied by particular opinions. The only and useful issue in liberalism is that its practice is similar to the diversity in psychological studies. It can considerably contribute to the growing number of ideas and conceptions and subsequently to selecting and finding the best solution for the time and place. It is no wonder that we found such a distorted picture not only in the health question but in almost all domains of thinking and acting. The only way out of liberalism - a historical phase between the past and the future - lies in the substantial elaboration of a new set of integrative principles which make the culture again simpler, more collective, transparent and helpful. We have to enter a new period of history as soon as possible. 


\section{HEALTH-RELATED QUALITY OF LIFE AND COST-OF-ILLNESS OF PSORIASIS PATIENTS IN IRAN}

Psoriasis represents a social and financial burden for patients and the healthcare system (See Chapter 2). Patients often suffer from disfigurement and from social stigmatization. Because the disease is usually persistent, patients with a diagnosis of psoriasis usually need lifelong care, which also means a lifetime of expenses. Raho et al. performed a systematic literature search to review the evidence available concerning the social burden and costs of psoriasis (the search included 'quality of life', 'burden' or 'stigmatization', 'psychological factors' in PubMed up to January 2010). (Raho et al., 2012) Results suggest that quality of life was affected by psoriasis to a degree comparable with diabetes or cancer.

\subsection{Description of the discussed health problem - psoriasis}

\subsubsection{Epidemiology and definition}

Psoriasis is a chronic inflammatory disease affecting approximately $2 \%$ of the population globally. (Michalek et al., 2017) In Europe, the prevalence of psoriasis varies largely across countries, it ranges between $0.73 \%$ in the United Kingdom to $2.90 \%$ in Italy. In Iran, the prevalence of psoriasis is estimated to be around $1 \%$. (Baghestani et al., 2005, Noorbala\&Kafaie, 2010) In the US, the estimated prevalence of diagnosed psoriasis is $3.15 \%$. However, it is reported to be less prevalent in Asia than in Europe.

HRQOL results of this chapter draw upon the following journal article:

MORADI, M., RENCZ, F.: GULÁCSI, L., MORADI, A., BROSZKY, V. (2015): Health status and quality of life in patients with psoriasis: Iranian cross-sectional survey. Arch Iran Med. 18(3), pp. 153-9. IF 0.931 
(Chandran\&Raychaudhuri, 2010) A quarter of patients develop the disease before the age of 20 years. A further peak in incidence is recorded in the fifth and sixth decades. (Leman\&Burden, 2008)

\subsubsection{Diagnosis of psoriasis}

Psoriasis is a chronic dermatological condition with multiple phenotypical variations and degrees of severity.

Diagnosis is primarily based on the clinical symptoms. The most common clinical subtype is chronic plaque psoriasis, which is also called psoriasis vulgaris, and it is characterised by well-demarcated bright red plaques covered by adherent silvery white scales. (Boehncke\&Schon, 2015) These may appear in any localisation, most often symmetrically, especially the scalp and extensor surfaces of extremities. The differential diagnosis includes other dermatological conditions, such as eczema, lichen planus and systemic lupus erythematosus. (Boehncke\&Schon, 2015) Another clinical subtype, guttate psoriasis is characterized by the rapid development of multiple small papules over wide areas of the body. Generalised pustular psoriasis is a rather rare form, presenting as multiple nonfollicular pustules within plaques of psoriasis. If occurs acutely, it is often associated with fever. There are many genetic and environmental factors described to determine the induction and/or exacerbation of psoriasis (Zeng et al., 2017), for example, stress is a well-known trigger factor playing a role in acute exacerbation of psoriasis (Ferreira et al., 2016). Psychological stress or an abnormal response to stressors were reported to modify the evolution of skin disorders. (Basavaraj et al., 2011)

\subsubsection{Characteristics of the disease}

Psoriasis has a variety of different presentations. The classic presentation is of well-defined red plaques with silver scale. The characteristic scale makes the disorder highly visible and intrusive on the patient's lifestyle. The visible nature of the disease ensures that psoriasis has both physical and psychosocial effects. In normal skin, epidermal cell reproduction and proliferation takes 28 days. In psoriasis this process is considerably accelerated to approximately 4 days, resulting in the deposit of immature cells on the skin. (Ryan, 2008) 
Up to $50 \%$ of patients with psoriasis have concurrent nail psoriasis, with a lifetime incidence of $80 \%$ to $90 \%$ in psoriasis patients. (Reich, 2009) Clinical manifestations of nail psoriasis are pitting, discolouration, onycholysis and subungual hyperkeratosis as well as nail plate crumbling and splinter haemorrhages. Nail psoriasis is associated with discomfort in many patients and leads to significant functional impairment and psychological stress. The often distressing appearance of affected nails impacts the patient tremendously in both work and social activities. Importantly, $80 \%$ of patients with psoriatic arthritis have nail psoriasis. (Baran, 2010)

The physical symptoms of psoriasis include itching, irritation, burning/stinging, sensitivity, and pain. Patients also suffer psychological distress, especially as a result of stigmatization, self-consciousness, and embarrassment, which can in turn affect employment and social activities. (van Voorhees\&Fried, 2009) Disease management will be dependent on disease severity, psychosocial effects and the patient's lifestyle. (Ryan, 2008)

Psoriasis is often associated with a number of comorbid conditions. (Takeshita et al., 2017a, Takeshita et al., 2017b) Psoriatic arthritis (PsA) is the inflammation of the joints, which is present in 20-40\% of individuals with psoriasis and has an estimated prevalence of $0.1-$ $1.0 \%$ in the general population. (Gladman et al., 2005, Mease\&Armstrong, 2014) Obesity, type 2 diabetes, metabolic syndrome (Takeshita et al., 2017a), depression and suicide, smoking, and alcohol consumption are also more common in patients with psoriasis. (Menter et al., 2011, Gupta et al., 1987, Ginsburg\&Link, 1989) Patients with psoriasis demonstrate a higher prevalence of cardiovascular risk factors and may have an increased risk for coronary heart disease, cerebrovascular disease or peripheral arterial disease. (Patel et al., 2011) Epidemiology studies found that psoriasis and Crohn's disease (CD) share common genetic background, with a 3.8 to 7.5-fold incidence of Crohn's disease among psoriasis patients compared with the general population. (Najarian\&Gottlieb, 2003, Menter et al., 2011)

\subsubsection{Disease severity in psoriasis}

According to the European consensus, the severity of psoriasis is defined based on the extent of body surface area (BSA) affected, Psoriasis Area and Severity Index (PASI) and 
Dermatology Life Quality Index (DLQI). (Mrowietz et al., 2011) Mild disease is defined as $(\mathrm{BSA} \leq 10$ or PASI $\leq 10)$ and $\mathrm{DLQI} \leq 10$, while moderate to severe psoriasis is defined as $(\mathrm{BSA}>10$ or PASI > 10) and DLQI > 10. (Finlay, 2005) (BSA, PASI and DLQI measures are introduced in detail in Chapter 5) The literature suggests that four-fifth of patients present with mild disease, whereas $20 \%$ have moderate to severe disease. (Menter et al., 2011)

\subsubsection{Health-related quality of life}

Psoriasis may interfere significantly with patients' health-related quality of life (HRQOL). (Bhosle et al., 2006, De Korte et al., 2004, Gonzalez et al., 2016) Despite being a non-lifethreatening disease, it poses a great deal of social and financial burden to the patients and the societies. (Raho et al., 2012)

The literature suggest that even if the disease involves small BSA, it can have a substantial psychological impact on one's personal well-being, especially when it affects face, décolletage, handnails or the genital area. (Menter et al., 2011) For example, psoriatic lesions on the face or scalp may be associated with considerable embarrassment and may considerably impair quality of life. (De Korte et al., 2004) Involvement of the genital skin occurs in $29-40 \%$ of patients with psoriasis, which may interfere with psychosocial wellbeing of patients. (Meeuwis et al., 2011)

It has been estimated that patients with moderate to severe psoriasis suffer from a significant (15-20\%) decrease in working ability. (Mustonen et al., 2015, Chan et al., 2009, Pearce et al., 2006, Meyer et al., 2010) In recent years, introduction of biological agents opened up new horizons in the treatment of the patients. Compared to standard treatment, they proved clinical efficacy, but at a higher cost. (Iskandar et al., 2017)

Measurement of HRQOL in psoriasis has a growing literature. A large number of generic as well as disease-specific questionnaires have been used is psoriasis patients so far (e.g. EQ5D, Medical Outcomes Study 36-Item Short Form (SF-36), Dermatology Life Quality Index (DLQI), Skindex-29, Skindex-17, Skindex-16, The Psoriasis Index of Quality of Life (PSORIQOL), Dermatology Quality of Life Scales (DQOLS). (Ali\&Cueva, 2017) Using 
valid HRQOL questionnaires both routine practice and clinical research is crucial. (Bronsard et al., 2010)

In randomized controlled trials (RCTs) of psoriasis treatments, DLQI is the most commonly used HRQOL instrument (83\%), followed by the SF-36 (31\%), EQ-5D) (15\%), and Psoriasis Disability Index (14\%) and Skindex (5\%). (Ali\&Cueva, 2017) The EQ-5D is the most commonly applied HRQOL measure in cost-effectiveness analyses of psoriasis interventions. (Gutknecht et al., 2016)

The DLQI plays a particularly important role in the management of psoriasis patients, it is not only recommended to use the DLQI to assess the burden of plaque-type psoriasis on the HRQOL in adult patients before the initiation of a systemic treatment and during follow-up to evaluate the therapeutic effect, but it is among eligibility criteria to receive biological therapy in many countries. (Wakkee et al., 2008, Rencz et al., 2015)

\subsubsection{Treatments of psoriasis}

The goals of psoriasis treatment are to gain initial and rapid control of the disease process, decrease the percentage of body surface area involved, decrease plaque lesions, achieve and maintain long-term remission, minimize adverse events, and improve patient HRQOL. (Lebwohl, 2005)

Treatment modalities are chosen on the basis of disease severity, relevant comorbidities, patient preference (including cost and convenience), efficacy, and evaluation of individual patient response. (Menter\&Griffiths, 2007) Therapy varies depending on disease severity and spread and will shift from control of acute flares to long-term maintenance. For patients with less than $20 \%$ body surface involvement, topical therapy is the most appropriate choice for initial treatment. (Tristani-Firouzi\&Krueger, 1998) Primary treatment options for localized psoriasis include tar preparations, corticosteroids, calcipotriene, tazarotene and anthralin. Tar has reported to show limited effectiveness and may be used at night with more appealing topical corticosteroid preparations during the day. Topical calcipotriene may be the safest treatment for long-term control of face or genital disease because there is no risk of atrophy. Topical tazarotene is more effective with less irritation when used in combination with 
topical corticosteroids. (Feldman, 2000) For lesions that are difficult to control with initial therapy, anthralin or tazarotene may be tried. (Pardasani et al., 2000)

The use of the various forms of phototherapy remains an essential treatment option for moderate to severe forms of psoriasis vulgaris and represents a safe and very effective treatment. (Zanolli, 2003)

Systemic therapy is suggested primarily for patients with moderate to severe psoriasis who cannot be sufficiently treated with topical therapy and/or phototherapy. Treatment of moderate to severe psoriasis includes systemic therapies, such as methotrexate, acitretin, cyclosporine, and biologic agents. (Sukarovska et al., 2007, Lebwohl, 2005) Methotrexate (MTX) is used most frequently for the treatment of moderate to severe plaque-type psoriasis, especially in cases with joint involvement or in pustular or erythrodermic forms. (Smith, 2000, Haider et al., 2014) Ciclosporin is indicated in patients with the most resistant forms of psoriasis, especially with plaque-type disease. Ciclosporin is used as a short-term therapy for 2 to 4 months; courses of treatment can be repeated at intervals. (Pathirana et al., 2009) Ciclosporin can be considered for long-term therapy only in individual cases, with frequent monitoring, particularly for kidney toxicity.

For decades, topical and oral retinoids have been used as antipsoriatic treatments. Etretinate, acitretin, and isotretinoin have been used in the treatment of psoriasis. Approved indications for acitretin are severe psoriasis that cannot be managed by topical treatments or phototherapy, as well as erythrodermic or pustular psoriasis. The acitretin treatment of women of reproductive age is discouraged due to the teratogenic potential of the drug. (Pathirana et al., 2009)

Over the past two decades, the treatment of psoriasis has undergone a revolution with the advent of biologic therapies including adalimumab, etanercept, infliximab, ixekizumab, secukinumab and ustekinumab and they are designed to target specific components of the immune system and are a major technological advancement over traditional immunosuppressive medications. (Sivamani et al., 2013) In Iran, only adalimumab and infliximab are available. (MoHME, 2017) Also, there are further new biologic substances under investigation (eg. brodalumab, risankizumab, guselkumab, tildrakizumab, targeting the 
interleukin-17 and interleukin 23 signaling pathway), which are very promising for the treatment of psoriasis. (Lønnberg et al., 2014, Dong\&Goldenberg, 2017) Efficacy and safety of the interleukin-17 inhibitor ixekizumab have been established and became a registered drug, and brodalumab has been approved by the US Food and Drug Administration in February 2017 and the European Medicines Agency adopted a positive opinion in May 2017.

It is also important to mention that an increasing number of biosimilar drugs are available to treat psoriasis (e.g. biosimilar infliximab, etanercept and adalimumab). Biosimilars are biotechnologically processed protein substances whose amino acid sequence is identical to the reference product. (Radtke\&Augustin, 2014, Nast et al., 2015)

\subsubsection{Assessment of treatment response in psoriasis}

The measures recommended to be used for the assessment of response to treatment by the European Medicines Agency (EMA) (2004) are summarized in Table 15. 
Table 15 Outcome measures suggested to be used in psoriasis by the EMA

\begin{tabular}{|l|l|}
\hline Outcome measure & Description \\
\hline $\begin{array}{l}\text { Visual assessment of } \\
\text { index lesions }\end{array}$ & $\begin{array}{l}\text { Measurements of at least 2 index lesions } \\
\text { representative of the disease (one from refractory area - } \\
\text { elbow or knee, and one from trunk) for separate variables } \\
\text { including erythema, scale and elevation on a 3-point scales. } \\
\text { Among skin signs, elevation is considered the most critical, } \\
\text { scale the least. }\end{array}$ \\
\hline $\begin{array}{l}\text { Body Surface Area } \\
\text { (BSA) }\end{array}$ & $\begin{array}{l}\text { Estimation of BSA affected by psoriasis may be done by } \\
\text { using hand area, which represents approximately 1\% of total } \\
\text { body surface. }\end{array}$ \\
\hline $\begin{array}{l}\text { Clinical signs score - } \\
\text { (TSS) }\end{array}$ & $\begin{array}{l}\text { Sum of signs (redness/erythema, scale/crusting, } \\
\text { thickening/elevation) and symptoms (pruritus) using 3-point } \\
\text { scales (e.g. 0=none, some=1, extensive=2). Score varies } \\
\text { from 0 to 12. Each level of severity (clear, mild, moderate) is } \\
\text { defined in a standardised fashion. }\end{array}$ \\
\hline $\begin{array}{l}\text { Physician's global } \\
\text { assessment of } \\
\text { improvement (PGA) }\end{array}$ & $\begin{array}{l}\text { Global assessment of the patient's overall severity of the } \\
\text { disease on 6 or 7-point scale, scored from « severe » to « } \\
\text { clear » }\end{array}$ \\
\hline $\begin{array}{l}\text { Lattice System } \\
\text { Physicians Global } \\
\text { Assessment (LS-PGA) }\end{array}$ & $\begin{array}{l}\text { LS-PGA incorporates ranges of the percent of BSA involved } \\
\text { and the overall plaque morphology. }\end{array}$ \\
\hline Source: Guidelme On cling
\end{tabular}

Source: Guideline on clinical investigation of medicinal products indicated for the treatment of psoriasis (EMA) (2004)

Health-related quality of life (HRQOL) may be a secondary or tertiary endpoint in pivotal clinical trials. Only validated HRQOL measures are recommended to measure the impact of a treatment, such as the dermatology-specific DLQI or Dermatology Quality Life Scales (DQOLS) or Skindex, or the psoriasis-specific Psoriasis Disability Index (PDI) and Psoriasis Life Stress Inventory (PLSI). However, these HRQOL measures have the drawback that they are not able to generate health utility values for economic evaluations.

\subsubsection{Costs of psoriasis}

In this chapter a brief summary is provided on the costs of psoriasis in various countries from data published after 2010 . 


\subsubsection{Economic burden of psoriasis in European countries}

In Denmark and Norway, Larsen et al. conducted a prospective, non-interventional study in a private dermatologist care setting, before and after the initiation of biological therapy. (Larsen et al., 2013) Overall, 163 psoriasis patients were enrolled to the study, who all received biological therapy. Total annual costs before and after the biological therapy were DKK 78,000 and DKK 286,000, respectively (year of costs 2010).

In France, a retrospective COI study based on health insurance database was performed by Le Moigne et al. from the third-party payer perspective. (Le Moigne et al., 2014) The mean annual total direct medical costs with and without biological therapy were $€ 16,214$ and $€ 3,356$ per patient, respectively (year of costs 2011). Cost of hospitalizations and biological drugs were responsible for the majority of between-group differences.

In Finland, Mustonen et al. assessed the direct and indirect costs of psoriasis a societal perspective. (Mustonen et al., 2013) According to data of 232 patients, total annual medication costs were $€ 1,083$ per patient. Costs of physician visits amounted to $€ 673$ and $€ 359$ in mild and severe psoriasis patients respectively. Biological therapy was associated with very high costs.

Three studies evaluated costs of psoriasis in Germany. In a multicentre, cross-sectional, retrospective study, Berger et al. measured the direct and indirect costs from patient's, thirdparty payer and societal perspectives in German departments and hospitals (year of costs 2002). (Berger et al., 2005) Altogether 192 patients were included. From a third-party payer perspective, per patient costs of psoriasis were $€ 864$ annually. Main cost drivers were prescribed medications (60\%) and inpatient stays (22\%). Complementary and alternative medications cost $€ 596$ to the patients per annum. Annual average cost of patients treated by systemic and photo therapy were $€ 4,985$ and $€ 1,173$, respectively. Indirect costs were as much as $€ 1,440$ per year.

Schöffski et. al. conducted a retrospective analysis, based on data of 184 patients from dermatological practices and hospital outpatient departments. (Schöffski et al., 2007) Total costs of psoriasis per patient was $€ 6,709$ on average (year of costs 2004). Higher costs were 
associated with more severe disease, higher hospitalization rate and larger number of sick leaves.

Steinke et al. compared costs of inpatient and outpatient care in psoriasis, and according to different treatment modalities from a societal perspective in a retrospective study with 120 patients between 2005 and 2006. (Steinke et al., 2013) They found that mean total annual costs per patient added up to $€ 7,092$ in Germany. Annual per patient costs of in- and outpatients were $€ 13,042$ and $€ 2,984$, respectively. Costs of patients treated by systemic biological therapy were $€ 30,200$ (inpatient) and $€ 11,601$ (outpatient).

In Hungary, Balogh et al. conducted a non-interventional, cross-sectional questionnaire survey involving 200 moderate-to-severe psoriasis patients from two academic dermatology departments. (Balogh et al., 2014) Cost calculation was performed from a societal perspective. The majority of the patients $(52 \%)$ were treated by biologics at the time of the survey. The mean annual total cost per patient was $€ 9,254$ (SD $€ 8,502$ ), with direct costs accounting for $86 \%$ (year of costs 2012). The mean total cost of patients treated by biologics was $€ 15,790$.

In Italy, Colombo et al. evaluated the COI associated with moderate to severe psoriasis based on data from 150 patients in multicenter, prospective study. (Colombo et al., 2008) The total costs, including direct and indirect items were measured from the patient's, societal and thirdparty payer's perspectives. Mean annual total costs of psoriasis amounted to $€ 8,371$ per patient (year of costs 2004). Moderate disease was associated with half the costs of the severe disease $(€ 5,226$ vs. $€ 11,434)$. Hospitalization was identified as the main driver of costs.

In the Netherlands, Driessen et al. collected health care resource utilization data 12 months before and after starting biologic therapy including 67 patients. (Driessen et al., 2010) Direct costs before and after biological therapy were $€ 10,146$ and $€ 17,712$ per patient per year, respectively.

In Spain, Carrascosa et al. performed a 12-month, multicentre, prospective longitudinal and observational study enrolling 797 psoriasis patients from a third party payer as well as a societal perspective. (Carrascosa et al., 2006) The mean total cost per patient was $€ 1,079 /$ year 
including direct and indirect costs. Prescription drugs accounted for the majority of costs $(46.6 \%)$.

In Sweden, a prevalence-based prospective study was carried out by Ghatnekar et al. including 164 psoriasis patients. (Ghatnekar et al., 2012) The mean total cost was $€ 994$ per patient per month, which results in a mean annual cost of $€ 11,928 /$ patient (year of costs 2009). Outpatient visits and phototherapy (49\%), biological drugs (20\%) and productivity loss $(22 \%)$ were accounted for the majority of costs.

Navarini et al. analysed resource utilisation data of 383 psoriasis patients in Switzerland. The analysis adopted a societal perspective. (Navarini et al., 2010) Annual total costs per patient were CHF1,800, 3,600 and 17,000-20,000 in mild, moderate and severe psoriasis, respectively (year of costs 2005).

In the UK, Fonia et al. conducted a retrospective observational study with 76 patients. Only direct medical costs were included from a third party payer perspective. (Fonia et al., 2010) Total cost of psoriasis care prior to biological treatment were $£ 4,207$ per patient annually, while after the initiation of biological treatment total costs increased significantly to $£ 11,981$ per patient (year of costs 2004).

\subsubsection{Economic burden of psoriasis outside of Europe}

In the US, Yu et al. conducted a COI study enrolling 56,528 psoriatic patients from societal perspective. (Yu et al., 2009) Compared with controls, psoriatic patients had significantly greater total healthcare costs (\$US5,529 vs \$US3,509) (year of costs 2010). In the line with the literature, patients with more severe psoriasis had greater total healthcare costs than patients with mild psoriasis (\$US10,593 vs \$US5,011), including higher drug costs (\$US4,738 vs \$US1,283).

Another study in the US by Beyer and Wolverton assessed the current total cost of systemic therapy for psoriasis. (Beyer\&Wolverton, 2010) Authors examined the annual trends in psoriasis drug spendings between 2000 to 2008 from a third party payer perspective. Overall, costs for systemic treatment of psoriasis ranged from \$US1,197 for methotrexate to \$US27,577 for alefacept. 
In a large study, based on the IMPACT database Kimball et al. estimated the incremental economic burden associated with psoriasis. (Kimball et al., 2011) The sample consisted of 114,512 psoriasis patients with and without comorbidities. The mean costs were $\$ 1,980$ and $\$ 4,992$ per patient per 6 months in patients with and without comorbidities, respectively (year of costs 2011).

In Canada, a COI study conducted by Levy et al. analysed 90 psoriasis patients' resource utilisation in three Canadian dermatology clinics from societal perspective. (Levy et al., 2012) The estimated mean annual cost of psoriasis was $\$ 7,999$ per patient (year of costs 2008). Direct costs accounted for more than half of the total costs (57\%) The mean lost productivity costs were $\$ 3442$ per patient.

In Malaysia, Tang and his colleagues conducted a retrospective study including 250 psoriasis patients from eight dermatology clinics. (Tang et al., 2013) The total annual per patient cost of psoriasis was RM 1,307 (year of costs 2008).

\subsubsection{Comparison of studies}

Cost-of-illness analysis is a well-recognized tool to demonstrate the financial burden of a disease. A better understanding of the psoriasis economic literature can help inform health policy decision-makers regarding the burden of the disease. The literature suggests that

psoriasis poses a considerable economic burden on societies. Main costs generated by biological drugs. The selected studies cover the period between 2002 and 2014. The studies outlined above cannot be directly compared because of the different countries, currencies, patient populations, health systems and unit costs. It seems that the annual health care spending on psoriasis patients has increased a lot by the introduction of biological drugs. While before the era of biologics, hospitalisation was the main driver of costs, now biologicals are. (Raho et al., 2012) In studies by Larsen, Driessen and Fonia 100\% of the patients received biological therapy, while Balogh examined a sample where $52 \%$ of the patients received biological drugs. (Larsen et al., 2013, Driessen et al., 2010, Fonia et al., 2010, Balogh et al., 2014) All these studies revealed significant increase in costs following the initiation of biologic therapy. Fonia found approximately $£ 9,500$ rise in drug costs, 
Driessen $€ 7,566$ PPPY in the direct costs mainly due to biological drugs, while Larsen observed DKK 208,000 mainly due to the cost of etanercept treatment. (Fonia et al., 2010, Driessen et al., 2010, Larsen et al., 2013) Besides, they found that inpatient admissions were significantly less frequent in patients treated with biologicals. Driessen reported that the number of day-care and hospital admission days per year was reduced by $94 \%$ and $64 \%$, respectively, after the introduction of biologics. (Driessen et al., 2010) (Table 16)

Other significant cost drivers are productivity loss and physician visits. The presence of comorbidities may also increase the costs, for example, in the study by Kimball et al., where incremental costs of comorbidities associated with psoriasis were investigated (Kimball et al., 2011), the presence of cardiovascular diseases increased mostly the costs related to psoriasis.

Disease severity was observed as an important predictor of costs in psoriasis. In the study by $\mathrm{Yu}$ et. al. patients with moderate to severe psoriasis had greater total health care costs compared with patients with mild psoriasis (\$10,593 vs. \$5,011). (Yu et al., 2009) Navarini et al. made a comparison regarding out-of-pocket payments in different disease severity, they found a considerable increase in total average out-of-pocket expenses depending on the severity of disease from CHF 630 per patient per year in mild psoriasis to CHF 2,400 in severe psoriasis. (Navarini et al., 2010) 
Table 16 Cost-of-illness studies in psoriasis

\begin{tabular}{|c|c|c|c|c|c|c|c|}
\hline Author & Country & $\begin{array}{c}\text { Year } \\
\text { of } \\
\text { costs }\end{array}$ & Perspective of the analysis & $\mathbf{N}$ & $\begin{array}{c}\text { Time } \\
\text { horizon of } \\
\text { the } \\
\text { analysis }\end{array}$ & $\begin{array}{c}\text { Rate of } \\
\text { biological } \\
\text { therapy }\end{array}$ & Cost drivers \\
\hline (Levy et al., 2012) & Canada & 2008 & Societal & 90 & 1 year & $13 \%$ & $43 \%$ - productivity loss \\
\hline (Larsen et al., 2013) & $\begin{array}{l}\text { Denmark and } \\
\text { Norway }\end{array}$ & 2010 & Societal/hospital point of view & 163 & 4 years & $100 \%$ & $89 \%$ - medication costs \\
\hline $\begin{array}{l}\text { (Mustonen et al., } \\
\text { 2015) }\end{array}$ & Finland & 2010 & Societal & 236 & 1 year & $5 \%$ & $\begin{array}{l}18 \% \text { - medication and } \\
\text { phototherapy }\end{array}$ \\
\hline $\begin{array}{l}\text { (Le Moigne et al., } \\
\text { 2014) }\end{array}$ & France & 2012 & Third party payer & 1924 & 9 years & $0.30 \%$ & Biological therapy \\
\hline (Berger et al., 2005) & Germany & 2002 & Third-party payer, societal, patient & 192 & 1 year & $0 \%$ & $\begin{array}{l}46 \% \text { - early retirement; } \\
18 \% \text { - medication }\end{array}$ \\
\hline $\begin{array}{l}\text { (Schöffski et al., } \\
\text { 2007) }\end{array}$ & Germany & 2004 & Third-party payer, societal & 184 & 1 year & $0 \%$ & $\begin{array}{l}46 \% \text { - medication, } 30 \% \\
\text { indirect costs }\end{array}$ \\
\hline (Steinke et al., 2013) & Germany & 2006 & Societal & 120 & 1 year & $6 \%$ & $\begin{array}{l}32 \% \text { - inpatient treatment; } \\
28 \% \text { - outpatient }\end{array}$ \\
\hline (Balogh et al., 2014) & Hungary & 2012 & Societal & 200 & 1 year & $52 \%$ & $79 \%$ - biological therapy \\
\hline $\begin{array}{l}\text { (Colombo et al., } \\
\text { 2008) }\end{array}$ & Italy & 2004 & Third-party payer, societal, patient & 150 & 1 year & $0 \%$ & $\begin{array}{l}32 \% \text { - productivity loss; } \\
30 \% \text { - hospitalization }\end{array}$ \\
\hline
\end{tabular}




\begin{tabular}{|c|c|c|c|c|c|c|c|}
\hline Author & Country & $\begin{array}{l}\text { Year } \\
\text { of } \\
\text { costs }\end{array}$ & Perspective of the analysis & $\mathbf{N}$ & $\begin{array}{c}\text { Time } \\
\text { horizon of } \\
\text { the } \\
\text { analysis }\end{array}$ & $\begin{array}{l}\text { Rate of } \\
\text { biological } \\
\text { therapy }\end{array}$ & Cost drivers \\
\hline $\begin{array}{l}\text { (Driessen et al., } \\
\text { 2010) }\end{array}$ & $\begin{array}{l}\text { The } \\
\text { Netherlands }\end{array}$ & 2009 & Societal & 67 & 1 year & $100 \%$ & biological therapy \\
\hline $\begin{array}{l}\text { (Carrascosa et al., } \\
\text { 2006) }\end{array}$ & Spain & 2003 & Third-party payer, societal & 797 & 1 year & N/A & $\begin{array}{l}47 \% \text { - treatment costs; } \\
19 \% \text { - hospitalization }\end{array}$ \\
\hline $\begin{array}{l}\text { (Ghatnekar et al., } \\
\text { 2012) }\end{array}$ & Sweden & 2009 & Societal & 164 & 1 month & $16 \%$ & $\begin{array}{l}49 \% \text { - outpatient visits and } \\
\text { light therapy; } 20 \% \text { - } \\
\text { biological drugs }\end{array}$ \\
\hline $\begin{array}{l}\text { (Navarini et al., } \\
\text { 2010) }\end{array}$ & Switzerland & 2005 & Societal & 3,596 & 1 year & N/A & ambulatory costs \\
\hline (Fonia et al., 2010) & UK & 2008 & Societal & 76 & 1 year & $100 \%$ & intensive care \\
\hline (Yu et al., 2009) & US & 2003 & Societal & 56,528 & 1 year & $0 \%$ & $29 \%$ - drug costs \\
\hline $\begin{array}{l}\text { (Beyer\&Wolverton, } \\
\text { 2010) }\end{array}$ & US & 2008 & Third-party payer & N/A & 9 years & N/A & alefacept treatment \\
\hline $\begin{array}{l}\text { (Kimball et al., } \\
\text { 2011) }\end{array}$ & US & 2011 & Third party payer & 114,512 & 6 months & N/A & $\begin{array}{l}\text { Treatment of } \\
\text { cardiovascular } \\
\text { comorbidities }\end{array}$ \\
\hline
\end{tabular}




\subsubsection{Health-related quality of life and disease burden studies of psoriasis in Middle Eastern countries}

We performed a PubMed search in July 2017 to identify publications on health-related quality of life and cost-of-illness studies in psoriasis, focusing on Middle Eastern countries. Our primary aim was to provide a broad review on HRQOL studies in psoriasis from Iran and the region. Secondarily, our objective was to complement the previous COI review (presented above) which involved publications only after 2010, with special focus on Iran and further 19 selected countries from the region, namely Afghanistan, Armenia, Azerbaijan, Bahrain, Egypt, Iran, Iraq, Jordan, Kuwait, Lebanon, Libya, Oman, Pakistan, Qatar, Saudi Arabia, Syria, Tunisia, Turkey, Turkmenistan, United Arab Emirates. The detailed search strategy is presented in the figure below (Figure 14).

Figure 14 Search strategy used in PubMed for quality of life and cost-of-illness studies in psoriasis in 20 selected countries in the Middle Eastern region

\footnotetext{
("Psoriasis"[Mesh] AND ("Cost of Illness"[Mesh] OR "Quality of Life"[Mesh])) AND (("afghanistan"[MeSH Terms] OR "afghanistan"[All Fields]) OR ("armenia"[MeSH Terms] OR "armenia"[All Fields]) OR ("azerbaijan"[MeSH Terms] OR "azerbaijan"[All Fields]) OR ("bahrain"[MeSH Terms] OR "bahrain"[All Fields]) OR ("egypt"[MeSH Terms] OR "egypt"[All Fields]) OR ("iran"[MeSH Terms] OR "iran"[All Fields]) OR ("iraq"[MeSH Terms] OR "iraq"[All Fields]) OR ("jordan"[MeSH Terms] OR "jordan"[All Fields]) OR ("kuwait"[MeSH Terms] OR "kuwait"[All Fields]) OR ("lebanon"[MeSH Terms] OR "lebanon"[All Fields]) OR ("libya"[MeSH Terms] OR "libya"[All Fields]) OR ("oman"[MeSH Terms] OR "oman"[All Fields]) OR ("pakistan"[MeSH Terms] OR "pakistan"[All Fields]) OR ("qatar"[MeSH Terms] OR "qatar"[All Fields]) OR "Saudi Arabia"[All Fields] OR ("syria"[MeSH Terms] OR "syria"[All Fields]) OR ("tunisia"[MeSH Terms] OR "tunisia"[All Fields]) OR ("turkey"[MeSH Terms] OR "turkey"[All Fields]) OR ("turkmenistan"[MeSH Terms] OR "turkmenistan"[All Fields]) OR "United Arab Emirates"[All Fields])
} 
The search resulted 39 hits, however 15 studies were excluded as these did not focus on psoriasis (N=8) (Borman et al., 2007, Esmail et al., 2015, Guler et al., 2015, Nas et al., 2017, Saad et al., 2011, Talli et al., 2016, Turan et al., 2009, Ullbro et al., 2003), were neither HRQOL nor cost-of-illness studies (N=4) (Ammar-Khodja et al., 2015, Demirel et al., 2013, El-Darouti et al., 2015, Gokdemir et al., 2008), did not report original studies (N=2) or were not from the selected 20 countries $(\mathrm{N}=1)$. (Mork et al., 2004)

None of the studies reported COI results in psoriasis.

HRQOL studies in psoriasis were available from Iran $(\mathrm{N}=4)$ (including our publication, see Chapter 6) (Moradi et al., 2015), Kuwait (N=2), Lebanon (N=1), Saudi Arabia (N=1), Tunisia $(\mathrm{N}=1)$ and Turkey $(\mathrm{N}=15)$, these are briefly summarized below.

\section{Iran}

In Iran, validity of the Persian version of the Psoriasis Disability Index (PDI) questionnaire was tested in a sample of psoriasis patients $(\mathrm{N}=125)$. (Aghaei et al., 2009)

HRQOL in skin diseases was analysed in a sample of 300 patients (psoriasis $\mathrm{N}=100$, alopecia areata $\mathrm{N}=100$, vitiligo $\mathrm{N}=100$ ) from one outpatient clinic. HRQOL was assessed by the Beck Depression Inventory (BDI), SF-36 and DLQI questionnaires. Significantly worse DLQI scores were detected in psoriasis cases than others and SF-36 score were significantly lower as well, BDI scores were the highest in psoriasis group indicating the importance of psychological effects of autoimmune skin diseases. (Ghajarzadeh et al., 2012)

The efficacy of methotrexate plus pioglitazone vs. methotrexate alone in the treatment of plaque-type psoriasis $(\mathrm{N}=44)$ was studied in a single-blinded randomized controlled trial. HRQOL as measured by the DLQI did not differ significantly between the two study arms. (Lajevardi et al., 2015)

Our publication on HRQOL in psoriasis in Iran was identified by the search, results are described in detail in Chapter 6. (Moradi et al., 2015) 


\section{Kuwait}

In Kuwait, the impact of different severity levels in psoriasis on HRQOL was assessed using the DQOLS involving a sample of 330 out-patients with psoriasis. Physical activities were affected in greater than $50 \%$ of cases and it increased significantly with the severity of psoriasis. Social relationships were affected in more than half of the patients. (Al-Mazeedi et al., 2006)

Similar impairment of HRQOL has been demonstrated by the dermatology-specific DLQI instrument in patients with kloids and hypertrophic scars $(\mathrm{N}=48)$ and psoriasis $(\mathrm{N}=48)$ and their scores were higher (worse HRQOL) than of the sex- and age-matched healthy controls ( $\mathrm{N}=48)$. (Balci et al., 2009)

\section{Lebanon}

A study in Lebanon assessing the preferences of patients with psoriasis $(\mathrm{N}=87)$ using vertical rating scale, time trade-off, and standard gamble methods. (Zug et al., 1995)

\section{Saudi Arabia}

The effect of Narrowband ultraviolet B phototherapy on HRQOL in psoriasis (N=72) was evaluated before and after treatment and significant improvement was detected both on DLQI and PASI scores. (Al Robaee\&Alzolibani, 2011)

\section{Tunisia}

In Tunisia, the Tunisian version of the Skindex-29 measure was evaluated involving 60 patients (psoriasis $\mathrm{N}=20$, vitiligo $\mathrm{N}=20$, onychomycosis $\mathrm{N}=20$ ). (Zghal et al., 2003)

\section{Turkey}

The most studies were performed in Turkey, the first was published in 2000, in which depression, anxiety, life satisfaction and affective expression levels were assessed in psoriasis patients $(\mathrm{N}=50)$. The outcomes applied were Beck Depression Inventory (BDI), Spielberger State-Trait Anxiety Scale (STAI I-II), Life Satisfaction Scale (LSS), Courtauld Emotional Control Scale (CECS), Body Image Satisfaction Scale (BIS) and PASI. Compared 
to controls, psoriasis patients reported significantly higher degrees of depression and more body cathexis problems. (Devrimci-Ozguven et al., 2000)

A cross-sectional survey involving subjects with psoriasis vulgaris $(\mathrm{N}=50)$, with lichen planus $(\mathrm{N}=30)$ and healthy control subjects $(\mathrm{N}=40)$ revealed significantly higher Beck depression scores among the patients than in healthy controls, and PASI correlated with the Beck depression score. (Akay et al., 2002)

Another paper reported the development and testing of a HRQOL instrument, namely the Psoriasis Quality of Life Questionnaire (PQLQ) questionnaire involving 75 patients with psoriasis, their relatives and physicians in the development (construct) of the questionnaire, and 156 psoriasis patients in the testing of its reliability and validity. (Inanir et al., 2006)

A study involving 66 female participants (psoriasis $\mathrm{N}=39$, healthy volunteers $\mathrm{N}=27$ ) and 70 male participants (psoriasis $\mathrm{N}=39$, healthy volunteers $\mathrm{N}=31$ ) highlighted that patients with psoriasis, especially females have distinct sexual dysfunction compared with healthy controls regardless of the coexistent depression. (Turel Ermertcan et al., 2006) Similar findings were reported from a smaller study (psoriasis $\mathrm{N}=24$ ). (Mercan et al., 2008)

Symptoms among psoriasis patients was evaluated in a study involving psoriasis patients $(\mathrm{N}=87)$, the outcome measures used were the PASI, DLQI and the Hamilton AnxietyDepression Scale (HAD). Authors found that pruritus was a very common symptom in psoriasis, as well as burning, exudation and bleeding, hence these should be considered in further scoring systems of the disease. (Bilac et al., 2009)

A study involving children and adolescents aged 8 to 18 years $(\mathrm{N}=48)$ with psoriasis confirmed that psoriasis is related to depression and impaired quality of life also in children. (Bilgic et al., 2010)

Indicators of HRQOL in psoriasis was analysed in a follow-up study involving psoriasis patients $(\mathrm{N}=154)$ aged 16 or older. (Aksoy et al., 2011)

Relationship between sleep apnoe and psoriasis was analysed $(\mathrm{N}=33)$ and results suggest that sleep apnoe occurs more frequently in psoriasis patients than in the general population. (Karaca et al., 2013) 
A comparison of psoriasis patients $(\mathrm{N}=51)$ and healthy controls $(\mathrm{N}=51)$ highlighted that psoriasis patients have higher negative problem orientation and impulsive-careless problemsolving style scores than the controls, as well as avoidant problem-solving style and lower life satisfaction. (Eskin et al., 2014)

HRQOL of patients with psoriatic arthritis (PsA, $\mathrm{N}=80)$ and psoriasis $(\mathrm{N}=40)$ patients and of healthy subjects $(\mathrm{N}=40)$ was compared and patients with psoriasis and PsA had worse HRQOL and patients with PsA had worse functional status than healthy individuals. (Tezel et al., 2015)

Impact of functional pruritus compared with mild psoriasis on HRQOL was assessed in total of 73 patients (psoriasis $\mathrm{N}=40$, functional pruritus $\mathrm{N}=33$ ) and similar negative impact was detected in the two diagnoses. (Altunay et al., 2014)

The relationship between HRQOL and the severity of psoriasis was analysed $(\mathrm{N}=127)$ in a cross-sectional survey. HRQOL of was strongly reduced and significant relationship was confirmed for DLQI with nail psoriasis and smoking and a linear, positive correlation was detected between the DLQI and BSA but not between the DLQI and PASI. (Cakmur\&Dervis, 2015)

Coping strategies of psoriasis patients were compared to control subjects (psoriasis vulgaris $\mathrm{N}=37$, control subjects $\mathrm{N}=42$ ) and in contrast to previous results in the literature, no significant differences in general psychiatric symptoms and coping strategies between the psoriasis patients and the control group. (Balta et al., 2016)

The TUR-PSO cross-sectional observational study involved 3971 psoriasis from 40 centers in Turkey. The DLQI and EQ-5D questionnaires were applied to assess patient's HRQOL. Mean DLQI was $7.03 \pm 6.02$, and the Anxiety/depression health dimension of the EQ-5D was the most frequently affected. Only $4.1 \%$ were on a biologic treatment, and only $30.5 \%$ of moderate to severe psoriasis patients were treated with systemic therapy. (Atakan et al., 2016) 


\subsubsection{Summary}

According to our best knowledge there is no COI study in psoriasis available in Iran or the Middle East region published in PubMed.

HRQOL studies in psoriasis in the Middle Eastern region (considering 20 selected countries) is increasing. Most studies are from Turkey, however, there are still many countries with no publication activity in the field. Patient samples are typically under 100, the highest sample was in Kuwait $(\mathrm{N}=330)$, only a recently published multicentric study from Turkey involved a large sample $(\mathrm{N}=3971)$. The majority were cross-sectional surveys. DLQI was the most often used HRQOL assessment tool.

\subsection{Research questions and hypotheses}

Several questionnaires have been used to measure health-related quality of life (HRQOL) in patients with psoriasis in Iran, including generic (e.g., SF-36) and disease-specific questionnaires (e.g., Psoriasis Disability Index - PDI, Dermatology Life Quality Index DLQI, Psoriasis Area and Severity Index - PASI) but to our knowledge there cannot be found any studies in the literature that assessed HRQOL of psoriasis patients with EQ-5D in Iran. (Ghajarzadeh et al., 2012, Ansar et al., 2013, Aghaei et al., 2009, Zandi et al., 2011)

Over the past decade, the literature on mapping the generic preference-based measure, EQ$5 \mathrm{D}$ in different diseases has rapidly grown. Heredi et al. mentioned that "According to the University of Oxford HERC online database of mapping studies (Dakin, 2013) only two papers and a conference abstract have been published about mapping EQ-5D in psoriasis, so far”. (Blome et al., 2013, Currie\&Conway, 2007, Norlin et al., 2012, Heredi et al., 2014) Therefore, four papers have been published about mapping EQ-5D in psoriasis.

All these researches investigated the relationship between the dermatology-specific DLQI questionnaire and the EQ-5D index or EQ VAS. These models could explain only 27.0$48.8 \%$ of the variance of EQ-5D.

To our knowledge, no research has been published about cost-of-illness in psoriasis from Iran until now.

The objectives of this cross-sectional study were: 
1. To measure HRQOL of psoriasis patients in Iran with the general measure of EQ-5D and several disease-specific instruments, and analyze the relationship between these outcome measures. Additionally, we compare HRQOL differences between subgroups of patients regarding treatment, clinical subtypes and localization of psoriatic lesions.

2. To compare HRQOL of psoriasis patients to the age-matched general population in Iran

3. Mapping EQ-5D index scores and EQ VAS scores from DLQI to provide utility values for economic evaluations.

4. To estimate annual per patient direct and indirect costs associated with psoriasis in Iran from a societal perspective.

5. To compare HRQOL and cost-of-illness in patients with psoriasis between Iran and Hungary.

\subsection{Methods}

\subsubsection{Study design}

A cross-sectional questionnaire survey including 262 patients has been carried out. 200 patients from Hungary and 62 from Iran enrolled to the study. The Iranian study was performed from May to August 2013 was conducted at Moradi Skin Laser Clinic in Shiraz, Iran. We used a questionnaire that incorporated self-designed items and validated HRQOL and disease severity measures. (Balogh et al., 2014, Heredi et al., 2014) The questionnaire consisted of two parts; the first was filled out by the patients and the second by their dermatologist. Patients were asked about demographic data (age, sex, marital status, weight, and height) and medical history (disease duration, family history, affected body sites). HRQOL was assessed by EQ-5D, EQ VAS, DLQI, and self-assessed disease severity visual analogue scale. All the patients were managed by a single dermatologist who provided data on clinical type of psoriasis, psoriasis treatment in the last 12 months, and moreover, he 
completed PASI, and physician's global assessment of disease activity visual analogue scale (PGA VAS) regarding each patient.

In the Hungarian questionnaire, patient could choose among these areas: face, neck, hands and palms, forearm, fingers and finger nails, legs and thigh in order to state in which part of their body they have the problem. In the Iranian Questionnaire some other parts were added into the questionnaire as follows: knee, ankle, chin, groin, elbow, armpit, finger and toenails according to the talk we had with two dermatologists in Iran. In Iran, usually patients with psoriasis do not use a travel coupon and ambulance mostly used for emergency reasons. So, this part was deleted from the Iranian version of questionnaire compared to that by Balogh et al.

Patients were asked to respond questions about their socio-economic background and demographics. In the Iranian questionnaire, salary categories were as follows: none to 2,500,000 Rials, 2,500,000 to 5,500,000 Rials, 5,500,000 to 7,500,000 Rials, 15,000,000 to 25,000,000 Rials and 25,000,000 to 35,000,000 Rials and more than 35,000,000 Rials. (1 Euro= 40400 Rial; (17 March 2017)

\subsubsection{EQ-5D}

In many countries, utility measures are required for allocation decisions. The EQ-5D is a standardised instrument for use as a measure of health outcome which was introduced in 1990. Applicable to a wide range of health conditions and treatments, it provides a simple descriptive profile and a single index value for health status. (Shaw et al., 2005, Wu et al., 2007)

The EQ-5D is one of the generic HRQOL instruments which has been extensively validated and been shown to be sensitive, internally consistent, and reliable in the general population and other patient groups including psoriasis. (Hurst et al., 1994, Dorman et al., 1997, Schrag et al., 2000) The conceptual basis of the EQ-5D is the holistic view of health, which includes the medical definition, as well as the fundamental importance of independent physical, emotional and social functioning. The concept of health in EQ-5D also encompasses both positive aspects (well-being) and negative aspects (illness). (Gusi et al., 2010) Yaling and his colleagues indicated (2014) that the validity and responsiveness of the EQ-5D was found to 
be good in people with skin diseases, especially plaque psoriasis or psoriatic arthritis. (Yang et al., 2015)

The EQ-5D consists of 2 pages - the EQ-5D descriptive system and the EQ visual analogue scale (EQ VAS). The EQ-5D descriptive system comprises the following 5 dimensions: mobility, self-care, usual activities, pain/discomfort and anxiety/depression). (Euroqolgroup, 1990) Each of these dimensions can be rated as 1 (no problem), 2 (some problem) or 3 (major problem) - this is the so called EQ-5D-3L version of the EQ-5D questionnaire. (Schrag et al., 2000) A new version has been launched recently with 5 levels, named as EQ-5D-5L. An EQ-5D health state may be converted to a single summary index by applying a formula that essentially attaches weights to each of the levels in each dimension. (Golicki et al., 2014, Herdman et al., 2011) This formula is based on the valuation of EQ-5D health states from general population samples thus EQ-5D index reflects the utility of a health status from the societal point of view.

While the general health status measure SF-36 has been used in previous studies comparing psoriasis treatments, there have been few applications of the EQ-5D in clinical trials of patients with moderate to severe plaque psoriasis. In a recent study, Blome et al. aimed to develop and test an algorithm for the transformation of DLQI scores into utilities. Both EQ5D global score and EQ VAS were used as utility measures. Correlations were computed to identify predictors of EQ-5D utilities. Linear stepwise regressions were conducted using DLQI and further possible predictors to find the optimal mapping algorithm. According to the findings, mapping of DLQI on EQ-5D in psoriasis patients currently has severe limitations in validity and clinical relevance. (Blome et al., 2013)

In our study, the validated Farsi version of the EQ-5D was administered in this study. Due to absence of local value set in Iran, the UK weights were applied to calculate EQ-5D scores (i.e. utilities) that can range from -0.594 to +1 , with higher scores referring to better quality of life (Dolan, 1997). EQ-5D is accompanied by a visual analogue scale (EQ VAS) on which patients are asked to provide a self-assessment of their own health in a range from 0 (worst imaginable health state) to 100 (best imaginable health state). 


\subsubsection{Dermatology Life Quality Index (DLQI)}

Dermatology Life Quality Index (DLQI) is the most commonly used dermatology-specific HRQOL questionnaire. (Finlay\&Khan, 1994, Lewis\&Finlay, 2004) It consists of 10 questions covering symptoms, feelings, daily activities, leisure, work and school, personal relationships and treatment side effects that assess patients' perception of the impact of skin condition of their HRQOL last week. Each question is scored on a 4-point Likert scale (0, not at all/not relevant; 1 , a little; 2 , a lot; 3 , very much). DLQI score is calculated by summing up the score of each question and therefore, total scores range between 0 (least impact on HRQOL) and 30 (maximum impact on HRQOL).

The Dermatology Life Quality Index (DLQI), developed in 1994, was the first dermatologyspecific Quality of Life instrument. It is a simple 10-question validated questionnaire which has been used in over 30 different skin conditions in over 33 countries and is available in 85 languages. (Basra et al., 2008). Its use has been described in over 800 publications including many multinational studies. The DLQI is the most frequently used instrument in studies of randomised controlled trials in dermatology. (Ali\&Cueva, 2017)

The DLQI questionnaire is designed for use in adults, i.e. patients over the age of 16. It is self-explanatory and can be simply handed to the patient who is asked to fill it in without the need for detailed explanation. It is usually completed in one to two minutes. Each question is answered by a tick box: "not at all", "a little", "a lot" or "very much". (Lewis\&Finlay, 2004) Each question refers to the impact of the skin disease on the patient's life over the previous week. The scoring of each question is described in Table 17.

The Dermatology Life Quality Index consists of 10 questions concerning symptoms and feelings, daily activities, leisure, work, and school, personal relationships and treatment (Table 18). 


\section{Table 17 Scoring of DLQI questions}

\begin{tabular}{|l|l|}
\hline Answer & Score \\
\hline Very much & 3 \\
\hline A lot & 2 \\
\hline A little & 1 \\
\hline Not at all & 0 \\
\hline Not relevant & 0 \\
\hline Question unanswered & 0 \\
\hline Question 7: "prevented work or studying" & 3 \\
\hline
\end{tabular}

Source: (Finlay\&Khan, 1994)

The DLQI is calculated by summing the score of each question resulting in a maximum of 30 and a minimum of 0 . The higher the score, the more QOL is impaired. The DLQI can also be expressed as a percentage of the maximum possible score of 30 (Power et al., 2009). The possible score range is from 0 (meaning no impact of skin disease on quality of life) to 30 (meaning maximum impact on quality of life) (Table 18 and Table 19).

Score 0 or 1 mean $s$ that psoriasis has no effect on patient's life. Score 2 to 5 mean that psoriasis has a small effect on patient's life, score 6 to 10 means that psoriasis has a moderate effect on patient's life, score 11 to 20 means psoriasis has a very large effect on patient's life and score 21 to 30 means psoriasis has an extremely large effect on patient's life. 
Table 18 Meaning of DLQI scores

\begin{tabular}{|l|l|}
\hline Score & Meaning \\
\hline $0-1$ & no effect at all on patient's life \\
\hline $2-5$ & small effect on patient's life \\
\hline $6-10$ & moderate effect on patient's life \\
\hline $11-20$ & very large effect on patient's life \\
\hline $21-30$ & extremely large effect on patient's life \\
\hline
\end{tabular}

Source: (Hongbo et al., 2005)

Table 19 The six dimensions of the DLQI

\begin{tabular}{|l|l|l|}
\hline Dimension & Number of question & Maximum total score \\
\hline Symptoms and feelings & Questions 1 and 2 & 6 \\
\hline Daily activities & Questions 3 and 4 & 6 \\
\hline Leisure & Questions 5 and 6 & 6 \\
\hline Work and School & Question 7 & 3 \\
\hline Personal relationships & Questions 8 and 9 & 6 \\
\hline Treatment & Question 10 & 3 \\
\hline
\end{tabular}

Source: (Finlay\&Khan, 1994, Hongbo et al., 2005)

\subsubsection{Psoriasis Area and Severity Index (PASI)}

A wide variety of scoring system has been proposed to assess severity of psoriasis. More than 44 different scoring systems were used in 171 randomized clinical trials of psoriasis therapies reviewed by Naldi et al. between 1997 and 2000. (Puzenat et al., 2010)

According to the literature, the Psoriasis Area and Severity Index (PASI) seems to be the most valid and reproducible clinical severity score in the management of adult patients with plaque-type psoriasis. Other scores (Lattice System Physician's Global Assessment - LSPGA, Self-Administered Psoriasis Area Severity Index - SAPASI and Salford Psoriasis Index SPI), however, appear to be interesting and require better evaluation. (Puzenat et al., 2010)

The PASI can be used in everyday clinical practice in the management of adult patients with plaque-type psoriasis, in particular, if a systemic treatment is considered. To assess the severity of plaque-type psoriasis in adult patients, it is recommended to assess during the examination the following symptoms: pruritus, cutaneous pain, burning sensations, bleeding, 
desquamation, sexual-life impairment and functional disability secondary to specific localisations of skin lesions (face, hands, nails, genital areas). (Paul et al., 2010)

PASI is a gold standard to measure the severity of psoriasis (Puzenat et al., 2010, Fredriksson\&Pettersson, 1978). PASI-72 (hereinafter PASI) combines the assessment of severity of lesions and the area affected into a single score in a range of 0 and 72 where highest score refers to worse disease severity. To make up the score, the three features of erythema, induration and desquamation are each assigned a number from 0 to 4 with 4 being the worst; and the extent of involvement of each body region is scored from 0 to 6 .

A patient's PASI is a measure of overall psoriasis severity and coverage. PASI consists of two major steps, for each body section (head, arms, trunk and legs) specify:

1. BSA (Body Surface Area): The body is divided into four regions comprising the head $(\mathrm{h})$, upper extremities $(\mathrm{u})$, trunk (t), and lower extremities (1). In each of these areas, the fraction of total surface area affected is graded on a 0-6 scale ( 0 for no involvement; up to 6 for greater than $90 \%$ involvement). The various body regions are weighted to reflect their respective proportion of body surface area (BSA) (Louden et al., 2004).

2. Severity of lesions

When using the PASI, psoriatic plaques are graded based on three criteria: redness $(\mathrm{R})$, thickness $(\mathrm{T})$, and scaliness $(\mathrm{S})$. Severity is rated for each index on a 0-4 scale ( 0 for no involvement up to 4 for severe involvement).

The composite PASI score can then be calculated by multiplying the sum of the individual-severity scores for each region by the weighted area-of-involvement score for that respective region, and then summing the four resulting quantities; mathematically this evaluation is as follows:

PASI $=0.1\left(R_{h}+T_{h}+S_{h}\right) A_{h}+0.2\left(R_{u}+T_{u}+S_{u}\right) A_{u}+0.3\left(R_{t}+T_{t}+S_{t}\right) A_{t}+0.4\left(R_{1}+T_{1}+S_{1}\right.$ ) $\mathrm{A}_{1}$

Where $R_{h}, R_{u}, R_{t}, R_{l}=$ redness score of plaques on the head, upper extremities, trunk, and lower extremities, respectively (0-4) $T_{h}, T_{u}, T_{t}, T_{l}=$ thickness score of plaques on 
the head, upper extremities, trunk, and lower extremities, respectively (0-4); $S_{\mathrm{h}}, \mathrm{S}_{\mathrm{u}}$, $S_{t}, S_{1}=$ scaliness score of plaques on the head, upper extremities, trunk, and lower extremities, respectively (0-4); and $\mathrm{A}_{\mathrm{h}}, \mathrm{A}_{\mathrm{u}}, \mathrm{A}_{\mathrm{t}}, \mathrm{A}_{\mathrm{l}}=$ area of psoriatic involvement score for the head, upper extremities, trunk, and lower extremities, respectively (0-6). (Louden et al., 2004)

All calculations are combined into a single score (PASI score) in the range of 0 (no psoriasis on the body) and up to 72 (the most severe case of psoriasis).

Typically, the PASI would be calculated before, during and after a treatment period in order to determine how well psoriasis responds to the treatment.

\subsubsection{Physician's global assessment visual analogue scale}

Physician's global assessment visual analogue scale (PGA VAS) is a 100-mm-long visual instrument that allows dermatologists to evaluate easily the current disease activity of the patient. Self-assessed disease severity visual analogue scale is basically similar to PGA VAS but it is scored by the patients themselves.

\subsubsection{Costing}

The costing was performed from societal perspective based on data on resource utilizations provided by the patients and their dermatologist in the questionnaire. Data were collected about direct medical costs, direct non-medical costs and indirect costs (absenteeism and presenteeism). Copayments were considered as a part of direct medical costs. Official unit costs of the Iranian Ministry of Health were applied, where available. Timeframe of the cost analysis was 12 months, and the year of costs was 2016. All the costs were converted to Euros on an exchange rate of EUR $1=$ IRR 42,000.

\subsubsection{Direct medical costs}

Data were collected from patients on the number of GP visits in the past one month, the number of dermatologist visits in the past three months and the number of hospitalizations over the past 12 months. According to the Iranian General Physicians' Association cost of a 
GP visit and a dermatologist outpatient visit are €5.34 and €8.21, respectively (2017h) (Table 20). The daily average cost of hospitalization may vary according to the type of hospital in Iran. The daily rate is the lowest in governmental hospitals (€31.71/day), followed by public hospitals (€45.95/day), whereas the cost may be as high as $€ 85.71 /$ day in private hospitals. In this study, all hospitalizations were considered at a public hospital rate. On average fourteen days of inpatient stays were calculated for each hospitalization.

Cost of ambulance transportation may again vary across different cities (2017a). For the capital, Tehran it is estimated to $€ 23.81$ per occasion (one-way trip). In comparison the price is about $€ 19.05 \mathrm{n}$ other larger cities, whereas $€ 14.29$ in smaller towns. As no data were collected regarding transportation to physician visits or to hospital, this cost item was not included in the cost calculation.

The patients' dermatologist provided data on the treatments applied in the past 12 months. Costs of drugs and topical treatments (i.e. ointments) were based on official pharmacy list prices. Where multiple generic products were available, the drug with lowest price was considered. Furthermore, patients answered questions about spa or a neuropath visits or any other treatments/services used, and also indicated the monthly amount payed for these. 
Table 20 Unit healthcare costs in Iran (2016)

\begin{tabular}{|l|l|l|}
\hline & $\begin{array}{l}\text { Unit cost in } \\
\text { IRR (2016) }\end{array}$ & $\begin{array}{l}\text { Unit cost in } \\
\text { EUR } \\
(2016)^{*}\end{array}$ \\
\hline Direct medical costs & & \\
\hline Cost of a GP visit & 220,000 & 5.24 \\
\hline Cost of an outpatient dermatologist visit & 345,000 & 8.21 \\
\hline Cost of hospitalization per day & & \\
\hline Governmental & $1,332,000$ & 31.71 \\
\hline Public & $1,930,000$ & 45.95 \\
\hline Private & $3,600,000$ & 85.71 \\
\hline Cost of ambulance transportation per occasion & & \\
\hline Tehran & $1,000,000$ & 23.81 \\
\hline Large cities & 800,000 & 19.05 \\
\hline Other cities & 600,000 & 14.29 \\
\hline Direct non-medical costs & & \\
\hline Cost of informal care per hour & 143,571 & 3.42 \\
\hline Transportation costs & & \\
\hline Cost of traveling 1 km by car & $6,000-12,000$ & $0.14-0.29$ \\
\hline Cost of public transportation (return ticket) & $5,000-14,000$ & $0.12-0.33$ \\
\hline Cost of traveling 1 km by train & 500 & 0.01 \\
\hline Indirect costs (productivity loss) & & \\
\hline Average hourly gross wage & 157,143 & 3.74 \\
\hline & & \\
\hline IRR 42,000 as of 00/02/2017 Soun & \\
\hline
\end{tabular}

*EUR $1=$ IRR 42,000 as of 01/02/2017 Source: http://www.ircurrency.com/, (2017f)

\subsubsection{Direct non-medical costs}

Direct non-medical costs may include costs of informal caregivers and transportations other than ambulance. To estimate costs of informal care, patients were asked to indicate how many 
hours of help they receive from informal caregivers such as family members or friends on a weekly average. Cost of informal care per hour was calculated at a rate of $€ 3.42 /$ hour.

Unit costs for transportation are provided in Table 20. Traveling $1 \mathrm{~km}$ by car in Iran costs approximately $€ 0.14$ to $€ 0.29$ depending on various factors, such as the type of car and fuel used. Price of a return bus ticket using public transportation amounts to $€ 0.12$ to $€ 0.33$ depending on the distance and the city. Traveling $1 \mathrm{~km}$ by train costs approximately $€ 0.01 \mathrm{in}$ Iran. In this study, only cost of informal care represents the direct non-medical costs, due to the lack of resource utilization data of transportation.

\subsubsection{Indirect costs}

The costs of productivity loss due to psoriasis were estimated by employing the Human Capital Approach based on patients' responses on the Work Productivity and Activity Impairment questionnaire. (Braakman-Jansen et al., 2012)

The WPAI (Work Productivity and Activity Impairment) questionnaire is used to assess the impact of diseases on work productivity. (Reilly et al., 1993) Psoriasis patients indicated the hours actually worked in the past week, the hours missed by cause of psoriasis and other reasons, and indicated the degree to which psoriasis affected productivity while working on an 11-point rating scale.

Both costs of absenteeism (working hours missed due to psoriasis) and presenteeism (reduced productivity while at work due to psoriasis) were calculated. The average gross hourly wage (€3.74/hour) was applied for the cost calculation.

\subsubsection{Data analysis}

Data analysis and cost calculation were performed using SPSS version 20.0 (SPSS Inc., Chicago, IL, USA). At first, descriptive statistics were implemented. Data were not normally distributed and therefore, the nonparametric Mann-Whitney U-test or Kruskal-Wallis test were used to test for differences in EQ-5D, EQ VAS, DLQI and PASI within subgroups of patients. Spearman's correlation was applied to evaluate the relationship between the

outcome measures. Also, bivariate linear regression was formulated to analyze the 
relationship between the general HRQOL measures EQ-5D and EQ VAS, and the disease specific instrument DLQI (mapping).

\subsection{Results}

\subsubsection{Patient characteristics}

Altogether 62 patients and their dermatologist completed the questionnaire. Mean age was 40.40 (SD 17.53, range 16-86), with $75.8 \%$ males (Table 21). The mean disease duration was 13.60 (SD 11.37) years. Twenty-four (38.7\%) participants were normal weight, 25 $(40.3 \%)$ were overweight, $5(8.1 \%)$ were indicated obese based on their Body Mass Index (BMI) score. Regarding the number of affected body sites, 27 (43.5\%), 20 (32.3\%) and 14 (22.6\%) patients reported involvement of 1-2, 3-4 and 5-7 regions, respectively. Most common localizations were ankles (38.7\%), elbows (38.7\%), knees (33.9\%), forearms (33.9\%), feet/legs (32.3\%), face (27.4\%), hands/palms (24.2\%), and neck/décolletage (22.6 $\%)$.

In total, $66.1 \%$ of the patients were diagnosed with chronic plaque psoriasis followed by scalp psoriasis $35.5 \%$, palmoplantar involvement $27.4 \%$, inverse psoriasis $25.8 \%$, guttate psoriasis $19.4 \%$, and nail psoriasis $19.4 \%$. Overall, 30 (48.4\%) patients used only topical therapy in the last 12 months and $24(38.7 \%)$ patients received systemic non-biological therapy, of whom 16 also applied topicals (Table 21). 
Table 21 Characteristics of the psoriasis patient population $(n=62)$

\begin{tabular}{|l|l|}
\hline & N, \% or mean, SD \\
\hline Males (n, \%) & $47(75.8 \%)$ \\
\hline Age, years (mean, SD) & $40.40(17.53)$ \\
\hline Medical history & \\
\hline Psoriasis duration, years (mean, SD) & $13.60(11.37)$ \\
\hline Body mass index - BMI, kg/m2 (mean, SD) & $25.66(3.29)$ \\
\hline Localization of psoriatic lesions (n, \%) & \\
\hline Ankles & $24(38.7 \%)$ \\
\hline Armpits & $11(17.7 \%)$ \\
\hline Elbows & $24(38.7 \%)$ \\
\hline Face/forehead & $17(27.4 \%)$ \\
\hline Forearms & $21(33.9 \%)$ \\
\hline Feet/legs & $20(32.3 \%)$ \\
\hline Groin & $11(17.7 \%)$ \\
\hline Hand/palm & $15(24.2 \%)$ \\
\hline Inframammary fold & $3(4.8 \%)$ \\
\hline Knees & $21(33.9 \%)$ \\
\hline Neck/décolletage & $17(22.6 \%)$ \\
\hline Number of body sites affected (n, \%) & \\
\hline 1-2 & $27(43.5 \%)$ \\
\hline 3-4 & $20(32.3 \%)$ \\
\hline 5-7 & $14(22.6 \%)$ \\
\hline Clinical types (n, \%) & \\
\hline Chronic plaque psoriasis & $41(66.1 \%)$ \\
\hline Erythrodermic psoriasis & $3(4.8 \%)$ \\
\hline Inverse psoriasis & $16(25.8 \%)$ \\
\hline Guttate psoriasis & $12(19.4 \%)$ \\
\hline Nail psoriasis & $12(19.4 \%)$ \\
\hline Palmoplantar psoriasis & $17(27.4 \%)$ \\
\hline Psoriatic arthritis & $3(4.8 \%)$ \\
\hline Pustular psoriasis & $2(3.2 \%)$ \\
\hline Scalp psoriasis & $22(35.5 \%)$ \\
\hline Treatment in the last 12 months (n, \%) & \\
\hline Systemic non-biological* & $24(38.7 \%)$ \\
\hline Methotrexate & $21(33.9 \%)$ \\
\hline Retinoid & $4(6.5 \%)$ \\
\hline Only topical* & $30(48.4 \%)$ \\
\hline Corticosteroid & $30(48.4 \%)$ \\
\hline Calcipotriol & $8(12.9 \%)$ \\
\hline Salicylic acid & $1(1.6 \%)$ \\
\hline None & $6(9.7 \%)$ \\
\hline
\end{tabular}

* Combinations may have occurred. 


\subsubsection{Health-related quality of life and disease severity}

Mean EQ-5D, EQ VAS, DLQI and PASI scores were 0.62 (SD 0.37), 60.18 (27.26), 10.19 (SD 6.46) and 12.94 (SD 8.28), respectively (Table 22). Average PGA VAS was found significantly lower than self-assessed disease severity VAS (34.66 vs 53.60, p<0.001). In terms of the five underlying dimensions of EQ-5D, 17.7\%, 25.8\%, 27.5\%, 62.9\%, and 62.9\% marked having some or severe problem in mobility, self-care, usual activities, pain/discomfort and anxiety/depression, respectively (Figure 15).

Table 22 Quality of life and disease severity of the Iranian psoriasis patients

\begin{tabular}{|l|l|}
\hline & N, \% or mean, SD \\
\hline EQ-5D score $(-0.594$ to 1$)$ & $0.62(0.37)$ \\
\hline EQ VAS $(0-100)$ & $60.18(27.26)$ \\
\hline DLQI $(0-30)$ & $10.19(6.46)$ \\
\hline PASI $(0-72)$ & $12.94(8.28)$ \\
\hline PGA VAS $(0-100 \mathrm{~mm})$ & $34.66(22.63)$ \\
\hline Self-assessed disease severity VAS $(0-100 \mathrm{~mm})$ & $53.60(26.72)$ \\
\hline
\end{tabular}


Figure 15 Proportion of the patients reporting problem in EQ-5D domains

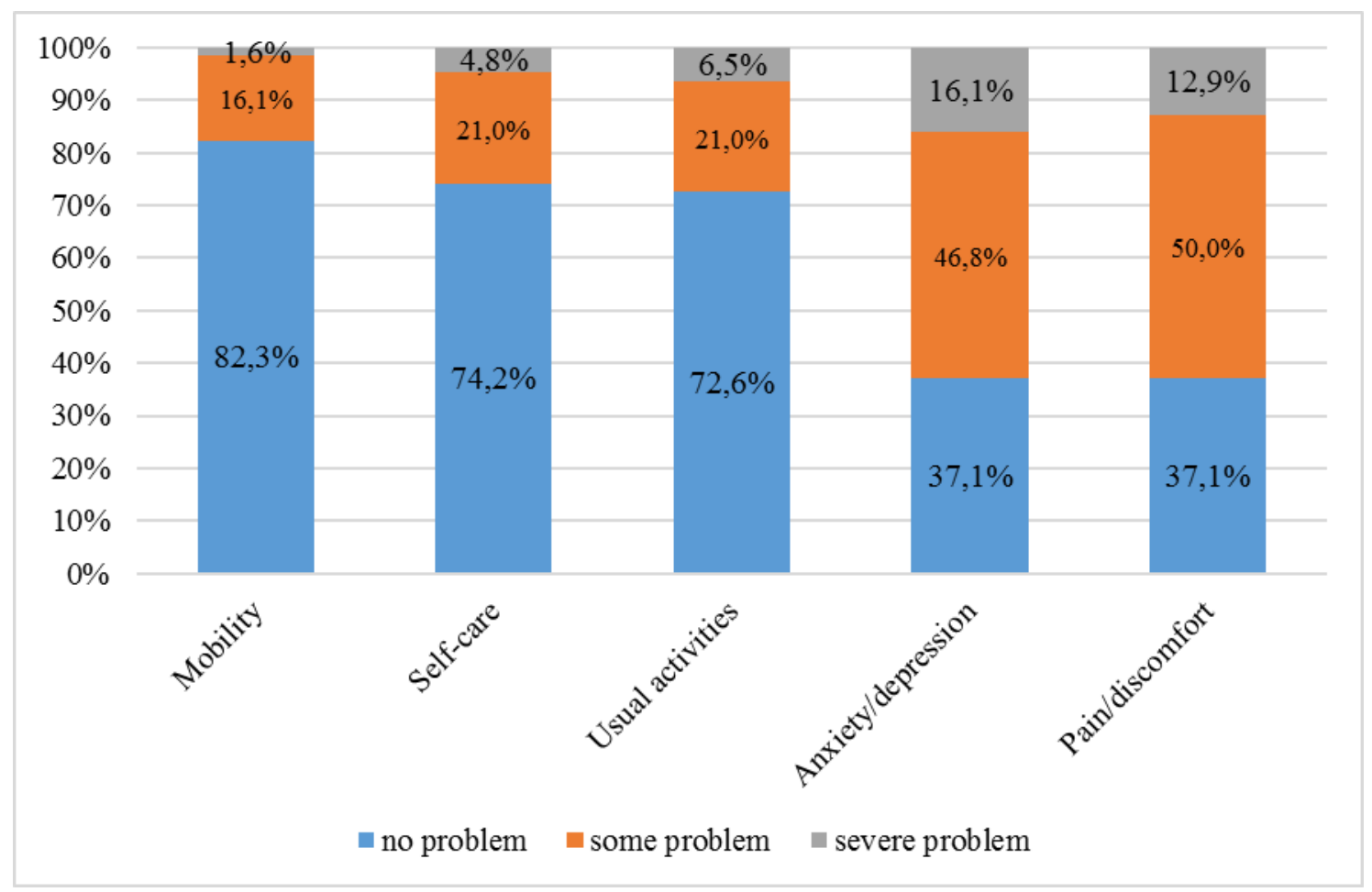

HRQOL and disease severity results of subgroups are presented in Table 22. No significant HRQOL difference was noted between males and females. Amongst clinical types, chronic plaque psoriasis patients showed the best or the second best general health state measured with any instrument; however this difference was not statistically significant. Nail psoriasis was associated with the highest HRQOL impairment in EQ-5D, EQ VAS and DLQI scores, neither this was significant. Besides, scalp psoriasis patients indicated significantly higher disease severity compared to the other clinical types (PASI=16.27, p<0.05). HRQOL was found significantly worse in those who had more body sites affected assessed by any outcome measure. To focus on localization of psoriatic lesions, patients with neck/décolletage involvement showed significantly higher HRQOL reduction in either instruments. Also psoriasis on feet/legs was related to fairly low EQ-5D and high PASI scores (0.46 and 16.54). 
Comparing patients based on their treatment applied in the last 12 months, those who received only topical therapy reported better HRQOL, although this difference was proven significance only regarding PASI scores (Table 23).

Table 23 Subgroup analysis of EQ-5D, EQ VAS, DLQI and PASI scores

\begin{tabular}{|c|c|c|c|c|}
\hline \multirow{2}{*}{ Variables } & \multicolumn{4}{|c|}{ Mean (SD) } \\
\hline & EQ-5D & EQ VAS & DLQI & PASI \\
\hline \multicolumn{5}{|l|}{ Sex } \\
\hline Female & $0.71(0.22)$ & $57.07(26.56)$ & $8.07(4.65)$ & $11.47(5.97)$ \\
\hline Male & $0.60(0.40)$ & $61.20(27.69)$ & $10.87(6.84)$ & $13.40(8.90)$ \\
\hline \multicolumn{5}{|l|}{ Clinical types } \\
\hline Chronic plaque psoriasis & $0.66(0.36)$ & $61.49(26.67)$ & $10.37(5.92)$ & $13.57(8.10)$ \\
\hline Inverse psoriasis & $0.55(0.33)$ & $55.31(29.52)$ & $11.87(6.59)$ & $15.36(10.24)$ \\
\hline Guttate psoriasis & $0.59(0.37)$ & $46.36(27.67)$ & $12.17(7.59)$ & $16.13(8.09)$ \\
\hline Nail psoriasis & $0.47(0.38)$ & $54.09(25.38)$ & $13.00(7.48)$ & $14.25(8.33)$ \\
\hline Palmoplantar psoriasis & $0.52(0.43)$ & $72.19(21.05)^{*}$ & $11.29(7.49)$ & $13.35(5.95)$ \\
\hline Scalp psoriasis & $0.57(0.36)$ & $57.14(29.01)$ & $11.82(7.97)$ & $16.27(8.16)^{*}$ \\
\hline \multicolumn{5}{|c|}{ Number of body sites affected } \\
\hline $1-2$ & $0.77(0.24)^{*}$ & $69.3(24.02)^{*}$ & $7.52(4.75)^{*}$ & $9.17(6.43)^{*}$ \\
\hline $3-4$ & $0.60(0.41)^{*}$ & $57.89(27.86)^{*}$ & $9.75(6.20)^{*}$ & $14.89(9.10)^{*}$ \\
\hline $5-7$ & $0.38(0.40)^{*}$ & $46.43(28.45)^{*}$ & $15.64(6.74)^{*}$ & $18.11(6.83)^{*}$ \\
\hline \multicolumn{5}{|l|}{ Localization of the lesions } \\
\hline Ankles & $0.61(0.40)$ & $58.33(29.91)$ & $11.08(7.38)$ & $15.01(7.54)$ \\
\hline Armpits & $0.54(0.43)$ & $45.91(27.82)$ & $14.00(8.15)$ & $15.93(6.84)$ \\
\hline Elbows & $0.64(0.33)$ & $54.79(27.92)$ & $10.50(5.92)$ & $15.41(8.31)$ \\
\hline Face/forehead & $0.53(0.42)$ & $55.59(28.61)$ & $11.65(6.45)$ & $15.33(9.91)$ \\
\hline Feet/legs & $0.46(0.44)^{*}$ & $53.95(28.51)$ & $12.10(7.59)$ & $16.54(10.17)^{*}$ \\
\hline Forearms & $0.57(0.42)$ & $51.57(31.73)$ & $12.14(7.55)$ & $16.47(8.03)^{*}$ \\
\hline Groin & $0.75(0.25)$ & 63.64(24.50) & $7.36(4.86)$ & $10.86(5.57)$ \\
\hline Hands/palms & $0.54(0.52)$ & 64.64(26.05) & $12.73(8.19)$ & $15.01(8.90)$ \\
\hline Knees & $0.52(0.39)$ & $59.33(30.45)$ & $10.81(6.23)$ & $13.26(7.17)$ \\
\hline Neck/décolletage & $0.36(0.49)^{*}$ & $45.00(30.57)^{*}$ & $16.21(7.17)^{*}$ & $18.65(9.65)^{*}$ \\
\hline \multicolumn{5}{|c|}{ Treatment in the last 12 months } \\
\hline Topical & $0.73(0.23)$ & $62.37(25.13)$ & $9.03(4.81)$ & $10.82(6.62)^{*}$ \\
\hline Systemic non-biological & $0.46(0.47)$ & $56.30(30.50)$ & $12.83(7.96)$ & $16.77(9.58)^{*}$ \\
\hline
\end{tabular}

*Mann-Whitney U test or Kruskal-Wallis test $\mathrm{p}<0.05$. For DLQI and PASI ' 0 ' and for all other measures, the highest value is the best possible outcome. 
Correlations between EQ-VAS, DLQI, PASI, PGA VAS and self-assessed disease severity VAS are described in Table 24.

Both EQ-5D and EQ VAS showed a moderate negative correlation with DLQI $\left(r_{s}=-0.44\right.$ for both, $\mathrm{p}<0.001)$, and PGA VAS as well as self-assessed disease severity VAS $\left(r_{\mathrm{s}}=-0.35\right.$ for both, $\mathrm{p}<0.01)$. Only EQ VAS was significantly associated with PASI $\left(\mathrm{r}_{\mathrm{s}}=-0.31, \mathrm{p}<0.01\right)$, however no significant association was reported with EQ-5D. Moderate positive correlations were found between DLQI, PASI, PGA VAS, and self-assessed disease severity VAS, This relationship was shown to be stronger compared to those with either EQ-5D or EQ VAS.

Table 24 Spearman's correlations between the outcome measures

\begin{tabular}{|l|l|l|l|l|l|}
\hline & $\begin{array}{l}\text { EQ-5D } \\
\text { score } \mathbf{( - 0 . 5 9 -} \\
\mathbf{1})\end{array}$ & $\begin{array}{l}\text { EQ } \\
\text { VAS } \\
\mathbf{( 0 - 1 0 0 )}\end{array}$ & DLQI & PASI & $\begin{array}{l}\text { PGA } \\
\text { VAS }\end{array}$ \\
\hline EQ VAS (0-100) & $0.41^{*}$ & - & $-0.44^{*}$ & $-0.31^{*}$ & $\begin{array}{l}- \\
0.51^{*}\end{array}$ \\
\hline DLQI (0-30) & $-0.44^{*}$ & $-0.44^{*}$ & - & $0.58^{*}$ & $0.61^{*}$ \\
\hline PASI (0-72) & -0.12 & $-0.31^{*}$ & $0.58^{*}$ & - & $0.58^{*}$ \\
\hline PGA VAS (0-100 mm) & $-0.35^{*}$ & $-0.51^{*}$ & $0.55^{*}$ & $0.58^{*}$ & - \\
\hline $\begin{array}{l}\text { Self-assessed disease } \\
\text { severity VAS (0-100 mm) }\end{array}$ & $-0.35^{*}$ & $-0.54^{*}$ & $0.48^{*}$ & $0.48^{*}$ & $0.55^{*}$ \\
\hline
\end{tabular}

*Spearman's rho significant $\mathrm{p}<0.05$. For EQ-5D and EQ-VAS the lowest value, whereas for all other measures the highest value is the worst possible outcome.

\subsubsection{Comparison of HRQOL in psoriasis patients to the Iranian general population}

One of the main advantages of the EQ-5D questionnaire is that being a generic measure of HRQOL results of patients can be compared to those of the general population in countries where population norms are available. In Iran, Karyani et al. published an EQ-5D-3L population norm in 2016. (Karyani et al., 2016) They surveyed overall 600 members of the general population who had health insurance in Tehran, Iran. 
The comparison of the health status by EQ-5D dimensions between psoriasis patients and the age-matched general population (40-49 years) is presented in Figure 16.

Figure 16 Comparison of the proportion of problems across the five domains of the EQ5D-3L in psoriasis patients and the age-matched general population

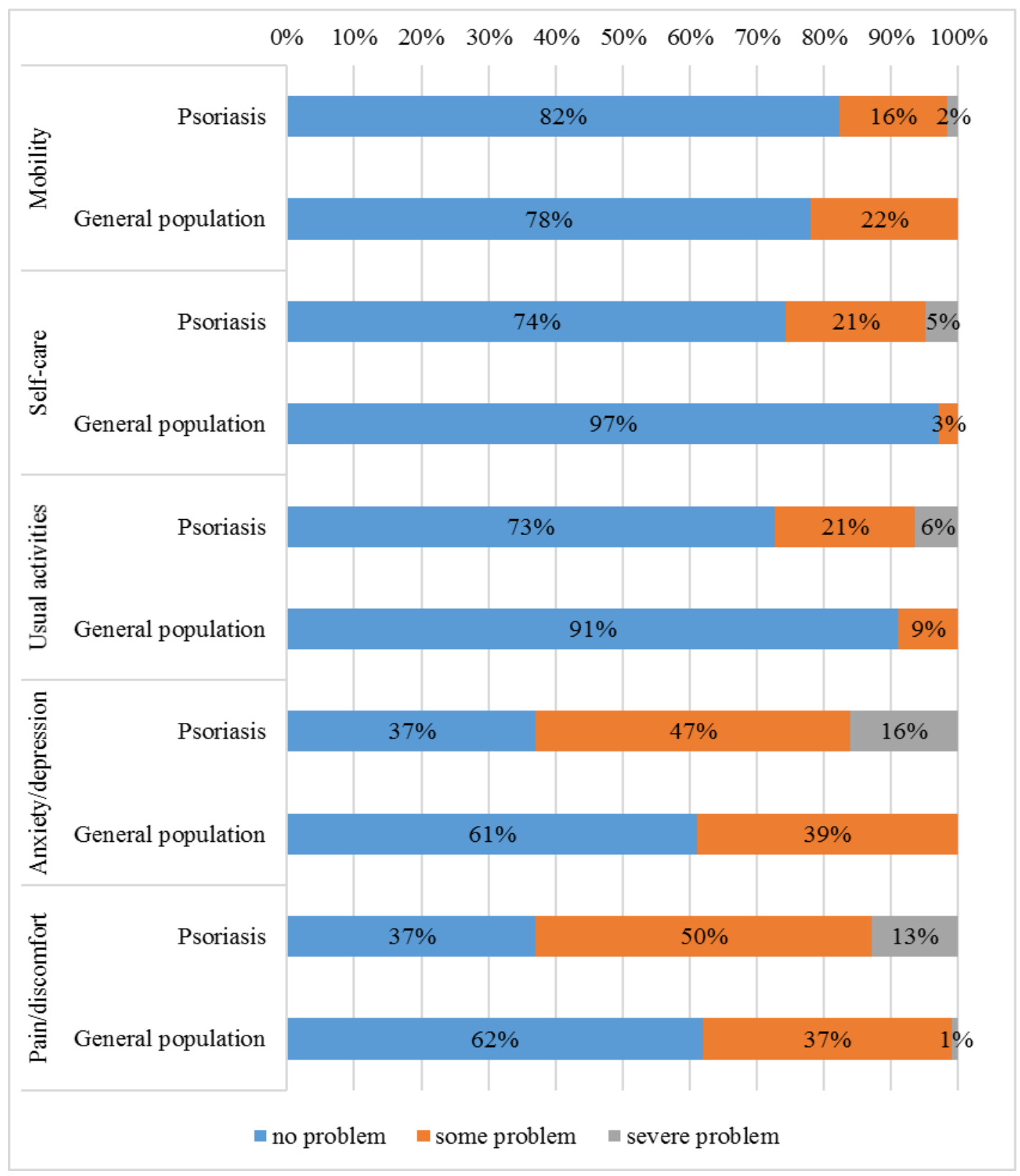

Source: (Karyani et al., 2016) 
In the mobility dimension the rate of reporting problems was approximately equal among psoriasis patients and the general public (18\% vs $22 \%)$. In the other four dimensions, considerably more problems occurred among psoriasis patients. Whereas few members of the general population reported severe problems in any dimension, psoriasis patients more often had such problems; for example, $16 \%$ in anxiety depression and $13 \%$ in pain discomfort.

\subsubsection{Mapping EQ-5D utilities}

A simple linear regression with EQ-5D as a function of the total DLQI score was performed (Fig. 4). Figure 17 shows a scatter plot of EQ-5D as a function of DLQI.

The black diagonal line in Figure 17 is the regression line and consists of the predicted score on EQ-5D for each possible value of DLQI. The distance between the points and the regression line represents the errors of predication. As it shows there are many points that are near the regression line; that shows the error of prediction for those points are small. Linear relationship of DLQI onto both EQ-5D and EQ-VAS was estimated: EQ-5D=0.88 $0.02 *$ DLQI (adjusted $\mathrm{r}^{2}=0.213$, ANOVA $\mathrm{p}<0.001$ ), EQ-VAS $=80.14-1.98 *$ DLQI (adjusted $\mathrm{r}^{2}=0.206$, ANOVA $\mathrm{p}<0.001$ ). Thus, 1 point increase in the DLQI results in 0.02

point decrease in the EQ-5D and 1.98 points decrease in EQ VAS. The DLQI score explained $22.6 \%$ of variance of EQ-5D and $22 \%$ of the variance of EQ-VAS (Figure 17 and Figure 18). 
Figure 17 Scatterplot and a linear relationship between EQ-5D and DLQI

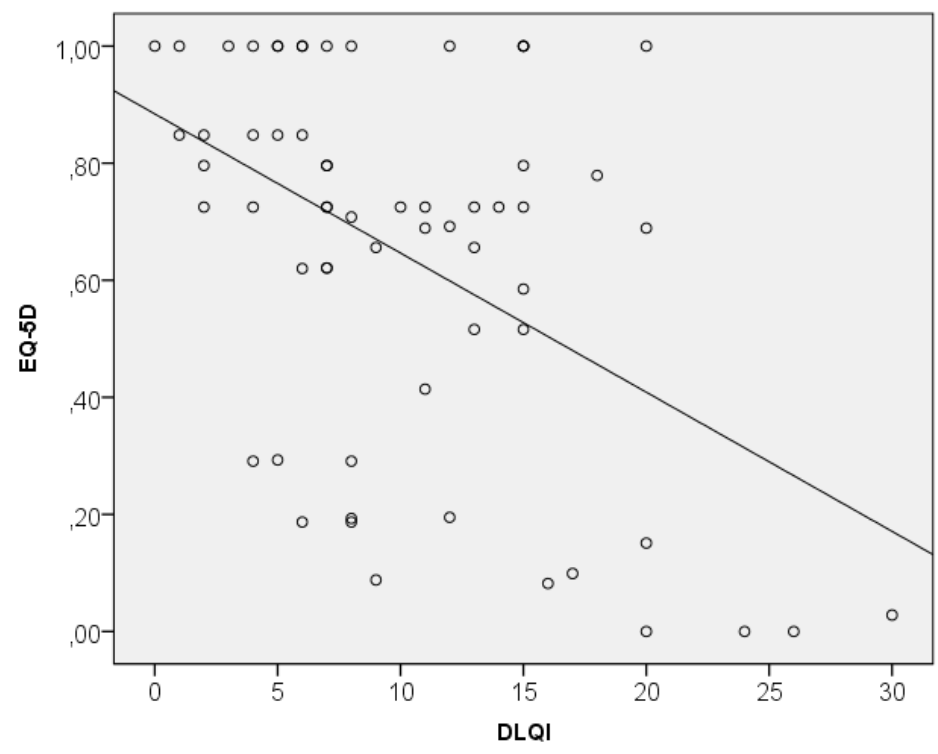

Figure 18 Scatterplot and a linear relationship between EQ-VAS and DLQI

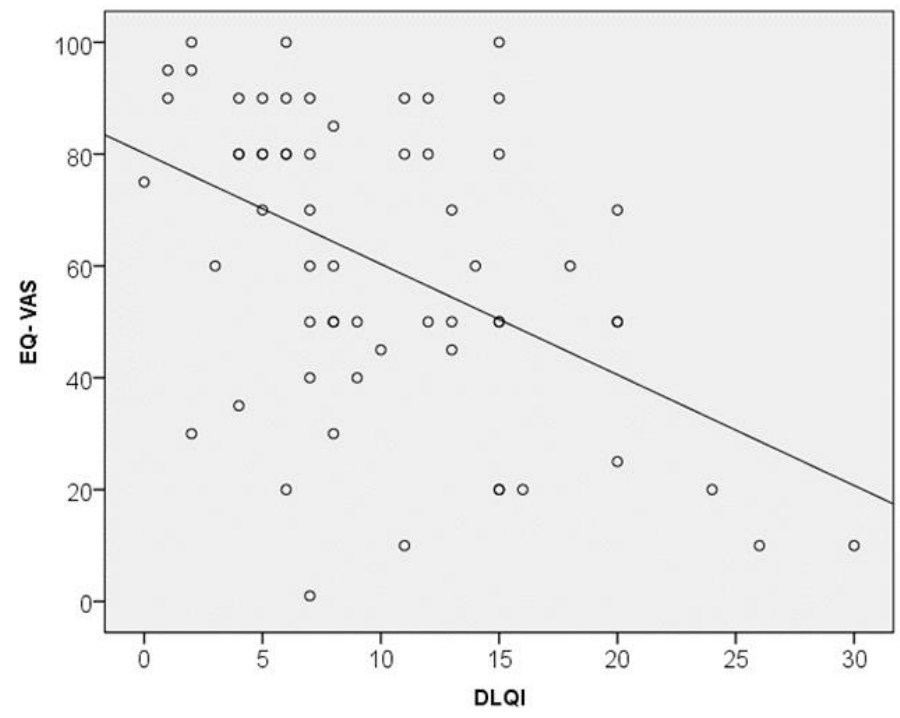




\subsubsection{Resource utilization in Iranian psoriasis}

Table 25 presents the data on healthcare utilization of the patient population. Out of the 62 psoriasis patients, $16(26 \%)$ used GP visit and 44 (71\%) outpatient dermatologist visit. Overall 20 patients $(34 \%)$ were hospitalized due to psoriasis in the past 12 months.

Table 25 Healthcare resource utilization in psoriasis patients

\begin{tabular}{|l|l|l|l|}
\hline Cost categories & $\mathbf{N}$ & $\begin{array}{l}\text { Utilization } \\
\text { (mean, SD) }\end{array}$ & $\begin{array}{l}\text { Utilization } \\
\text { (median) }\end{array}$ \\
\hline Direct medical costs & & & \\
\hline GP visit (occasions/1 month) & 16 & $0.42(0.92)$ & 0 \\
\hline Outpatient dermatologist visit (occasions/3 months) & 44 & $1.27(1.36)$ & 1 \\
\hline Hospitalisation (occasions / year) & 20 & $1.05(1.90)$ & 0 \\
\hline Direct non-medical costs & & & \\
\hline Informal care (hours/week) & 18 & $2.11(4.74)$ & 0 \\
\hline Indirect costs (productivity loss) & & & \\
\hline Absenteeism (hours/week) & 8 & $3.6(11.26)$ & 0 \\
\hline Presenteeism (hours/week) & 22 & $7.75(14.57)$ & 0 \\
\hline
\end{tabular}

Eighteen patients (29\%) used informal care. A mean of 2.11 (SD 4.74) hours of informal care were utilized weekly (Figure 19). The maximum hours of informal care used was 25 hours a week. 
Figure 19 Informal care utilization in psoriasis patients (hours/week)

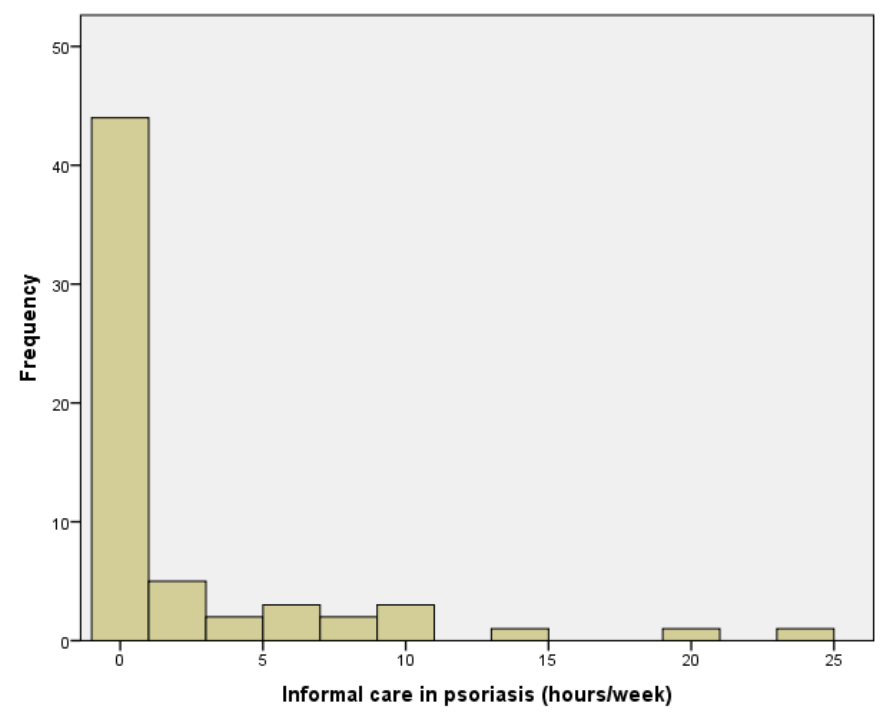

Overall 8 patients (18\%) missed from work due to psoriasis. The mean weekly working hours missed were 3.6 (SD 11.26) (Figure 20).

Figure 20 Absenteeism in psoriasis patients (hours/week)

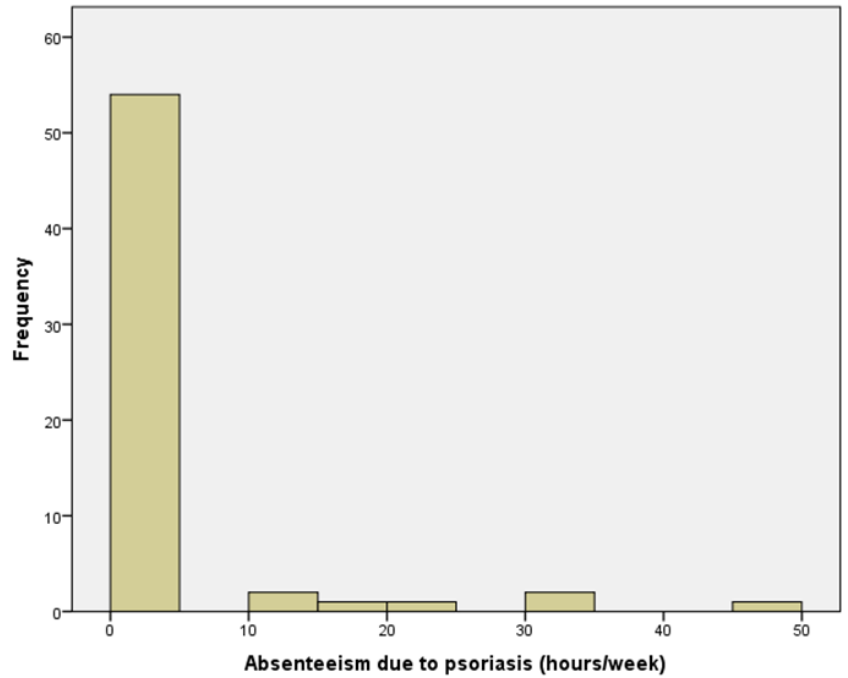


Overall 22 patients (35\%) were bothered by their disease at work. The mean weekly working hours lost due to presenteeism were 7.75 (SD 14.57) (Figure 21).

Figure 21 Presenteeism in psoriasis patients (hours/week)

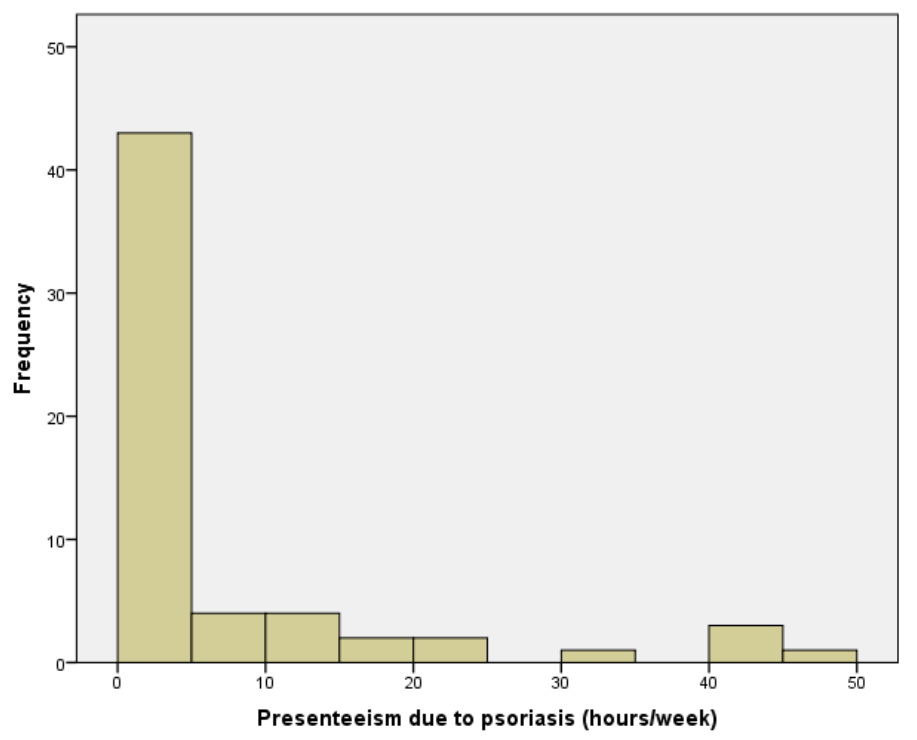

\subsubsection{Cost-of-illness of psoriasis in Iran}

Total annual per patient cost of psoriasis in Iran in 2016 was 141,664,957 Rial, which equates to $€ 3,373$ (SD $€ 4,757$ ). Mean per patient annual costs in Rial are presented in Table 26, while in EUR in Table 27. 
Table 26 Annual costs of psoriasis in Iran in IRR (2016)

\begin{tabular}{|c|c|c|c|c|}
\hline $\begin{array}{l}\text { Health care utilisation and } \\
\text { costs }\end{array}$ & $\begin{array}{l}\text { Mean annual } \\
\text { costs (SD) }\end{array}$ & Median & Minimum & Maximum \\
\hline TOTAL COSTS & $\begin{array}{l}141,664,957 \\
(199,792,454)\end{array}$ & $63,042,872$ & 0 & $\begin{array}{l}817,432,16 \\
4\end{array}$ \\
\hline Direct medical costs & $\begin{array}{l}33,131,694 \\
(53,765,564)\end{array}$ & $5,670,000$ & 0 & $\begin{array}{l}237,820,00 \\
0\end{array}$ \\
\hline GP visit & $\begin{array}{l}1,107,097 \\
(2,416,216)\end{array}$ & 0 & 0 & $10,560,000$ \\
\hline Outpatient dermatologist visit & $\begin{array}{l}1,758,387 \\
(1,872,746)\end{array}$ & 0 & 0 & $8,280,000$ \\
\hline Hospitalisation & $\begin{array}{l}28,327,419 \\
(51,413,111)\end{array}$ & 0 & 0 & $\begin{array}{l}216,160,00 \\
0\end{array}$ \\
\hline Drugs and ointments & $\begin{array}{l}1,919,032 \\
(3,169,851)\end{array}$ & 180,000 & 0 & $17,580,000$ \\
\hline Spa & 2,097 & 0 & 0 & 70,000 \\
\hline Neuropath visit & $6,129(31,485)$ & 0 & 0 & 240,000 \\
\hline Other & $11,532(26,820)$ & 0 & 0 & 100,000 \\
\hline Direct non-medical costs & $\begin{array}{l}15,774,285 \\
(35,409,141)\end{array}$ & 0 & 0 & $\begin{array}{l}171,710,91 \\
6\end{array}$ \\
\hline Informal care & $\begin{array}{l}15,774,285 \\
(35,409,141)\end{array}$ & 0 & 0 & $\begin{array}{l}171,710,91 \\
6\end{array}$ \\
\hline $\begin{array}{l}\text { Indirect costs (productivity } \\
\text { loss) }\end{array}$ & $\begin{array}{l}92,758,978 \\
(170,200,439)\end{array}$ & 0 & 0 & $\begin{array}{l}808,972,16 \\
4\end{array}$ \\
\hline Absenteeism & $\begin{array}{l}29,390,810 \\
(91,967,982)\end{array}$ & 0 & 0 & $\begin{array}{l}490,286,16 \\
0\end{array}$ \\
\hline Presenteeism & $\begin{array}{l}63,368,168 \\
(119,095,947)\end{array}$ & 0 & 0 & 416,743 \\
\hline
\end{tabular}


Table 27 Annual costs of psoriasis in Iran in EUR (2016)

\begin{tabular}{|l|l|l|l|l|}
\hline & $\begin{array}{l}\text { Mean annual costs } \\
\text { (SD) }\end{array}$ & Median & $\begin{array}{l}\text { Minimu } \\
\text { m }\end{array}$ & Maximum \\
\hline TOTAL COSTS & $3372.98(4756.96)$ & 1501.01 & 0 & 19,462 \\
\hline Direct medical costs & $788.85(1280.13)$ & 135.00 & 0 & 5662.38 \\
\hline GP visit & $26.36(57.53)$ & 0 & 0 & 251.43 \\
\hline $\begin{array}{l}\text { Outpatient dermatologist } \\
\text { visit }\end{array}$ & $41.87(44.59)$ & 0 & 0 & 197.14 \\
\hline Hospitalization & $674.46(1224.12)$ & 0 & 0 & 5146.67 \\
\hline Drugs and ointments & $45.69(75.47)$ & 4.29 & 0 & 418.57 \\
\hline Spa & $0.05(0.26)$ & 0 & 0 & 1.67 \\
\hline Neuropath visit & $0.15(0.75)$ & 0 & 0 & 5.71 \\
\hline Other & $0.27(0.64)$ & 0 & 0 & 2.38 \\
\hline Direct non-medical costs & $375.58(843.07)$ & 0 & 0 & 4088.36 \\
\hline Informal care & $375.58(843.07)$ & 0 & 0 & 4088.36 \\
\hline $\begin{array}{l}\text { Indirect costs (productivity } \\
\text { loss) }\end{array}$ & $2208.55(4052.39)$ & 0 & 0 & $19,261.24$ \\
\hline Absenteeism & $699.78(2189,71)$ & 0 & 0 & 11673.48 \\
\hline Presenteeism & $1508.77(2835.61)$ & 0 & 0 & 9922.46 \\
\hline
\end{tabular}

Direct medical, direct non-medical and indirect costs were €789, €376 and €2209, representing $23 \%, 11 \%$ and $65 \%$ of the total costs, respectively. Hospitalizations were responsible for the majority of direct medical costs $(€ 674 ; 85 \%)$, which accounted for about one-fifth of the total per patient costs of psoriasis. Costs of drugs and ointments were about $€ 46$ annually, which takes less than $6 \%$ of direct medical costs. Per patient annual costs of outpatient visits and GP visits were $€ 42$ and $€ 26$, respectively. Other costs including spa and neuropath visits were negligible (Table 27). Overall, €376 was attributable to informal care, which represented $11 \%$ of the total costs. The highest costs were related to productivity loss. Total indirect costs amounted to €2209, with a share of $€ 700(32 \%)$ and $€ 1509$ (68\%) 
between absenteeism and presenteeism, respectively. Absenteeism and presenteeism were responsible for $21 \%$ and $45 \%$ of the total per patient annual cost of psoriasis in Iran (Figure 22).

Figure 22 Distribution of cost across cost categories in psoriasis in Iran

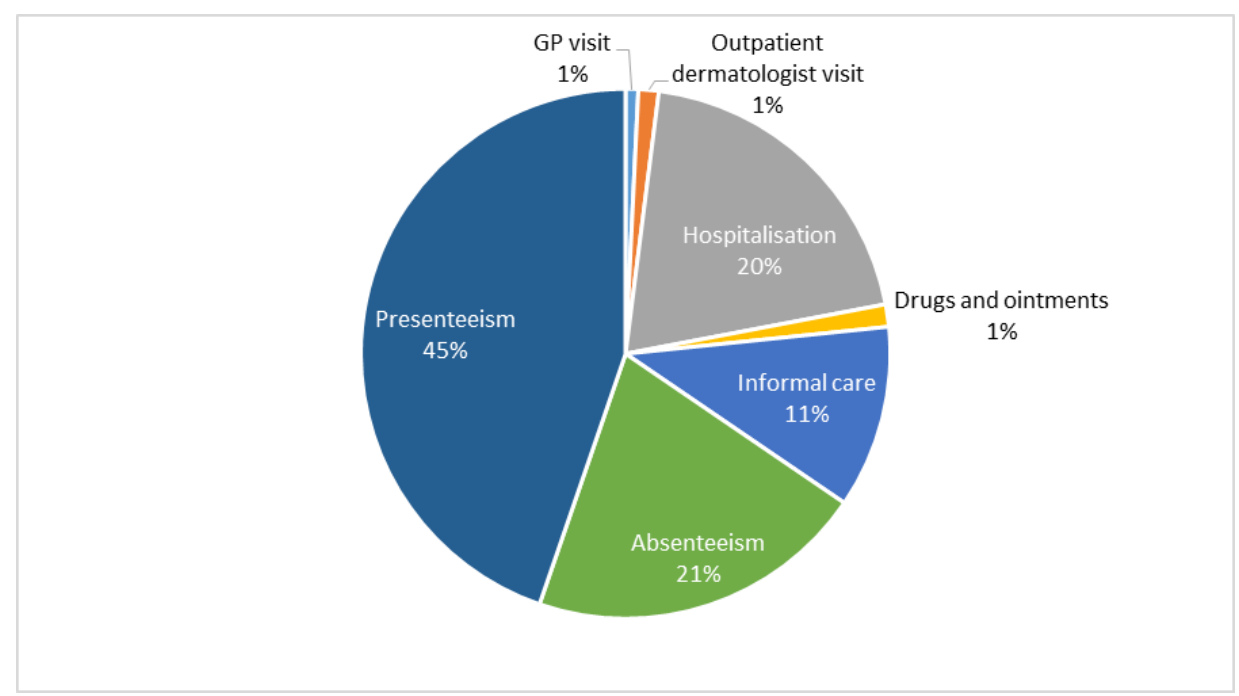




\subsection{Discussion}

\subsubsection{Comparison with previous studies on HRQOL from Iran}

To our knowledge, this is the first study from Iran that measured HRQOL with EQ-5D and EQ VAS. Considerable general HRQOL impairment experienced by psoriasis patients was observed expressed either in EQ-5D (0.62) or in EQ VAS (60.18). Previous studies from Iran have mainly used non-preference-based outcome measures; nevertheless, these instruments except for SF-36 are not feasible to calculate utilities that can be used in economic evaluations. In a survey by Ghajarzadeh et al. involving 100 psoriasis patients with mean age of 36.2 years reported SF-36 and DLQI scores of 59.8 (SD 19.8) and 12.8 (SD 6.1), respectively. (Ghajarzadeh et al., 2012) Ansar et al. reported mean SF-36 score 65.05 (SD 15.51) of 100 psoriasis patients with mean age of 40.45 years. (Ansar et al., 2013) (However, none of these two studies calculated utilities from SF-36 scores. Aghaei et al. described HRQOL of mean 28 (SD 10.66), 10.3 (SD 5.2), and 11.35 (SD 6.00) scores on $\mathrm{PDI}^{2}$, DLQI, and PASI, respectively in 125 chronic plaque psoriasis patients. (Aghaei et al., 2009) In a study of Zandi et al. 97 psoriasis patients with mean age of 35.3 years were characterized by mean HRQOL of 14.1 on DLQI and 18.6 scores on PASI, respectively. (Zandi et al., 2011)

Amongst the 5 dimensions beyond the EQ-5D score, $62.9 \%$ patients reported having some or severe problems in anxiety/depression and pain/discomfort (Figure 15). This seems consistent with earlier evidences that suggested prevalence of clinical depression about $69.4 \%$ amongst Iranian psoriasis patients. (Layegh et al., 2010) This is also supported by findings of Ghajarzadeh et al. where average $\mathrm{BDI}^{3}$ score of psoriasis patients was observed 17.1 (SD 12.3) which approximates the upper borderline between mild and moderate depression. (Ghajarzadeh et al., 2012)

Interestingly, psoriasis on the face and/or forehead was not accompanied by significantly worse HRQOL compared to other body sites measured with any instrument including PASI.

2 ranges from 0 to 45 , where higher score refer to worse HRQOL

${ }^{3}$ ranges from 0 to 63 , where higher score refers to worse depression state 
This finding contradicts to results of a recent Iranian research where authors argued that facial psoriasis patients had significantly higher PASI scores compared to those without facial involvement. (Keshavarz et al., 2013) In an earlier Iranian study conducted by Zandi et al. erythrodermic and pustular types of psoriasis were predictors of the greatest HRQOL impairment measured by DLQI (22.3 and 20.8 scores); nonetheless the comparison of our results with these evidences is hampered by the very small patient number in these subgroups of our study. (Zandi et al., 2011)

Females of our survey showed better HRQOL measured with EQ-5D, DLQI or PASI but not significantly. In contrast, a recently published study from Iran pointed out that female patients reported significantly lower scores in SF-36 than males. (Ansar et al., 2013)

Analyzing the correlations between the outcome measures revealed moderate correlation between the general measure of EQ-5D and EQ VAS and disease-specific DLQI and PASI. Not unexpectedly, disease-specific tools (DLQI, PASI, PGA VAS, self-assessed disease severity VAS) correlated with each other stronger than with EQ-5D or EQ VAS. The relationship of DLQI and PASI in psoriasis was discussed in a prior study from Iran and found lower DLQI related higher PASI scores $(\mathrm{p}<0.001)$ but authors did not report correlation coefficient between these two measures. (Zandi et al., 2011)

It is notable that average PGA VAS was found significantly lower than self-assessed disease severity VAS (34.66 vs 53.60, p<0.001) and suggests an immense discrepancy in disease perception between patients and their physician. Thus, more attention should be paid on assessment of patients' HRQOL that might also support finding the optimal treatment choices. 


\subsubsection{Comparison of HRQOL findings between the findings of Iranian and the Hungarian study}

A very similar questionnaire to this survey was used to assess HRQOL and costs of Hungarian moderate-to-severe psoriasis patients by Herédi et al. and Balogh et al. (Heredi et al., 2014, Balogh et al., 2014); therefore we can compare some main findings of these two studies.

A comparison between the findings of Iranian and Hungarian studies are summarized in Table 28, Table 29, Table 30 and Table 31. (Balogh et al., 2014, Heredi et al., 2014, Moradi et al., 2015)

Mostly the same cross-sectional questionnaire survey was carried out in two countries, Iran and Hungary. Details of the questionnaire and little difference between the questionnaires explained in study design part (6.2.1). Altogether 200 adult psoriasis patients enrolled from two Hungarian university clinics and 62 from an Iranian clinic. Besides HRQOL assessment, data on demographics, applied treatments, affected body sites and clinical types were collected. Mean age of the Hungarian and Iranian patients were $51.2 \pm 12.9$ years with $69 \%$ males, and $40.4 \pm 17.5$ years with $76 \%$ males, respectively. (Table 28 )

Table 28 Characteristics of the Hungarian and Iranian patients

\begin{tabular}{|c|c|c|}
\hline & Hungary & Iran \\
\hline $\mathbf{N}$ & $\mathbf{2 0 0}$ & $\mathbf{6 2}$ \\
\hline Age (mean, SD) & $51.2(12.9)$ & $40.4(17.5)$ \\
\hline Males \% & $69 \%$ & $76 \%$ \\
\hline BMI (mean, SD) & $29.89(5.44)$ & $25.66(3.29)$ \\
\hline $\begin{array}{c}\text { Disease duration } \\
\text { (mean, SD) }\end{array}$ & $21.96(11.67)$ & $13.60(11.37)$ \\
\hline
\end{tabular}

First of all, it should be highlighted, that more than half of the Hungarian patients used systemic biological therapy in the last 12 months but none in the Iranian study. Amongst the Hungarian patients $18 \%$ used none or only topical therapy in the last 12 months, $31 \%$ 
systemic non-biological treatment and 52\% biologicals, whereas in Iran $48 \%$ of the patients applied only topicals and $39 \%$ treated with non-biological systematic therapy.

Mean EQ-5D, DLQI and PASI of the Hungarian and the Iranian sample were $0.69 \pm 0.3$, $6.29 \pm 7.3,8.01 \pm 10$, and $0.62 \pm 0.37,10 \pm 6.5,13 \pm 8.3$, respectively (Table 29). In both researches, psoriatic lesions on the neck/décolletage were associated with the highest HRQOL impairment $(\mathrm{p}<0.05)$. In this current study a very likely explanation for this is that out of the 17 patients with neck/décolletage involvement, 10 reported skin lesions on 5-7 body sites. Regarding clinical types, in Hungary the palmoplantar involvement while in Iran nail psoriasis patients reported the worst general HRQOL (mean EQ-5D scores: $0.36 \pm 0.3$ and $0.47 \pm 0.4$ ). In Iran patients received only topical therapy in the last 12 months reported better HRQOL, compared to those on systemic non-biological treatment while in Hungary, patients on biologicals reported the best HRQOL. (Heredi et al., 2014)

Table 29 Health-related quality of life and disease severity of Hungarian and Iranian patients

\begin{tabular}{|c|c|c|}
\hline & Hungary & Iran \\
\hline \multicolumn{3}{|c|}{ Health-related quality of life and disease severity (mean, SD) } \\
\hline EQ-5D & $0.69(0.3)$ & $0.62(0.37)$ \\
\hline DLQI & $6.29(7.3)$ & $10(6.5)$ \\
\hline PASI & $8.1(10)$ & $13(8.3)$ \\
\hline \multicolumn{3}{|c|}{ Treatment (during the last 12 months) } \\
\hline None or topical therapy & $18 \%$ & $48 \%$ \\
\hline Systematic non-biological & $31 \%$ & $39 \%$ \\
\hline Biological & $51 \%$ & $0 \%$ \\
\hline
\end{tabular}

Correlation between EQ-5D and DLQI was found very similar across the two countries $\left(\mathrm{r}_{\mathrm{s}}=-\right.$ 0.43- and $-0.44, \mathrm{p}<0.001)$, but EQ-5D showed significant correlation with PASI $\left(\mathrm{r}_{\mathrm{s}}=-0.43\right.$, p<0.001) only in Hungary. (Table 29) Strong positive correlation was identified between DLQI and PASI in both countries but only in those patients who received systemic therapy: Iran $\left(r_{s}=0.72, p<0.001\right)$ and Hungary (systemic non-biological: $r_{s}=0.65, p<0.001$, biological: 
$\left.\mathrm{r}_{\mathrm{s}}=0.76, \mathrm{p}<0.001\right)$. Correlation between EQ-5D and DLQI was found very similar across the two countries $\left(\mathrm{r}_{\mathrm{s}}=-0.43\right.$ - and $\left.-0.44, \mathrm{p}<0.001\right)$, but EQ-5D showed significant correlation with PASI $\left(r_{s}=-0.43, p<0.001\right)$ only in Hungary (Table 29).

A strong positive correlation was identified between DLQI and PASI in both countries but only in those patients who received systemic therapy: $\operatorname{Iran}\left(r_{s}=0.72, p<0.001\right)$ and Hungary (systemic non-biological: $\mathrm{r}_{\mathrm{s}}=0.65, \mathrm{p}<0.001$, biological: $\left.\mathrm{r}_{\mathrm{s}}=0.76, \mathrm{p}<0.001\right)$. (Table 30)

Table 30 Spearman's correlations between the outcome measures in Iran and Hungary

\begin{tabular}{|c|c|c|c|c|c|c|}
\hline Countries & \multicolumn{3}{|c|}{ IRAN } & \multicolumn{2}{c|}{ HUNGARY } \\
\hline Measures & $\begin{array}{c}\text { EQ-5D } \\
\text { score } \\
\mathbf{( - 0 . 5 9 - 1 )}\end{array}$ & $\begin{array}{c}\text { DLQ } \\
\text { I }\end{array}$ & PASI & $\begin{array}{c}\text { EQ-5D } \\
\text { score } \\
\mathbf{- 0 . 5 9 - 1 )}\end{array}$ & DLQI & PASI \\
\hline $\begin{array}{c}\text { EQ VAS (0- } \\
\text { 100) }\end{array}$ & $0.41^{*}$ & - & - & $0,56^{*}$ & $-0,43$ & - \\
\hline DLQI (0-30) & $-0.44^{*}$ & - & $0.58^{*}$ & $-0,48^{*}$ & - & $0,81^{*}$ \\
\hline PASI (0-72) & -0.12 & $0.58^{*}$ & - & $-0,43^{*}$ & $0,81^{*}$ & - \\
\hline
\end{tabular}

*Significant $\mathrm{p}<0.05$. For DLQI and PASI ' 0 ' and for all other measures the highest value is the best possible outcome.

Results of the comparison suggest that disease severity, treatments, and culture or countryspecific differences might lead to variations in the relationship between the outcomes measures used in psoriasis. Per patient annual costs of psoriasis in Iran and Hungary are compared in Table 33 by relevant cost categories.

\subsubsection{International comparison of HRQOL results}

We compared our findings to results of earlier cross-sectional studies regarding the relationships between the investigated HRQOL measures (Table 31).

We noticed weak correlation between EQ-5D and PASI similarly to a paper of Norlin et al. from Sweden and of Blome et al. from Germany. (Norlin et al., 2012, Blome et al., 2013) EQ VAS correlated stronger with PASI likewise according to Blome et al. (Blome et al., 2013) 
In the line with all of the previous studies, we identified similar moderate correlation between DLQI and both EQ-5D and EQ VAS. DLQI and PASI were moderately correlated with the value of $r_{s}=0.58$ and also, Norlin et al. found similar result in Sweden. (Norlin et al., 2012)

In a study from Iran, mean age of the patients was 40.4, however in the other studies the mean age of the patients were more than 50 .

EQ-5D has a greatest value in Hjortsberg et al. from Sweden and Finland (0.75) and in Moradi et al. from Iran has the lowest value (0.62). DLQI has the greatest value in Moradi et al. (10.19) and then in Blome et al. (8.6 and 7.5), Hjortsberg et al. (6.8) and the lowest value in from Herédi et al. (6.29). Therefore, psoriasis has more effect on Iranian patients and also Iranian patients have the lowest quality of life compare to the other studied countries. 
Table 31 Comparison of the relationship between EQ-5D, DLQI and PASI with previous studies

\begin{tabular}{|c|c|c|c|c|c|c|c|c|}
\hline \multirow[b]{2}{*}{$\begin{array}{l}\text { Author, } \\
\text { year }\end{array}$} & \multirow[b]{2}{*}{ Country } & \multirow[b]{2}{*}{$\begin{array}{l}\mathbf{N}(\text { mean } \\
\text { age) }\end{array}$} & \multirow{2}{*}{$\begin{array}{l}\text { HRQOL } \\
\text { and } \\
\text { disease } \\
\text { severity } \\
\text { (mean) }\end{array}$} & \multicolumn{5}{|c|}{ Correlations } \\
\hline & & & & $\begin{array}{l}\text { EQ-5D } \\
\& \\
\text { PASI }\end{array}$ & $\begin{array}{l}\text { EQ V } \\
\text { AS \& } \\
\text { PASI }\end{array}$ & $\begin{array}{l}\text { EQ- } \\
\text { 5D \& } \\
\text { DLQI }\end{array}$ & $\begin{array}{l}\text { EQ VA } \\
\text { S \& } \\
\text { DLQI }\end{array}$ & $\begin{array}{l}\text { PASI \& } \\
\text { DLQI }\end{array}$ \\
\hline $\begin{array}{l}\text { This } \\
\text { study, } \\
2014\end{array}$ & Iran & $\begin{array}{l}62(40.4 \\
\text { years) }\end{array}$ & $\begin{array}{l}\text { EQ-5D= } \\
0.62 \\
\text { EQ } \\
\text { VAS }=60.1 \\
8 \\
\text { DLQI=10.1 } \\
9 \\
\text { PASI }=12.9 \\
4\end{array}$ & -0.12 & $-0.31 *$ & $-0.44^{*}$ & $-0.44^{*}$ & $0.58^{*}$ \\
\hline $\begin{array}{l}\text { (Heredi } \\
\text { et al., } \\
2014) * *\end{array}$ & Hungary & $\begin{array}{l}200(51.2 \\
\text { years })\end{array}$ & $\begin{array}{l}\text { EQ- } \\
5 \mathrm{D}=0.69 \\
\text { EQ- } \\
\text { VAS=64.4 } \\
3 \\
\text { DLQI=6.29 } \\
\text { PASI=8.01 } \\
\end{array}$ & $-0.43^{*}$ & $-0.42 *$ & $-0.48^{*}$ & $-0.43^{*}$ & $0.81^{*}$ \\
\hline \multirow{2}{*}{$\begin{array}{l}\text { (Blome et } \\
\text { al., 2013) }\end{array}$} & \multirow{2}{*}{ Germany ${ }^{\mathrm{i}}$} & $\begin{array}{l}\text { Develop- } \\
\text { ment } \\
\text { database: } \\
1,511 \\
\text { (50.5 } \\
\text { years) }\end{array}$ & $\begin{array}{l}\text { EQ- } \\
5 \mathrm{D}=77.1 \\
\text { EQ } \\
\text { VAS=64.4 } \\
\text { DLQI=8.6 } \\
\text { PASI=11.4 }\end{array}$ & \multirow{2}{*}{$-0.17 *$} & \multirow{2}{*}{$-0.24 *$} & \multirow[b]{2}{*}{ - } & \multirow[b]{2}{*}{ - } & \multirow[b]{2}{*}{ - } \\
\hline & & $\begin{array}{l}\text { Cross- } \\
\text { validation } \\
\text { database: } \\
2,009 \\
(51,5 \\
\text { years) }\end{array}$ & $\begin{array}{l}\text { EQ- } \\
\text { 5D=n.a. } \\
\text { EQ- } \\
\text { VAS=64.5 } \\
\text { DLQI=7.5 } \\
\text { PASI=10.1 }\end{array}$ & & & & & \\
\hline $\begin{array}{l}\text { (Norlin et } \\
\text { al., 2012) }\end{array}$ & Sweden & $\begin{array}{l}2,450(54 \\
\left.\text { years }^{\S}\right)\end{array}$ & $\begin{array}{l}\text { EQ- } \\
5 \mathrm{D}=0.77^{\S} \\
\mathrm{DLQI}=4^{\S} \\
\text { PASI }=4.7^{\S}\end{array}$ & $-0.25^{*}$ & - & $-0.55^{*}$ & & $0.51^{*}$ \\
\hline \multirow{2}{*}{$\begin{array}{l}\text { (Hjortsbe } \\
\text { rg et al., } \\
\text { 2011) }\end{array}$} & Sweden & $\begin{array}{l}163(51 \\
\text { years) }\end{array}$ & \multirow{2}{*}{$\begin{array}{l}\text { EQ- } \\
5 \mathrm{D}=0.75 \\
\mathrm{DLQI}=6.8\end{array}$} & \multirow{2}{*}{-} & \multirow[b]{2}{*}{ - } & \multirow{2}{*}{$-0.52 *$} & \multirow{2}{*}{$-0.50^{*}$} & \multirow{2}{*}{-} \\
\hline & Finland & $\begin{array}{l}110(53 \\
\text { years })\end{array}$ & & & & & & \\
\hline
\end{tabular}

* indicates a statistical significance of $\mathrm{p}<0.05$ 


\subsubsection{Comparison with other EQ-5D studies in Iran}

A research conducted on 28 March 2017 on US National Library of Medicine, National Institutes of Health (Pubmed database, https://www.ncbi.nlm.nih.gov/pubmed/) to identify previous studies using the EQ-5D in Iran. The research detail was "eq-5d[All Fields] AND ("iran"[MeSH Terms] OR "Iran"[All Fields])".

Sixteen studies were found. Five numbers of studies were not related to Iran and Iranian, so as a result only 11 of them remained (Table 32).

The earliest study was published in year 2012, 2 studies in 2013, one study in 2014, 2 studies in 2015 and 5 studies in 2016. Our psoriasis study was among the 11 studies that were identified. (Moradi et al., 2015)

One study used EQ-5D and demographic questionnaire in their study on haemodialysis patients (Saffari et al., 2013). The other 10 studies used EQ-5D along with other kinds of methods or questionnaires, such as socio-demographic questionnaires, SF-36, TTO, VAS, DLQI, PASI, Type 2 Diabetes and Health Promotion Scale (T2DHPS). (Seyedifar et al., 2016, Karyani et al., 2016, Yousefi et al., 2016, Goudarzi et al., 2016, Assadi\&Afshari, 2016, Javanbakht et al., 2015, Moradi et al., 2015, Saffari et al., 2015, Hosseini Nejhad et al., 2013, Javanbakht et al., 2012)

A cross-sectional analytical study was conducted by Karyani et al. to measure HRQOL in Bthalassemia patients using ED-5D along with information about participants' demographic, socioeconomic, and health status was gathered. (Karyani et al., 2016) Another study also used ED-5D with information about participants' demographic in order to conduct their survey on patients with type 2 diabetes. (Saffari et al., 2015)

Six studies used Visual Analogue Scale (VAS) along with ED-5D including the paper we published. (Seyedifar et al., 2016, Goudarzi et al., 2016, Hosseini Nejhad et al., 2013, Javanbakht et al., 2012, Moradi et al., 2015, Assadi\&Afshari, 2016) 
Table 32 EQ-5D studies in Iran

\begin{tabular}{|c|c|c|c|c|c|c|}
\hline & $\begin{array}{l}\text { Author, } \\
\text { year }\end{array}$ & Method used & $\begin{array}{l}\text { Population } \\
\text { studied }\end{array}$ & $\begin{array}{l}\text { Sampl } \\
\text { e size }\end{array}$ & $\begin{array}{l}\text { Mean } \\
\text { EQ-5D } \\
\text { score }\end{array}$ & $\begin{array}{l}\text { Mean EQ } \\
\text { VAS score }\end{array}$ \\
\hline 1 & $\begin{array}{l}\text { (Seyedifar et } \\
\text { al., 2016) }\end{array}$ & EQ-5D-3L & $\begin{array}{l}\text { Beta } \\
\text { Thalassemia }\end{array}$ & 528 & $\begin{array}{l}0.85 \\
(\mathrm{SD} \\
0.01) \\
\end{array}$ & $\begin{array}{l}72.5 \\
(\mathrm{SD} 0.81)\end{array}$ \\
\hline 2 & $\begin{array}{l}\text { (Karyani et } \\
\text { al., 2016) }\end{array}$ & EQ-5D-3L & $\begin{array}{l}\text { General } \\
\text { population }\end{array}$ & 600 & $\begin{array}{l}0.74 \\
(\mathrm{SD} \\
0.16)\end{array}$ & N/A \\
\hline 3 & $\begin{array}{l}\text { (Yousefi et } \\
\text { al., 2016) }\end{array}$ & EQ-5D-5L, SF-6D & Breast cancer & 163 & $\begin{array}{l}0.685 \\
(0.216)\end{array}$ & $\mathrm{N} / \mathrm{A}$ \\
\hline 4 & $\begin{array}{l}\text { (Goudarzi et } \\
\text { al., 2016) }\end{array}$ & EQ-5D-3L, VAS & $\begin{array}{l}\text { General } \\
\text { population }\end{array}$ & 869 & N/A & $\begin{array}{l}79.58(\mathrm{SE} \\
0.54)\end{array}$ \\
\hline 5 & $\begin{array}{l}\text { (Assadi\& } \\
\text { Afshari, } \\
\text { 2016) }\end{array}$ & $\begin{array}{l}\text { TTO, VAS, EQ- } \\
\text { 5D-3L, EQ VAS }\end{array}$ & $\begin{array}{l}\text { Acute } \\
\text { poisoning }\end{array}$ & 82 & N/A & $45-81$ \\
\hline 6 & $\begin{array}{l}\text { (Javanbakht } \\
\text { et al., 2015) }\end{array}$ & $\begin{array}{l}\text { EQ-5D-3L, EQ } \\
\text { VAS, SF-36 }\end{array}$ & $\begin{array}{l}\text { Beta } \\
\text { Thalassemia }\end{array}$ & 196 & $\begin{array}{l}0.86 \\
(95 \% \\
\text { CI: } 0.83- \\
0.89)\end{array}$ & $\begin{array}{l}71.85(95 \% \\
\text { CI: } 69.13- \\
74.58)\end{array}$ \\
\hline 7 & $\begin{array}{l}\text { (Moradi et } \\
\text { al., 2015) }\end{array}$ & $\begin{array}{l}\text { EQ-5D-3L, EQ } \\
\text { VAS, DLQI, PASI }\end{array}$ & Psoriasis & 62 & $\begin{array}{l}0.62 \\
(0.37)\end{array}$ & $\begin{array}{l}60.18 \\
(27.26)\end{array}$ \\
\hline 8 & $\begin{array}{l}\text { (Saffari et } \\
\text { al., 2015) }\end{array}$ & $\begin{array}{l}\text { Type } 2 \text { Diabetes } \\
\text { and Health } \\
\text { Promotion Scale } \\
\text { (T2DHPS), EQ-5D- } \\
\text { 3L }\end{array}$ & $\begin{array}{l}\text { Type } 2 \\
\text { diabetes }\end{array}$ & 368 & $\mathrm{~N} / \mathrm{A}$ & N/A \\
\hline 9 & $\begin{array}{l}\text { (Hosseini } \\
\text { Nejhad et al., } \\
\text { 2013) }\end{array}$ & EQ-5D-3L, VAS & $\begin{array}{l}\text { Type } 2 \\
\text { diabetes }\end{array}$ & 3472 & N/A & N/A \\
\hline 10 & $\begin{array}{l}\text { (Saffari et } \\
\text { al., 2013) }\end{array}$ & EQ-5D-3L & $\begin{array}{l}\text { Haemodialysi } \\
\text { s }\end{array}$ & 362 & $\begin{array}{l}\text { Males: } \\
0.71 \text { (SD } \\
0.33) \text {, } \\
\text { Females: } \\
0.59 \text { (SD } \\
0.45)\end{array}$ & $\begin{array}{l}\text { Males: } \\
64.01 \text { (SD } \\
16.61) \\
\text { Females: } \\
0.479 \\
\text { Female } \\
65.47 \text { (SD } \\
21.72) \\
\end{array}$ \\
\hline 11 & $\begin{array}{l}\text { (Javanbakht } \\
\text { et al., 2012) }\end{array}$ & EQ-5D-3L, VAS & $\begin{array}{l}\text { Type } 2 \\
\text { diabetes }\end{array}$ & 3472 & $\begin{array}{l}0.70 \\
(95 \% \text { CI } \\
0.69- \\
0.71)\end{array}$ & $\begin{array}{l}56.8(95 \% \\
\text { CI 56.15- } \\
57.5)\end{array}$ \\
\hline
\end{tabular}

N/A: not available - scores were not reported in the study, only psychometric properties, e.g. correlations with other HRQOL instruments. 
The SF-36 measures general health in clinical studies and SF-6D is a classification for describing health derived from a section of SF-36. Yousefi and et al. compared the performance of the EQ-5D and the SF-6D in different state of breast cancer. (Yousefi et al., 2016) Another cross-sectional study, gathered data by using a socio-demographic questionnaire, EQ-5D, and SF-36 instruments on patients with $\beta$-thalassemia. (Javanbakht et al., 2015)

Mean EQ-5D-3L index score in psoriasis patients was 0.62, which is lower than experienced by patients with type 2 diabetes (0.70), breast cancer (0.69) and beta thalassemia (0.86) patients In Iran (Table 32).

\subsubsection{Comparison of cost-of-illness in psoriasis patients in Iran and Hungary}

Comparison of annual per patient costs of psoriasis in Iran and Hungary are presented in Table 33.

Table 33 Comparison of annual cost in psoriasis in Iran and Hungary

\begin{tabular}{|l|l|l|}
\hline \multirow{2}{*}{} & \multicolumn{2}{|c|}{ Mean EUR (SD) } \\
\cline { 2 - 3 } & \multicolumn{1}{|c|}{ Iran (2016) } & \multicolumn{1}{c|}{$\begin{array}{c}\text { Hungary (2012) } \\
\text { (Balogh et al., 2014) }\end{array}$} \\
\hline & \multicolumn{1}{|c|}{ N=62 } & \multicolumn{1}{c|}{ N=200 } \\
\hline TOTAL COSTS & $\mathbf{3 , 3 7 3}$ & $\mathbf{9 , 2 5 4}$ \\
\hline Direct medical costs & $\mathbf{7 8 9}(\mathbf{2 3 \%})$ & $\mathbf{7 , 5 9 5}(\mathbf{8 2 \%})$ \\
\hline GP visit & $26(0.8 \%)$ & $22(0.2 \%)$ \\
\hline Outpatient dermatologist visit & $42(1 \%)$ & $36(0.4 \%)$ \\
\hline Hospitalizations & $674(20 \%)$ & $136(1 \%)$ \\
\hline Topical and systemic non-biological therapy & $46(1 \%)$ & $256(3 \%)$ \\
\hline Biological therapy & - & $7,339(79 \%)$ \\
\hline Spa & $0.05(0.001 \%)$ & - \\
\hline Other & $0.36(0.01 \%)$ & $60(0.7 \%)$ \\
\hline Direct non-medical costs & $\mathbf{3 7 6 ( 1 1 \% )}$ & $\mathbf{1 4 8 ( 2 \% )}$ \\
\hline Informal care & $376(11 \%)$ & $117(1 \%)$ \\
\hline Transportation & N/A & $31(0.3 \%)$ \\
\hline Indirect costs (productivity loss) & $\mathbf{2 , 2 0 9 ( 6 5 \% )}$ & $\mathbf{1 , 2 5 5 ( 1 4 \% )}$ \\
\hline
\end{tabular}


Total per patient costs of psoriasis were almost three-fold in Hungary compared to Iran $(€ 9,254$ vs. $€ 3,373)$. The large difference in costs is attributable to the application of biological therapy in approximately $50 \%$ of the Hungarian sample. The major driver of costs in Iran was productivity loss (65\%), while biological therapy in Hungary (79\%). However, in Hungary the second largest cost item after biological therapy was productivity loss, accounting for $14 \%$ of the total costs. As opposed to Hungary, where biologics represented the largest part of direct medical costs, in Iran hospitalizations were responsible for $85 \%$ of the direct medical costs and $20 \%$ of the total costs. Costs of hospitalizations were almost 5 times higher in Iran (€674) compared to Hungary (€136). Interestingly, in Iran costs of informal care $(€ 376)$ also accounted for over times of that in Hungary (€117). (Mean annual cost of informal caregiving was €3.0 in Hungary and €3.42 in Iran. (Balogh et al., 2014) The comparison between the two countries clearly demonstrates how biological therapy has changed the management of psoriasis patients over the past decade. Biological therapy is very costly, nevertheless it reduces the number of hospitalizations, and therefore decrease the productivity loss in these patients; moreover less is spent on informal caregiving.

\subsubsection{Comparison of cost-of illness of psoriasis and other diseases in Iran}

Results of the most recent cost-of-illness studies from Iran in other diseases are summarized in Table 34. It seems that per patient annual costs of psoriasis are similar to that of chronic hepatitis B infection, but reasonably less than liver cirrhosis, hepatocellular carcinoma, breast cancer, gastric cancer, common variable immunodeficiency or thalassemia major. However, many chronic diseases such as diabetes, irritable bowel syndrome, gastro-oesophageal reflux (GERD) and dyspepsia account for significantly lower per patient annual costs in comparison

with psoriasis. It can be expected, nevertheless that annual per patient costs in a sample of psoriasis patients with high rate of biological therapy would double or triple the costs observed in our study.

A more precise and detailed comparison of other studies in Table 34 and our findings in psoriasis are hampered by the different perspectives of analysis, cost categories considered. 
Table 34 Recent cost-of-illness studies in Iran

\begin{tabular}{|c|c|c|c|c|c|}
\hline Author, year & Disease & $\begin{array}{c}\text { Cost categories } \\
\text { included (direct } \\
\text { medical, direct } \\
\text { non-medical, } \\
\text { indirect) }\end{array}$ & $\begin{array}{l}\text { Year } \\
\text { of } \\
\text { costs }\end{array}$ & Timeframe & $\begin{array}{l}\text { Per patient } \\
\quad \text { costs }\end{array}$ \\
\hline \multirow{3}{*}{$\begin{array}{l}\text { (Kavosi et al., } \\
\text { 2014) }\end{array}$} & Chronic hepatitis B & \multirow{3}{*}{ Direct and indirect } & \multirow{3}{*}{2012} & & 3095 USD \\
\hline & Liver cirrhosis & & & \multirow[t]{2}{*}{1 year } & 17,483 USD \\
\hline & Hepatocellular carcinoma & & & & 32,958 USD \\
\hline $\begin{array}{l}\text { (Esmaeilzadeh } \\
\text { et al., 2016) }\end{array}$ & Thalassemia Major & $\begin{array}{lr}\text { Direct } & \text { medical } \\
\text { costs, direct non- } \\
\text { medical costs, } \\
\text { indirect costs }\end{array}$ & 2015 & 1 year & 8322 USD \\
\hline $\begin{array}{l}\text { (Izadi et al., } \\
\text { 2016) }\end{array}$ & Gastric cancer & Direct costs & 2015 & 1 year & $\begin{array}{l}74,705,158 \text { IRR } \\
(60,141,384 \text { IRR } \\
\text { by the insurance } \\
\text { and } 14,563,774 \\
\text { by patients) }\end{array}$ \\
\hline \multirow{3}{*}{$\begin{array}{l}\text { (Zare et al., } \\
2016)\end{array}$} & Chronic hepatitis C & \multirow[t]{3}{*}{ Direct costs } & \multirow[t]{3}{*}{2015} & \multirow[t]{3}{*}{1 year } & 1,626 USD \\
\hline & Liver cirrhosis & & & & 6,117 USD \\
\hline & $\begin{array}{l}\text { Hepatocellular carcinoma } \\
\text { (HCC) }\end{array}$ & & & & $\begin{array}{l}11,044 \text { USD } \\
\text { (PPP) }\end{array}$ \\
\hline $\begin{array}{l}\text { (Sadeghi et al., } \\
\text { 2015) }\end{array}$ & $\begin{array}{l}\text { Common variable } \\
\text { immunodeficiency }\end{array}$ & $\begin{array}{l}\text { Direct, indirect and } \\
\text { intangible costs }\end{array}$ & 2015 & 1 year & 274,200 USD \\
\hline \multirow{5}{*}{$\begin{array}{l}\text { (Moghimi- } \\
\text { Dehkordi } \\
\text { al., 2011b) }\end{array}$} & $\begin{array}{l}\text { Irritable bowel syndrome } \\
\text { (IBS) }\end{array}$ & \multirow[t]{5}{*}{$\begin{array}{l}\text { Direct and indirect } \\
\text { costs }\end{array}$} & \multirow[t]{5}{*}{$\begin{array}{l}2006- \\
2007\end{array}$} & \multirow[t]{5}{*}{6 months } & 160 USD (PPP) \\
\hline & $\begin{array}{l}\text { Functional constipation } \\
\text { (FC) }\end{array}$ & & & & 147 USD (PPP) \\
\hline & $\begin{array}{l}\text { Unspecified-FBD } \\
\text { FBD) }\end{array}$ & & & & 103 USD (PPP) \\
\hline & $\begin{array}{l}\text { Functional abdominal } \\
\text { bloating (FAB) }\end{array}$ & & & & 96 USD (PPP) \\
\hline & Functional diarrhea (FD) & & & & 42 USD (PPP) \\
\hline \multirow{3}{*}{$\begin{array}{l}\text { (Moghimi- } \\
\text { Dehkordi } \\
\text { al., 2011a) }\end{array}$} & $\begin{array}{l}\text { Gastro-oesophageal reflux } \\
\text { (GERD) }\end{array}$ & \multirow[t]{3}{*}{$\begin{array}{l}\text { Direct } \\
\text { indirect cost }\end{array}$} & \multirow[t]{3}{*}{$\begin{array}{l}2006- \\
2007\end{array}$} & \multirow[t]{3}{*}{6 months } & $\begin{array}{ll}98+14 & \text { USD } \\
\text { (PPP) } & \\
\end{array}$ \\
\hline & Dyspepsia & & & & $108+12$ \\
\hline & GERD and dyspepsia & & & & $101+33$ \\
\hline $\begin{array}{l}\text { (Esteghamati } \\
\text { et al., 2009) }\end{array}$ & Diabetes & $\begin{array}{l}\text { Direct and indirect } \\
\text { costs }\end{array}$ & 2004 & 1 year & 152 USD \\
\hline $\begin{array}{l}\text { (Davari et al., } \\
\text { 2013) }\end{array}$ & Breast Cancer & medical & 2010 & 5 years & 10,905 USD \\
\hline
\end{tabular}




\subsubsection{Limitations}

Some limitations of this study should be noted. At first, sample size was quite small, however this study was a part of a larger study including a total of 262 psoriasis patients ( 200 psoriasis patients from Hungary and 62 from Iran). Most patients were presented with chronic plaque psoriasis and only a few patients involved with rare clinical types, e.g., pustular and erythrodermic psoriasis. All the patients treated by a single physician at a clinic in Shiraz, Iran. In the Iranian study, there were no inclusion criteria specified to this survey and hence, every patient regardless of disease severity was allowed to participate, while in the Hungarian study only patients with moderate-to-severe psoriasis were recruited. The cost analysis also has some important limitations. First, due to the retrospective study design patients might have had difficulties to recall all treatments and health care services they utilized. Secondly, no data were collected about travelling to physician's visits or to the hospital, thus this cost item was not included in the cost analysis. Finally, none of the patients of this study received biological therapies; however, infliximab, etanercept, and adalimumab have legal license for distribution in Iran. As biologicals have very high costs compared to any other treatments applied in psoriasis, the average per patient annual costs in this study are relevant only for a subgroup of patients, but not the entire psoriasis patient population of the country.

\subsubsection{Conclusions}

In conclusion, this is the first study from Iran that assesses HRQOL of psoriasis patients with EQ-5D and EQ VAS and the first cost-of-illness study in psoriasis patients. HRQOL impairment measured with either EQ-5D or EQ VAS is considerable; some or severe problems were most frequently emerged in anxiety/depression and pain/discomfort dimensions. Psoriasis patients have significantly decreased HRQOL measured by the EQ-5D compared to the general public in Iran. Moreover, EQ-5D scores evaluated in this study provide country-specific data for cost-utility analyses. Annual total costs of psoriasis in Iran exceeds $€ 3,000$ per patient, which is considerably higher than that of diabetes, gastroesophageal reflux disease or irritable bowel syndrome. The major cost drivers were

productivity loss, hospitalizations and informal care. Further researches are suggested to measure HRQOL and cost-of-illness in a larger sample and explore more variables that influence HRQOL and costs of Iranian psoriasis patients. 


\section{SUMMARY}

Specific points related to the topics of this thesis were discussed in details at the end of each chapter. Therefore, here I provide a brief summary of the main findings and highlight some points that are specifically relevant to Iran and point out some health economic and policy implications of the studies.

Technological innovation has brought a remarkable development to the health care sector over the past decades. In recent years, breakthroughs in various clinical fields have contributed greatly to the quality improvements in health care and the patient's condition.

However, due to the high costs of the new technologies, it became increasingly important to assess the health economic aspects of their introduction.

The process of priority setting and its criteria in Iran's health care system is not so transparent and explicit like in many developing countries. Health Technology Assessment (HTA) has been established in the healthcare system of Iran but what is needed is a clear political will to push HTA objectives forward. Health system in Iran has gone through several reforms in the past thirty years with many challenges and successes. Generally, health-sector reforms should include sustainable and purposeful changes to improve efficiency, equity, and effectiveness, otherwise change could be harmful rather than useful.

This thesis focused on HRQOL a key outcome in both clinical care and health economic analyses. HRQOL assessments rely on patients' reports, how they perceive their life affected by a disease. In health economic evaluations, however, societal perspective is used to evaluate different health states, therefore, it is important to understand how lay people value different aspects of health. In our first study (Chapter 5 An empirical investigation into the concept of health), therefore, we investigated the notion of health among the general population. Results suggest that people attach high importance both to emotional and physical factors (e.g., positive emotional feeling, optimism, fitness) and social aspects (e.g. goal and harmony, love). The study revealed some further aspects that are outside the narrow definition of health, i.e. people reported (among other factors) security, education, social 
responsibility, motivation, loving animals as relevant factors for health. This experimental study highlights how broad the concept of health can be across individuals and points out the importance of involving patients in medical decision-making by exploring their thoughts, perspective and needs regarding their health and treatment. More importantly, these findings open a nice avenue for further research by raising the question whether the health state evaluations (e.g. the EQ-5D questionnaire) used for health economic analyses sufficiently represent and cover all the important aspects that the society considers highly relevant for health.

Concept of health and the importance people attach to different attributes of it, how people perceive health, is highly influenced by cultural factors. These factors also can affect peoples' health related lifestyle, their decisions on participation in health care and acceptance of treatments. Therefore, subjective reports on health, the HRQOL results found in one jurisdiction are not necessarily applicable in other countries. Hence, the second empirical study (Chapter 6 Health-related quality of life and cost-of-illness of psoriasis patients in Iran) of this thesis aimed to adapt a Hungarian disease burden survey to Iran, in order to assess the HRQOL of Iranian patients with psoriasis and compare with the Hungarian results. Psoriasis is a lifelong dermatological chronic disease. Biological drugs have been developed in the past decades for the treatment of psoriasis and revolutionized psoriasis care being more effective than traditional treatments. However, biological drugs have put economic pressure on the societies due to their high costs. Availability and financing of these agents highly varies between countries, thus the benefits also bring challenges and concerns about the value for money. Nevertheless, there is very little information on the HRQOL and economic impact of the disease in the international literature, and practically none in Iran. Little is known on how people in Iran perceive psoriasis, how it affects their health, including their beauty/attractiveness perception, whether the disease has stigma effects and/or deterioration in sociability - aspects that can vary substantially between cultures and societies and thus cannot be directly transferred from one country to another. Moreover, there is a lack of HRQOL and cost data that hampers cost-effectiveness analyses based on country-specific inputs. 
Our findings revealed that the negative impact on patients' HRQOL was higher for men than women. In addition, the impact on HRQOL increased with the number of body areas involved by the disease. The highest negative impact on HRQOL was observed when the skin of the neck/décolletage region or hands were involved, and the lowest when the groin was affected. Comparison between the findings of Iranian and Hungarian study revealed that, disease severity, treatments, and culture or country-specific differences might lead to variations in the relationship between the outcome measures used in psoriasis. Furthermore, the study provided the first cost results in psoriasis in Iran. Average annual per patient costs of psoriasis exceed $€ 3,300$ with the main cost drivers are productivity loss, hospitalizations and informal care. With the widespread use of biologics to treat psoriasis in Iran, the costs are expected to soar, whereas based on experiences from other countries less hospitalizations, better HRQOL outcomes and less missed work hours can be expected.

This research has various economic and health policy implications for Iran. Although biological drugs brought the potential to dramatically change the management of patients with psoriasis, in Iran, access to biological drug treatment is limited. Due to the high cost of biological drugs, most of the patients cannot have access to the biologic therapies. Lack of insurance coverage of the biological drugs can lead to economic problems for the patient in obtaining them. Private companies (not related to the state) import these kinds of medicines and due to the frequent change of the currency value, the price of imported drugs are unstable. I believe that our findings can contribute to the improvement of psoriasis care by highlighting that this chronic skin disease imposes high burden on the individuals and has significant economic impact to the society. Moreover, our study provides reliable input data for costeffectiveness analyses of biological drugs that can support sustainable financing decisions and long-term health planning. Our experiences with adapting a disease burden survey from another country to Iran can serve as a useful experience for other clinical fields with lack of HRQOL and disease burden data. 


\section{PUBLICATIONS RELATED TO THE THESIS}

\section{Published papers}

MORADI, M., RENCZ, F.: GULÁCSI, L., MORADI, A., BROSZKY, V. (2015): Health status and quality of life in patients with psoriasis: Iranian cross-sectional survey. Arch Iran Med. 18(3), pp. 153-9. doi: 0151803/AIM.004. IF 0.931

MAGYARI-BECK I., MORADI M. (2014): Creative Techniques in the Framework of Market and Evolution. Society and Economy 36:(4) pp. 565-577. doi: 10.1556/SocEc.36.2014.4.7

MORADI, M., KOVÁCS, Á. (2017): Az egészségügyi forrás allokáció aktuális kérdései Iránban; egészségügyi technológiaelemzés. Köz-gazdaság. [accepted for publication]

\section{Other publications}

\section{Poster presentations}

MORADI, M. (2013): Pricing and reimbursement of pharmaceuticals in Iran. Value in Health, 16(7), pp. A474-A475., Presented at: International Society for Pharmacoeconomics and Outcomes Research (ISPOR) 16 ${ }^{\text {th }}$ Annual European Congress, 2-6 November 2013, Dublin, Ireland

BRODSZKY, V., MORADI, M., GULÁCSI, L., BAJI, P., BALOGH, O., PÉNTEK, M. (2013): Indirect comparison of the biologics in patients with psoriasis; a meta-analysis of randomized, double blind clinical trials in bayesian framework. Value in Health 16(7), pp. A501-A502.

Presented at: International Society for Pharmacoeconomics and Outcomes Research (ISPOR) $16^{\text {th }}$ Annual European Congress, 2-6 November 2013, Dublin, Ireland 
MORADI, M., RENCZ, F. (2014): A comparative cross-sectional study on health-related quality of life in psoriasis from Hungary and Iran. Value in Health, 17(7), p. A612., Presented at: International Society for Pharmacoeconomics and Outcomes Research (ISPOR) $17^{\text {th }}$ Annual European Congress, 8-12 November 2014, Amsterdam, The Netherlands

\section{Conference papers}

MORADI, M. (2013): Health system in Iran. PhD student conference at Corvinus University of Budapest, 30 May 2013

MORADI, M. (2014): Evaluation of the quality of life in patients with psoriasis; cross sectional study from Iran. Corvinus Health Policy and Health Economics Conference Series 2014/2, at Corvinus University of Budapest, 31 March 2014

MAGYARI-BECK I., MORADI M. (2014): An empirical investigation into the concept of health. [Гигиена Культуры.Здоровье культуры - культура здоровья]. Working paper presented at the Russian Conference. Budapest, 2014. 10. 14 - 19. Location: Russian Cultural Centre. 
ABBASI, M. (2012): Ethics in health technology assessment. Bioethics Journal, 2, pp. 101116.

AGHAEI, S., MORADI, A. \& ARDEKANI, G. S. (2009): Impact of psoriasis on quality of life in Iran. Indian J Dermatol Venereol Leprol, 75, p. 220.

AKAY, A., PEKCANLAR, A., BOZDAG, K. E., ALTINTAS, L. \& KARAMAN, A. (2002): Assessment of depression in subjects with psoriasis vulgaris and lichen planus. J Eur Acad Dermatol Venereol, 16, pp. 347-352.

AKOBUNDU, E., JU, J., BLATT, L. \& MULLINS, C. D. (2006): Cost-of-illness studies: a review of current methods. Pharmacoeconomics, 24, pp. 869-890.

AKSOY, B., ALTAYKAN-HAPA, A., EGEMEN, D. \& ATAKAN, N. (2011): Indicators of health quality in 154 Turkish patients with psoriasis. J Dermatol, 38, pp. 600-603.

AL-MAZEEDI, K., EL-SHAZLY, M. \& AL-AJMI, H. S. (2006): Impact of psoriasis on quality of life in Kuwait. Int J Dermatol, 45, pp. 418-424.

AL ROBAEE, A. A. \& ALZOLIBANI, A. A. (2011): Narrowband ultraviolet B phototherapy improves the quality of life in patients with psoriasis. Saudi Med J, 32, pp. 603-606.

ALI, F. M. \& CUEVA, A. C. (2017): A systematic review of the use of quality-of-life instruments in randomized controlled trials for psoriasis. Br J Dermatol, 176, pp. 577 593.

ALTUNAY, I. K., ATIS, G., ESEN, K. \& KUCUKUNAL, A. (2014): Impact of functional pruritus compared with mild psoriasis on quality of life: a cross-sectional questionnaire study in Turkey. Am J Clin Dermatol, 15, pp. 365-370.

AMMAR-KHODJA, A., BENKAIDALI, I., BOUADJAR, B., SERRADJ, A., TITI, A., BENCHIKHI, H., et al. (2015): EPIMAG: International Cross-Sectional Epidemiological Psoriasis Study in the Maghreb. Dermatology, 231, pp. 134-144.

ANSAR, A., JAHANGARD, L., PAHLEVANI, P., RASOULI, B., TORABIAN, S. \& RASOULI, S. (2013): Quality of life in patients with psoriasis vulgaris: A casecontrol study. Dermatology and Cosmetic, 4, pp. 113-119.

ANSARIPOUR, A., UYL-DE GROOT, C., STEENHOEK, A. \& REDEKOP, W. (2014): The Drug Reimbursement Decision-Making System in Iran. Value in Health Regional Issues, 3C, pp. 174-181.

ARAB-ZOZANI, M., HABIB JALILIAN, H., OSKOUEI, M., DEHGHANIAN, M. \& AGHBALAGHI, Z. (2017): Implementing health technology assessment in Iran: a stakeholder analysis. BMJ Open 7, pp. A1-A78.

ARNESEN, T. M. \& NORHEIM, O. F. (2003): Quantifying quality of life for economic analysis: time out for time tradeoff. Med Humanit, 29, pp. 81-86.

ARYANKHESAL, A., SHELDON, T. A. \& MANNION, R. (2013): Role of pay-forperformance in a hospital performance measurement system: a multiple case study in Iran. Health Policy Plan, 28, pp. 206-214. 
ASSADI, R. \& AFSHARI, R. (2016): Suicidal Attempt With Intentional Poisoning Seems a Comorbid Illness With an Increased Burden. Int J High Risk Behav Addict, 5, p. e24380.

ATAKAN, N., YAZICI, A. C., OZARMAGAN, G., INALOZ, H. S., GURER, M. A., SABUNCU, I., et al. (2016): TUR-PSO: A cross-sectional, study investigating quality of life and treatment status of psoriasis patients in Turkey. J Dermatol, 43, pp. 298-304.

BAGHESTANI, S., ZARE, S. \& MAHBOOBI, A.-A. (2005): Skin disease patterns in Hormozgan, Iran. International Journal of Dermatology, 44, pp. 641-645.

BAHADORI, M., RAVANGARD, R., ALIMOHAMMADZADEH, K. \& HOSSEINI, S. M. (2015): Plan and road map for health reform in Iran. Bmj, 351, p. h4407.

BALCI, D. D., INANDI, T., DOGRAMACI, C. A. \& CELIK, E. (2009): DLQI scores in patients with keloids and hypertrophic scars: a prospective case control study. J Dtsch Dermatol Ges, 7, pp. 688-692.

BALOGH, O., BRODSZKY, V., GULACSI, L., HEREDI, E., HERSZENYI, K., JOKAI, H., et al. (2014): Cost-of-illness in patients with moderate to severe psoriasis: a crosssectional survey in Hungarian dermatological centres. Eur J Health Econ, 15(Suppl 1), pp. S101-109.

BALTA, I., KARADAG, A. S., SELEK, S., ONDER, S., KANBAY, A. \& BURAKGAZIYILMAZ, H. (2016): General psychiatric symptoms, quality of sleep, and coping strategies in patients with psoriasis vulgaris. Int J Dermatol, 55, pp. 60-64.

BARADARAN-SEYED, Z. \& MAJDZADEH, R. (2012): Evidence-Based Health Care, Past Deeds at a Glance, Challenges and the Future Prospects in Iran. Iranian J Publ Health, 41, pp. 1-7.

BARAN, R. (2010): The burden of nail psoriasis: an introduction. Dermatology, 221(Suppl 1), pp. $1-5$.

BARATI MARNANI, A., TEYMOURZADEH, E., BAHADORI, M., RAVANGARD, R. \& SAEID POUR, J. (2012): Challenges of a large health insurance organization in iranA qualitative study. International Journal of Collaborative Research on Internal Medicine \& Public Health

BASAKHA, M., YAVARI, K., SADEGHI, H. \& NASERI, A. (2014): Health care cost disease as a threat to Iranian aging society. J Res Health Sci, 14, pp. 152-156.

BASAVARAJ, K. H., NAVYA, M. A. \& RASHMI, R. (2011): Stress and quality of life in psoriasis: an update. Int J Dermatol, 50, pp. 783-792.

BASRA, M. K., FENECH, R., GATT, R. M., SALEK, M. S. \& FINLAY, A. Y. (2008): The Dermatology Life Quality Index 1994-2007: a comprehensive review of validation data and clinical results. Br J Dermatol, 159, pp. 997-1035.

BEHESHTIAN, M., KHOSRAVI, A., OLYAEEMANESH, A., MALEKAFZALI, H., BONAKDAR ESFAHANI, S., HOSSEINY GHAVAMABAD, L., et al. (2015): Developing a household survey tool for health equity: A practical guide in Islamic Republic of Iran. Med J Islam Repub Iran, 29, p. 305.

BELLIENI, C. (2014): Sport, Disability and an Original Definition of Health. Zenit

BERGER, K., EHLKEN, B., KUGLAND, B. \& AUGUSTIN, M. (2005): Cost-of-illness in patients with moderate and severe chronic psoriasis vulgaris in Germany. J Dtsch Dermatol Ges, 3, pp. 511-518.

BEYER, V. \& WOLVERTON, S. E. (2010): Recent trends in systemic psoriasis treatment costs. Arch Dermatol, 146, pp. 46-54. 
BHOSLE, M. J., KULKARNI, A., FELDMAN, S. R. \& BALKRISHNAN, R. (2006): Quality of life in patients with psoriasis. Health and Quality of Life Outcomes, 4, pp. 35-35.

BILAC, C., ERMERTCAN, A. T., BILAC, D. B., DEVECI, A. \& HORASAN, G. D. (2009): The relationship between symptoms and patient characteristics among psoriasis patients. Indian J Dermatol Venereol Leprol, 75, pp. 551.

BILGIC, A., BILGIC, O., AKIS, H. K., ESKIOGLU, F. \& KILIC, E. Z. (2010): Psychiatric symptoms and health-related quality of life in children and adolescents with psoriasis. Pediatr Dermatol, 27, pp. 614-617.

BLAXTER, M. Health. (2010), Polity. Cambridge.

BLOME, C., BEIKERT, F. C., RUSTENBACH, S. J. \& AUGUSTIN, M. (2013): Mapping DLQI on EQ-5D in psoriasis: transformation of skin-specific health-related quality of life into utilities. Arch Dermatol Res, 305, pp. 197-204.

BOCCUZZI, S. J. (2003): Indirect Health Care Costs. In: WEINTRAUB, W. S. (ed.) Cardiovascular Health Care Economics. Humana Press. Totowa, NJ:

BOEHNCKE, W. H. \& SCHON, M. P. (2015): Psoriasis. Lancet, 386, pp. 983-994.

BORMAN, P., TOY, G. G., BABAOGLU, S., BODUR, H., CILIZ, D. \& ALLI, N. (2007): A comparative evaluation of quality of life and life satisfaction in patients with psoriatic and rheumatoid arthritis. Clin Rheumatol, 26, pp. 330-334.

BRAAKMAN-JANSEN, L., TAAL, E., KUPER, I. \& VAN DE LAAR, M. (2012): Productivity loss due to absenteeism and presenteeism by different instruments in patients with RA and subjects without RA. Rheumatology (Oxford) 51, pp. 354-361.

BRAZIER, J. E., YANG, Y., TSUCHIYA, A. \& ROWEN, D. L. (2010): A review of studies mapping (or cross walking) non-preference based measures of health to generic preference-based measures. Eur J Health Econ, 11, pp. 215-225.

BRODSZKY, V., BAJI, P., BALOGH, O. \& PENTEK, M. (2014): Budget impact analysis of biosimilar infliximab (CT-P13) for the treatment of rheumatoid arthritis in six Central and Eastern European countries. Eur J Health Econ, 15(Suppl 1), pp. S65-71.

BRODSZKY, V., RENCZ, F., PENTEK, M., BAJI, P., LAKATOS, P. L. \& GULACSI, L. (2016): A budget impact model for biosimilar infliximab in Crohn's disease in Bulgaria, the Czech Republic, Hungary, Poland, Romania, and Slovakia. Expert Rev Pharmacoecon Outcomes Res, 16, pp. 119-125.

BRONSARD, V., PAUL, C., PREY, S., PUZENAT, E., GOURRAUD, P. A., ARACTINGI, S., et al. (2010): What are the best outcome measures for assessing quality of life in plaque type psoriasis? A systematic review of the literature. J Eur Acad Dermatol Venereol, 24(Suppl 2), pp. 17-22.

BYFORD, S., TORGERSON, D. J. \& RAFTERY, J. (2000): Cost of illness studies. BMJ : British Medical Journal, 320, pp. 1335-1335.

CAKMUR, H. \& DERVIS, E. (2015): The relationship between quality of life and the severity of psoriasis in Turkey. Eur J Dermatol, 25, pp. 169-176.

CARRASCOSA, J. M., PUJOL, R., DAUDEN, E., HERNANZ-HERMOSA, J. M., BORDAS, X., SMANDIA, J. A., et al. (2006): A prospective evaluation of the cost of psoriasis in Spain (EPIDERMA project: phase II). J Eur Acad Dermatol Venereol, 20, pp. 840-845.

CHAN, B., HALES, B., SHEAR, N., HO, V., LYNDE, C., POULIN, Y., et al. (2009): Workrelated lost productivity and its economic impact on Canadian patients with moderate to severe psoriasis. J Cutan Med Surg, 13, pp. 192-197. 
CHANDRAN, V. \& RAYCHAUDHURI, S. P. (2010): Geoepidemiology and environmental factors of psoriasis and psoriatic arthritis. J Autoimmun, 34, pp. J314-321.

CHERAGHALI, A. (2006): Iran pharmaceutical market. Iran J. Pharm. Res, pp. 1-7.

CHERAGHALI, A. (2016): Newly Defined Role of Pharmacoeconomics in Iran National Medicine Policy. Shiraz E-Med J, 17, p. e35258.

CHERAGHALI, A. M. (2013): Impacts of international sanctions on Iranian pharmaceutical market. Daru, 21, pp. 64.

CHERAGHALI, A. M. (2017): Trends in Iran Pharmaceutical Market. Iran J Pharm Res, 16, pp. 1-7.

CHUANG, L. H. \& WHITEHEAD, S. J. (2012): Mapping for economic evaluation. Br Med Bull, 101, pp. 1-15.

CLEVERLEY, W. O. \& CAMERON, A. E. Essentials of Health Care Finance. (2007), Jones \& Bartlett Learning. Sudbury, Massachusetts.

COlOMBO, G. L., AltOMARE, G. F., PERIS, K., MARTINI, P., QUARTA, G., CONGEDO, M., et al. (2008): Moderate and severe plaque psoriasis: cost-of-illness study in Italy. Therapeutics and Clinical Risk Management, 4, pp. 559-568.

Constitution of the Islamic Republic of Iran. (1979).

COOPER, B. S. \& RICE, D. P. (1976): The economic cost of illness revisited. Soc Secur Bull, 39, pp. 21-36.

CURRIE, C. J. \& CONWAY, P. (2007): PSK11 evaluation of the association between EQ5D utility and dermatology life quality index (DLQI) score in patients with psoriasis. Value in Health, 10, pp. A470-A471.

CZIMBALMOS, Á., NAGY, Z., VARGA, Z. \& HUSZTIK, P. (1999): Páciens megelégedettségi vizsgálat. Népegészségügy, LXXX, pp. 4-19.

CSÍKSZENTMIHÁLYI, M. Flow The psychology of optimal experience (1990), Harperprennial. New York.

DAKIN, H. (2013): Review of studies mapping from quality of life or clinical measures to EQ-5D: an online database. Health Qual Life Outcomes, 11, pp. 151.

DALIENTO, L., MAPELLI, D. \& VOLPE, B. (2006): Measurement of cognitive outcome and quality of life in congenital heart disease. Heart, 92, pp. 569-574.

DAVARI, M., HAYCOX, A. \& WALLEY, T. (2012): The Iranian health insurance system; past experiences, present challenges and future strategies. Iran J Public Health, 41, pp. 1-9.

DAVARI, M., YAZDANPANAH, F., ASLANI, A., HOSSEINI, M., NAZARI, A. R. \& MOKARIAN, F. (2013): The Direct Medical Costs of Breast Cancer in Iran: Analyzing the Patient's Level Data from a Cancer Specific Hospital in Isfahan. Int J Prev Med, 4, pp. 748-754.

DE KORTE, J., SPRANGERS, M. A., MOMBERS, F. M. \& BOS, J. D. (2004): Quality of life in patients with psoriasis: a systematic literature review. J Investig Dermatol Symp Proc, 9, pp. 140-147.

DEHNAVIEH, R., NOORI HEKMAT, S., SEPEHRIAN, R., GHORBANI NIA, R. \& SHARIFI, T. (2015): Systematic review of prioritization criteria for topics of HTA projects: suggestions for Iran Journal of Novel Applied Sciences, 4, pp. 940-946.

DEMIREL, R., GENC, A., UCOK, K., KACAR, S. D., OZUGUZ, P., TOKTAS, M., et al. (2013): Do patients with mild to moderate psoriasis really have a sedentary lifestyle? Int J Dermatol, 52, pp. 1129-1134. 
DEVRIMCI-OZGUVEN, H., KUNDAKCI, T. N., KUMBASAR, H. \& BOYVAT, A. (2000): The depression, anxiety, life satisfaction and affective expression levels in psoriasis patients. J Eur Acad Dermatol Venereol, 14, pp. 267-271.

DINARVAND, R. (2009): New National Drug Policy in Iran leading to Expanded Pharmaceutical Market and Extended Access of Public to Medicines. Iranian Journal Public health, 38, pp. 158-161.

DOAEE, S., OLIYAEEMANESH, A., NEJATI, M., MOBINIZADEH, M., ABOEE, P. \& EMAMI RAZAVI, S. H. (2012): Establishment of health technology assessment in Iran Journal of Family and Reproductive Health 6, pp. 73-78.

DOLAN, P. (1997): Modeling valuations for EuroQol health states. Med Care, 35, pp. 10951108.

DONG, J. \& GOLDENBERG, G. (2017): New biologics in psoriasis: an update on IL-23 and IL-17 inhibitors. Cutis, 99, pp. 123-127.

DORMAN, P. J., WADDELL, F., SLATTERY, J., DENNIS, M. \& SANDERCOCK, P. (1997): Is the EuroQol a Valid Measure of Health-Related Quality of Life After Stroke? Stroke, 28, pp. 1876-1882.

DOSHMANGIR, L., RASHIDIAN, A., JAFARI, M., TAKIAN, A. \& RAVAGHI, H. (2015): Opening the Black Box: The Experiences and Lessons From the Public Hospitals Autonomy Policy in Iran. Arch Iran Med, 18, pp. 416-424.

DRIESSEN, R. J., BISSCHOPS, L. A., ADANG, E. M., EVERS, A. W., VAN DE KERKHOF, P. C. \& DE JONG, E. M. (2010): The economic impact of high-need psoriasis in daily clinical practice before and after the introduction of biologics. $\mathrm{Br} \mathbf{J}$ Dermatol, 162, pp. 1324-1329.

EDLUND, M. J. So What's Your Definition of Health? (2012) Available from: https://www.psychologytoday.com/blog/getting-healthy-now/201205/so-whatsyour-definition-health [Last accessed: 04/23/2017].

EL-DAROUTI, M. A., GAWDAT, H. I., HEGAZY, R. A., TAWDY, A. M., FAWZY, M. M. \& ABDEL HALIM, D. M. (2015): Crude Coal Tar and Ultraviolet (UV) A radiation (Modified Goeckerman Technique) in Treatment of Psoriasis. Acta Dermatovenerol Croat, 23, pp. 165-170.

Emergency Medical Services: Tariffs and Mandates for Private Ambulance Centers. (2017a) Available from: http://fouriyat.ir/ [Last accessed: 22/08/2017].

ESKIN, M., SAVK, E., USLU, M. \& KUCUKAYDOGAN, N. (2014): Social problemsolving, perceived stress, negative life events, depression and life satisfaction in psoriasis. J Eur Acad Dermatol Venereol, 28, pp. 1553-1559.

ESMAEILI, R., HADIAN, M., RASHIDIAN, A., SHARIATI, M. \& GHADERI, H. (2014): Family medicine in Iran: facing the health system challenges. Glob J Health Sci, 7, pp. 260-266.

ESMAEILZADEH, F., AZARKEIVAN, A., EMAMGHOLIPOUR, S., AKBARI SARI, A., YASERI, M., AHMADI, B., et al. (2016): Economic Burden of Thalassemia Major in Iran, 2015. J Res Health Sci, 16, pp. 111-115.

ESMAIL, E. S., ASAL, F. H., YUSSIF, M. \& ELFERT, A. A. (2015): Low dose ribavirin has been effective in the treatment of incapacitating muco-cutaneous extrahepatic manifestations in patients with hepatitis $\mathrm{C}$ with contraindication or no access for approved antiviral treatment. Arab J Gastroenterol, 16, pp. 125-128. 
ESTEGHAMATI, A., KHALILZADEH, O., ANVARI, M., MEYSAMIE, A., ABBASI, M., FOROUZANFAR, M., et al. (2009): The economic costs of diabetes: a populationbased study in Tehran, Iran. Diabetologia, 52, pp. 1520-1527.

European Medicines Agency Evaluation of Medicines for Human Use. Guideline on clinical investigation of medicinal products indicated for the treatment of psoriasis (2004) Available

from: http://www.ema.europa.eu/docs/en_GB/document_library/Scientific_guideline/200 9/09/WC500003329.pdf [Last accessed: 23/04/2017].

EUROQOLGROUP. (1990): EuroQol--a new facility for the measurement of health-related quality of life. Health Policy, 16, pp. 199-208.

FACEY, K. (2006): Health Technology Assessment (HTA) Glossary In: TOPFER, L.A., CHAN, L. (eds.) Health Technology Assessment. INAHTA Secretariat. Stockholm.

FAZAELI, S., AHMADI, M., RASHIDIAN, A. \& SADOUGHI, F. (2014): A framework of a health system responsiveness assessment information system for iran. Iran Red Crescent Med J, 16, p. e17820.

FELDMAN, B. M., GRUNDLAND, B., MCCULLOUGH, L. \& WRIGHT, V. (2000): Distinction of quality of life, health related quality of life, and health status in children referred for rheumatologic care. J Rheumatol, 27, pp. 226-233.

FELDMAN, S. R. (2000): Advances in Psoriasis Treatment. Dermatology Online Journal, 6, p. 4.

FERRANS, C. E., ZERWIC, J. J., WILBUR, J. E. \& LARSON, J. L. (2005): Conceptual model of health-related quality of life. J Nurs Scholarsh, 37, pp. 336-342.

FERREIRA, B. I., ABREU, J. L., REIS, J. P. \& FIGUEIREDO, A. M. (2016): Psoriasis and Associated Psychiatric Disorders: A Systematic Review on Etiopathogenesis and Clinical Correlation. J Clin Aesthet Dermatol, 9, pp. 36-43.

FINLAY, A. Y. (2005): Current severe psoriasis and the rule of tens. Br J Dermatol, 152, pp. 861-867.

FINLAY, A. Y. \& KHAN, G. K. (1994): Dermatology Life Quality Index (DLQI)--a simple practical measure for routine clinical use. Clin Exp Dermatol, 19, pp. 210-216.

FONIA, A., JACKSON, K., LEREUN, C., GRANT, D. M., BARKER, J. N. \& SMITH, C. H. (2010): A retrospective cohort study of the impact of biologic therapy initiation on medical resource use and costs in patients with moderate to severe psoriasis. $\mathrm{Br} \mathrm{J}$ Dermatol, 163, pp. 807-816.

FOURNIER, M. F. (2012): Knowledge mobilization in the context of health technology assessment: an exploratory case study. Health Res Policy Syst, 10, p. 10.

FREDRIKSSON, T. \& PETTERSSON, U. (1978): Severe psoriasis--oral therapy with a new retinoid. Dermatologica, 157, pp. 238-244.

GARRIDO, M. V., ORGANIZATION, W. H., SYSTEMS, E. O. O. H. \& POLICIES. Health Technology Assessment and Health Policy-making in Europe: Current Status, Challenges and Potential. (2008), World Health Organization.

GBD Mortality and Causes of Death Collaborators (2016): Global, regional, and national life expectancy, all-cause mortality, and cause-specific mortality for 249 causes of death, 1980-2015: a systematic analysis for the Global Burden of Disease Study 2015. Lancet, 388, pp. 1459-1544.

Georgetown University. National Center for Cultural Competence. Definitions of Health, Illness and Sickness. (2017b) Available from: 
https://nccc.georgetown.edu/body_mind_spirit/definitions_health_sickness.html [Last accessed: 23/04/2017].

GHAJARZADEH, M., GHIASI, M. \& KHEIRKHAH, S. (2012): Associations between skin diseases and quality of life: a comparison of psoriasis, vitiligo, and alopecia areata. Acta Med Iran, 50, pp. 511-515.

GHASSEMI, S. \& DEHNAVIEH, R. (2016): Applying the results of Health Technology Assessment reports in developing countries, the pale face of coin. Technol Health Care, 24, pp. 781-782.

GHATNEKAR, O., LJUNGBERG, A., WIRESTRAND, L. E. \& SVENSSON, A. (2012): Costs and quality of life for psoriatic patients at different degrees of severity in southern Sweden - a cross-sectional study. Eur J Dermatol, 22, pp. 238-245.

GINSBURG, I. H. \& LINK, B. G. (1989): Feelings of stigmatization in patients with psoriasis. J Am Acad Dermatol, 20, pp. 53-63.

GLADMAN, D. D., ANTONI, C., MEASE, P., CLEGG, D. O. \& NASH, P. (2005): Psoriatic arthritis: epidemiology, clinical features, course, and outcome. Ann Rheum Dis, 64(Suppl 2), pp. 14-17.

GODLEE, F. (2011): What is health? BMJ, 343, p. d4817.

GOKDEMIR, G., ARI, S. \& KOSLU, A. (2008): Adherence to treatment in patients with psoriasis vulgaris: Turkish experience. J Eur Acad Dermatol Venereol, 22, pp. 330335.

GOLICKI, D., NIEWADA, M., HOUT, B. V., JANSSEN, M. F. \& PICKARD, A. S. (2014): Interim EQ-5D-5L Value Set for Poland: First Crosswalk Value Set in Central and Eastern Europe. Value in Health Regional Issues, 4, pp. 19-23.

GONZAlEZ, J., CUNNINGHAM, K., PERLMUTTER, J. \& GOTTLIEB, A. (2016): Systematic Review of Health-Related Quality of Life in Adolescents with Psoriasis. Dermatology, 232, pp. 541-549.

GOODMAN, C. S. HTA 101: Introduction to Health Technology Assessment. (2004), publisher not identified.

GOUDARZI, R., ZERAATI, H., AKBARI SARI, A., RASHIDIAN, A. \& MOHAMMAD, K. (2016): Population-Based Preference Weights for the EQ-5D Health States Using the Visual Analogue Scale (VAS) in Iran. Iran Red Crescent Med J, 18, p. e21584.

GRAD, F. P. (2002): The Preamble of the Constitution of the World Health Organization. Bulletin of the World Health Organization, 80, pp. 981-981.

GROSS, P. R., LEVITT, N. \& LEWIS, M. W. The Flight from Science and Reason. (1996), New York Academy of Sciences. New York.

GULACSI, L., BONCZ, I. \& DRUMMOND, M. (2004): Issues for countries considering introducing the "fourth hurdle": the case of Hungary. Int J Technol Assess Health Care, 20, pp. 337-341.

GULÁCSI, L., BRODSZKY, V., BAJI, P., RENCZ, F. \& PÉNTEK, M. (2017): The Rituximab Biosimilar CT-P10 in Rheumatology and Cancer: A Budget Impact Analysis in 28 European Countries. Adv Ther (Advances in Therapy), 34, pp. 11281144.

GULER, S., TEKATAS, A., ARICAN, O., KAPLAN, O. S. \& DOGRU, Y. (2015): Restless legs syndrome and insomnia frequency in patients with psoriasis. Ideggyogy Sz, 68, pp. 331-336.

GUPTA, M. A., GUPTA, A. K. \& HABERMAN, H. F. (1987): Psoriasis and psychiatry: an update. Gen Hosp Psychiatry, 9, pp. 157-166. 
GUSI, N., OLIVARES, P. R. \& RAJENDRAM, R. (2010): The EQ-5D Health-Related Quality of Life Questionnaire. In: PREEDY, V. R. \& WATSON, R. R. (eds.) Handbook of Disease Burdens and Quality of Life Measures. Springer. New York.

GUTKNECHT, M., KRENSEL, M. \& AUGUSTIN, M. (2016): Health economic analyses of psoriasis management: a systematic literature search. Arch Dermatol Res, 308, pp. 601-616.

HAIDER, S., WAHID, Z., NAJAM US, S. \& RIAZ, F. (2014): Efficacy of Methotrexate in patients with plaque type psoriasis. Pakistan Journal of Medical Sciences, 30, pp. 1050-1053.

HAJIZADEH, M. \& NGHIEM, H. S. (2011): Out-of-pocket expenditures for hospital care in Iran: who is at risk of incurring catastrophic payments? Int J Health Care Finance Econ, 11, pp. 267-285.

HENSHALL, C., OORTWIJN, W., STEVENS, A., GRANADOS, A. \& BANTA, D. (1997): Priority setting for health technology assessment. Theoretical considerations and practical approaches. Priority setting Subgroup of the EUR-ASSESS Project. Int J Technol Assess Health Care, 13, pp. 144-185.

HERDMAN, M., GUDEX, C., LLOYD, A., JANSSEN, M. F., KIND, P., PARKIN, D., et al. (2011): Development and preliminary testing of the new five-level version of EQ5D (EQ-5D-5L). Quality of Life Research, 20, pp. 1727-1736.

HEREDI, E., RENCZ, F., BALOGH, O., GULACSI, L., HERSZENYI, K., HOLLO, P., et al. (2014): Exploring the relationship between EQ-5D, DLQI and PASI, and mapping EQ-5D utilities: a cross-sectional study in psoriasis from Hungary. Eur J Health Econ, 15(Suppl 1), pp. S111-119.

HJORTSBERG, C., BERGMAN, A., BJARNASON, A., HEIKKILA, H., HJELMGREN, J., SVENSSON, A., et al. (2011): Are treatment satisfaction, quality of life, and selfassessed disease severity relevant parameters for patient registries? Experiences from Finnish and Swedish patients with psoriasis. Acta Derm Venereol, 91, pp. 409-414

HODGSON, T. A. \& MEINERS, M. R. (1982): Cost-of-Illness Methodology: A Guide to Current Practices and Procedures. The Milbank Memorial Fund Quarterly. Health and Society, 60, pp. 429-462.

HONGBO, Y., THOMAS, C. L., HARRISON, M. A., SALEK, M. S. \& FINLAY, A. Y. (2005): Translating the science of quality of life into practice: What do dermatology life quality index scores mean? J Invest Dermatol, 125, pp. 659-664.

HOSSEINI NEJHAD, Z., MOLAVI VARDANJANI, H., ABOLHASANI, F., HADIPOUR, M. \& SHEIKHZADEH, K. (2013): Relative effect of socio-economic status on the health-related quality of life in type 2 diabetic patients in Iran. Diabetes Metab Syndr, 7, pp. 187-190.

HUBER, M., KNOTTNERUS, J. A., GREEN, L., VAN DER HORST, H., JADAD, A. R., KROMHOUT, D., et al. (2011): How should we define health? BMJ, 343, pp. d4163.

HURST, N. P., JOBANPUTRA, P., HUNTER, M., LAMBERT, M., LOCHHEAD, A. \& BROWN, H. (1994): Validity of EuroQol — a generic health status instrument-in patients with rheumatoid arthritiseconomic and health outcomes research group. Rheumatology, 33, pp. 655-662.

HYLAND, M. E. (1997): Quality-of-life measures as providers of information on value-formoney of health interventions. Comparison and recommendations for practice. Pharmacoeconomics, 11, pp. 19-31. 
ILLYÉS, G. Kháron ladikján (In Charon's Boat). (1976), Szépirodalmi könyvkiadó. Budapest, Hungary.

INANIR, I., AYDEMIR, O., GUNDUZ, K., DANACI, A. E. \& TUREL, A. (2006): Developing a quality of life instrument in patients with psoriasis: the Psoriasis Quality of Life Questionnaire (PQLQ). Int J Dermatol, 45, pp. 234-238.

IndexMundi (2017a): Age structure: Iran Available from: http://www.indexmundi.com/iran/age_structure.html [Last accessed: 22/08/2017].

IndexMundi (2017b): Iran GDP per capita (PPP) Available from: http://www.indexmundi.com/iran/gdp_per_capita_(ppp).html [Last accessed: 22/08/2017].

Institute for Health Metrics and Evaluation. (2017c) Available from: http://www.healthdata.org/results/country-profiles [Last accessed: 22/08/2017].

Institute for Health Metrics and Evaluation: Hungary. (2017d) Available from: http://www.healthdata.org/hungary [Last accessed: 22/08/2017].

Institute for Health Metrics and Evaluation: Iran. (2017e) Available from: http://www.healthdata.org/iran; [Last accessed: 22/08/2017].

IR Currency. (2017f) Available from: http://www.ircurrency.com/ [Last accessed: 22/08/2017].

ISKANDAR, I. Y., ASHCROFT, D. M., WARREN, R. B., LUNT, M., MCELHONE, K., SMITH, C. H., et al. (2017): Comparative effectiveness of biologic therapies on improvements in quality of life in patients with psoriasis. Journal.

Islamic Republic of Iran Health Sector Review-Volume II: Background Sections. (2008). WorldBank.

IZADI, A., SIRIZI, M. J., ESMAEELPOUR, S. \& BAROUNI, M. (2016): Evaluating Direct Costs of Gastric Cancer Treatment in Iran - Case Study in Kerman City in 2015. Asian Pac J Cancer Prev, 17, pp. 3007-3013.

JAMSHIDI, H. R., FOROUTAN, N. \& SALAMZADEH, J. (2014): "Budget impact analyses": a practical policy making tool for drug reimbursement decisions. Iran $\mathrm{J}$ Pharm Res, 13, pp. 1105-1109.

JAVANBAKHT, M., ABOLHASANI, F., MASHAYEKHI, A., BARADARAN, H. R. \& JAHANGIRI NOUDEH, Y. (2012): Health related quality of life in patients with type 2 diabetes mellitus in Iran: a national survey. PLoS One, 7, p. e44526.

JAVANBAKHT, M., KESHTKARAN, A., SHABANINEJAD, H., KARAMI, H., ZAKERINIA, M. \& DELAVARI, S. (2015): Comparison of Blood Transfusion Plus Chelation Therapy and Bone Marrow Transplantation in Patients with betaThalassemia: Application of SF-36, EQ-5D, and Visual Analogue Scale Measures. Int J Health Policy Manag, 4, pp. 733-740.

JEFFERSON, T., DEMICHELI, V. \& MUGFORD, M. Elementary Economic Evaluation in Health Care. (2000), BMJ Books. London.

JO, C. (2014): Cost-of-illness studies: concepts, scopes, and methods. Clinical and Molecular Hepatology, 20, pp. 327-337.

JOEL E, S. (2006): Cost-of-Illness Studies-A Primer. RTI-UNC Center of Excellence in Health Promotion Economics, pp. 1-39.

KARACA, S., FIDAN, F., ERKAN, F., NURAL, S., PINARCI, T., GUNAY, E., et al. (2013): Might psoriasis be a risk factor for obstructive sleep apnea syndrome? Sleep Breath, 17, pp. 275-280. 
KARYANI, A., RASHIDIAN, A., SEFIDDASHTI, S. \& SARI, A. (2016): Self-reported health-related quality of life (HRQOL) and factors affecting HRQOL among individuals with health insurance in Iran. Epidemiol Health. 38, p. e2016046.

KAVOSI, Z., ZARE, F., JAFARI, A. \& FATTAHI, M. R. (2014): Economic burden of hepatitis B virus infection in different stages of disease; a report from southern iran. Middle East J Dig Dis, 6, pp. 156-161.

KEBRIAEEZADEH, A., KOOPAEI, N. N., ABDOLLAHIASL, A., NIKFAR, S. \& MOHAMADI, N. (2013): Trend analysis of the pharmaceutical market in Iran; 19972010; policy implications for developing countries. Daru, 21, pp. 52.

KESHAVARZ, E., ROKNSHARI, S., SHIRALI MOHAMMADPOUR, R. \& ROKNSHARI, M. (2013): Clinical Features and Severity of Psoriasis: A Comparison of Facial and Nonfacial Involvement in Iran. Arch Iran Med, 16, pp. 25 -28.

KESHAVARZIAN, M. \& MOFIDIAN, S. (2014): An Overview on Iran Health Care Financing System: Challenges and Solutions. Journal of Health Policy and Sustainable Health, 1, pp. 131-136.

KHAMMARNIA, M., KESHTKARAN, A., KAVOSI, Z. \& HAYATI, R. (2014): The Household Health Spending and Impoverishment: Findings from the Households Survey in Shiraz, Iran. Bangladesh Med Res Counc Bull, 40, pp. 58-62.

KHANGAH, H., JANNATI, A., IMANI, A., SALIMLAR, S., DERAKHSHANI, N. \& RAEF, B. (2017): Comparing the Health Care System of Iran with Various Countries. Journal, 6, p. e34459.

KIMBALL, A. B., GUERIN, A., TSANEVA, M., YU, A. P., WU, E. Q., GUPTA, S. R., et al. (2011): Economic burden of comorbidities in patients with psoriasis is substantial. J Eur Acad Dermatol Venereol, 25, pp. 157-163.

LAJEVARDI, V., HALLAJI, Z., DAKLAN, S., ABEDINI, R., GOODARZI, A. \& ABDOLREZA, M. (2015): The efficacy of methotrexate plus pioglitazone vs. methotrexate alone in the management of patients with plaque-type psoriasis: a single-blinded randomized controlled trial. Int J Dermatol, 54, pp. 95-101.

LANKARANI, K., ALAVIAN, S. \& PEYMANI, P. (2013): Health in the Islamic Republic of Iran, challenges and progresses. Medical Journal of Islamic Republic of Iran, 27, pp. 42-49.

LARG, A. \& MOSS, J. R. (2011): Cost-of-illness studies: a guide to critical evaluation. Pharmacoeconomics, 29, pp. 653-671.

LARSEN, C. G., ANDERSEN, P. H., LORENTZEN, H., ZACHARIAE, C., HULDTNYSTROM, T., DOTTERUD, L. K., et al. (2013): Clinical and economic impact of etanercept in real-life: a prospective, non-interventional study of etanercept in the treatment of patients with moderate to severe plaque psoriasis in private dermatologist settings (ESTHER). Eur J Dermatol, 23, pp. 774-781.

LAYEGH, P., ARSHADI, H., SHAHRIARI, S., PEZESHKPOUR, F. \& NAHIDI, Y. (2010): A Comparative Study on the Prevalence of Depression and Suicidal Ideation in Dermatology Patients Suffering from Psoriasis, Acne, Alopecia Areata and Vitiligo. Iranian Journal of Dermatology pp. 106-111.

LE MOIGNE, M., SOMMET, A., LAPEYRE-MESTRE, M., BOURREL, R., MOLINIER, L., PAUL, C., et al. (2014): Healthcare cost impact of biological drugs compared with traditional systemic treatments in psoriasis: a cohort analysis in the French insurance database. J Eur Acad Dermatol Venereol, 28, pp. 1235-1244. 
LEBWOHL, M. (2005): A clinician's paradigm in the treatment of psoriasis. J Am Acad Dermatol, 53, pp. S59-69.

LEMAN, J. A. \& BURDEN, A. D. (2008): Treatment of severe psoriasis with infliximab. Therapeutics and Clinical Risk Management, 4, pp. 1165-1176.

LEVY, A. R., DAVIE, A. M., BRAZIER, N. C., JIVRAJ, F., ALBRECHT, L. E., GRATTON, D., et al. (2012): Economic burden of moderate to severe plaque psoriasis in Canada. Int J Dermatol, 51, pp. 1432-1440.

LEWIS, V. \& FINLAY, A. Y. (2004): 10 years experience of the Dermatology Life Quality Index (DLQI). J Investig Dermatol Symp Proc, 9, pp. 169-180.

LIPSCOMB, J., GOTAY, C. C. \& SNYDER, C. Outcomes Assessment in Cancer: Measures, Methods and Applications. (2004), Cambridge University Press. Cambridge.

LØNNBERG, A. S., ZACHARIAE, C. \& SKOV, L. (2014): Targeting of interleukin-17 in the treatment of psoriasis. Clinical, Cosmetic and Investigational Dermatology, 7, pp. 251-259.

LOTFI, F., GORJI, H., MAHDAVI, G. \& HADIAN, M. (2015): Asymmetric Information in Iranian's Health Insurance Market: Testing of Adverse Selection and Moral Hazard. Global Journal of Health Science, 7, pp. 146-155.

LOUDEN, B. A., PEARCE, D. J., LANG, W. \& FELDMAN, S. R. (2004): A Simplified Psoriasis Area Severity Index (SPASI) for rating psoriasis severity in clinic patients. Dermatol Online J, 10, p. 7.

LU, G., BRAZIER, J. E. \& ADES, A. E. (2013): Mapping from disease-specific to generic health-related quality-of-life scales: a common factor model. Value Health, 16, pp. 177-184.

MAUSKOPF, J. A., SUllivan, S. D., ANNEMANS, L., CARO, J., MUllinS, C. D., NUIJTEN, M., et al. (2007): Principles of good practice for budget impact analysis: report of the ISPOR Task Force on good research practices--budget impact analysis. Value Health, 10, pp. 336-347.

MCGREGOR, M. (2003): Cost-utility analysis: Use QALYs only with great caution. CMAJ: Canadian Medical Association Journal, 168, pp. 433-434.

MEASE, P. J. \& ARMSTRONG, A. W. (2014): Managing Patients with Psoriatic Disease: The Diagnosis and Pharmacologic Treatment of Psoriatic Arthritis in Patients with Psoriasis. Drugs, 74, pp. 423-441.

MEDICINE, I. \& TECHNOLOGY, C. H. C. Quality of Life and Technology Assessment. (1989), National Academies Press. Washington.

Medilexicon. (2014a) Available from: http://www.medilexicon.com/ [Last accessed: 23/04/2017].

MEEUWIS, K. A., DE HULLU, J. A., VAN DE NIEUWENHOF, H. P., EVERS, A. W., MASSUGER, L. F., VAN DE KERKHOF, P. C., et al. (2011): Quality of life and sexual health in patients with genital psoriasis. Br J Dermatol, 164, pp. 1247-1255.

MEHRDAD, R. (2009): Health System in Iran. JMAJ, 52, pp. 69-73.

MENTER, A. \& GRIFFITHS, C. E. (2007): Current and future management of psoriasis. Lancet, 370, pp. 272-284.

MENTER, A., KORMAN, N. J., ELMETS, C. A., FELDMAN, S. R., GELFAND, J. M., GORDON, K. B., et al. (2011): Guidelines of care for the management of psoriasis and psoriatic arthritis: section 6. Guidelines of care for the treatment of psoriasis and psoriatic arthritis: case-based presentations and evidence-based conclusions. J Am Acad Dermatol, 65, pp. 137-174. 
MERCAN, S., ALTUNAY, I. K., DEMIR, B., AKPINAR, A. \& KAYAOGLU, S. (2008): Sexual dysfunctions in patients with neurodermatitis and psoriasis. J Sex Marital Ther, 34, pp. 160-168.

MERHDAD, R. (2009): Health System in Iran. JMAJ, 52, pp. 69-73.

Merriam-Webster Collegiate Dictionary. (2014b), Merriam-Webster Inc. USA

MEYER, N., PAUL, C., FENERON, D., BARDOULAT, I., THIRIET, C., CAMARA, C., et al. (2010): Psoriasis: an epidemiological evaluation of disease burden in 590 patients. J Eur Acad Dermatol Venereol, 24, pp. 1075-1082.

MICHALEK, I. M., LORING, B. \& JOHN, S. M. (2017): A systematic review of worldwide epidemiology of psoriasis. Journal of the European Academy of Dermatology and Venereology, 31, pp. 205-212.

Ministry of Health and Medical Education- Food and Drug administration of Iran. (2017g) Available from: http://www.fda.gov.ir/en/ [Last accessed: 23/04/2017].

MOBINIZADEH, M., DOAVEE, S., OLYAEEMANESH, A., AZADBAKHT, M., NEJATI, M. \& ABOEE, P. (2014): Health Technology Assessment of CAD/CAM in Dentistry. Int J Travel Med Glob Health, 2, pp. 81-85.

MOBINIZADEH, M., RAEISSI, P., NASIRIPOUR, A., OLYAEEMANESH, A. \& TABIBI, S. (2016): A model for priority setting of health technology assessment: the experience of AHP-TOPSIS combination approach. Daru

MOGHIMI-DEHKORDI, B., VAHEDI, M., KHOSHKROOD MANSOORI, B., KASAEIAN, A., SAFAEE, A., HABIBI, M., et al. (2011a): Economic burden of gastro-oesophageal reflux disease and dyspepsia: A community-based study. Arab J Gastroenterol, 12, pp. 86-89.

MOGHIMI-DEHKORDI, B., VAHEDI, M., POURHOSEINGHOLI, M. A., KHOSHKROOD MANSOORI, B., SAFAEE, A., HABIBI, M., et al. (2011b): Economic burden attributable to functional bowel disorders in Iran: a cross-sectional population-based study. J Dig Dis, 12, pp. 384-392.

MOHTASHAM, F., YAZDIZADEH, B., ZALI, Z., MAJDZADEH, R. \& NEDJAT, S. (2016): Health technology assessment in Iran: Barriers and solutions. Med J Islam Repub Iran, 30, p. 321.

MONTAZERI, A., GOSHTASEBI, A., VAHDANINIA, M. \& GANDEK, B. (2005): The Short Form Health Survey (SF-36): Translation and validation study of the Iranian version. Quality of Life Research, 14, pp. 875-882.

MORADI-LAKEH, M., SHAKERIAN, S. \& ESTEGHAMATI, A. (2012): Immunization against Haemophilus Influenzae Type b in Iran; Cost-utility and Cost-benefit Analyses. Int J Prev Med, 3, pp. 332-340.

MORADI-LAKEH, M. \& VOSOOGH-MOGHADDAM, A. (2015): Health Sector Evolution Plan in Iran; Equity and Sustainability Concerns. Int J Health Policy Manag, 4, pp. 637-640.

MORADI, M., RENCZ, F., BRODSZKY, V., MORADI, A., BALOGH, O. \& GULACSI, L. (2015): Health status and quality of life in patients with psoriasis: an Iranian crosssectional survey. Arch Iran Med, 18, pp. 153-159.

MORK, C., OZEK, M. \& WAHL, A. K. (2004): [Psoriasis and psoriatic arthritis--is climate therapy a treatment or a leisure activity?]. Tidsskr Nor Laegeforen, 124, pp. 60-62.

MROWIETZ, U., KRAGBALLE, K., REICH, K., SPULS, P., GRIFFITHS, C. E. M., NAST, A., et al. (2011): Definition of treatment goals for moderate to severe psoriasis: a European consensus. Archives of Dermatological Research, 303, pp. 1-10. 
MUMFORD, L. \& WINNER, L. Technics and Civilization. (2010), University of Chicago Press. Chicago.

MUSTONEN, A., MATTILA, K., LEINO, M., KOULU, L. \& TUOMINEN, R. (2013): The Costs of Psoriasis Medications. Dermatology and Therapy, 3, pp. 169-177.

MUSTONEN, A., MATTILA, K., LEINO, M., KOULU, L. \& TUOMINEN, R. (2015): How much of the productivity losses among psoriasis patients are due to psoriasis. BMC Health Services Research, 15, p. 87.

NAHVIJOU, A., DAROUDI, R., TAHMASEBI, M., HASHEMI, F., HEMAMI, M., SARI, A., et al. (2016): Cost-Effectiveness of Different Cervical Screening Strategies in Islamic Republic of Iran: A Middle-Income Country with a Low Incidence Rate of Cervical Cancer. PLoS One, 11, p. e0156705.

NAJAFI, F., KARAMI-MATIN, B., REZAEI, S., RAJABI-GILAN, N. \& SOOFI, M. (2016): Health system responsiveness after health sector evolution plan (HSEP): An inpatient survey in Kermanshah in 2015. Medical Journal of the Islamic Republic of Iran, 30, pp. 387-387.

NAJARIAN, D. J. \& GOTTLIEB, A. B. (2003): Connections between psoriasis and Crohn's disease. J Am Acad Dermatol, 48, pp. 805-821.

NAS, K., CAPKIN, E., DAGLI, A. Z., CEVIK, R., KILIC, E., KILIC, G., et al. (2017): Gender specific differences in patients with psoriatic arthritis. Mod Rheumatol, 27, pp. 345-349.

NASSERI, K., SADRIZADEH, B., MALEK-AFZALI, H., MOHAMMAD, K., CHAMSA, M., CHERAGHCHI-BASHI, M. T., et al. (1991): Primary health care and immunisation in Iran. Public Health, 105, pp. 229-238.

NAST, A., ROSUMECK, S. \& SEIDENSCHNUR, K. (2015): Biosimilars: a systematic review of published and ongoing clinical trials of antipsoriatics in chronic inflammatory diseases. J Dtsch Dermatol Ges, 13, pp. 294-300.

NAVARINI, A. A., LAFFITTE, E., CONRAD, C., PIFFARETTI, P., BROCK, E., RUCKDAESCHEL, S., et al. (2010): Estimation of cost-of-illness in patients with psoriasis in Switzerland. Swiss Med Wkly, 140, pp. 85-91.

NIKBAKHT, A. \& KAFI, M. The history of traditional medicine and herbal plants in Iran 2008. International Society for Horticultural Science (ISHS), Leuven, Belgium, pp. 255-258.

NOJOMI, M., MORADI-LAKEH, M., VELAYATI, A., NAGHIBZADEH-TAHAMI, A., DADGOSTAR, H., GHORABI, G., et al. (2016): Health technology assessment of non-invasive interventions for weight loss and body shape in Iran. Med J Islam Repub Iran, pp. 76-83.

NOORBALA, M. T. \& KAFAIE, P. (2010): Pattern of skin diseases in the Central Iran Yazd. Journal of Pakistan Association of Dermatologists 20, pp. 137-141.

NORLIN, J. M., STEEN CARLSSON, K., PERSSON, U. \& SCHMITT-EGENOLF, M. (2012): Analysis of three outcome measures in moderate to severe psoriasis: a registry-based study of 2450 patients. Br J Dermatol, 166, pp. 797-802.

NOURAEI MOTLAGH, S., ABOLGHASEM GORJI, H., MAHDAVI, G. \& GHADERI, H. (2015): Main Determinants of Supplementary Health Insurance Demand: (Case of Iran). Glob J Health Sci, 7, pp. 285-294.

NOVIN, I. (2016): Iranian Pharmaceuticals Industry Analysis Report Journal.

Nursing Organization Of Islamic Republic Iran. (2017h) Available from: http://ino.ir/tabid/4076/ID/42746/ [Last accessed: 22/08/2017]. 
OLYAEEMANESH, A., DOAEE, S., MOBINIZADEH, M., NEDJATI, M., ABOEE, P. \& EMAMI-RAZAVI, S. (2014): Health technology assessment in Iran: challenges and views. Med J Islam Repub Iran

OLYAEEMANESH, A. \& MAJDZADEH, R. (2016): Health technology assessment: A necessity in post-sanctions Iran while implementing the health transformation plan. Med J Islam Repub Iran

ORLEWSKA, E. \& GULACSI, L. (2009): Budget-impact analyses: a critical review of published studies. Pharmacoeconomics, 27, pp. 807-827.

Oxford Dictionary of English. (2010): NY, USA, Oxford University Press.

PANDIT, N. Sociology \& Health for Physiotherapists. (2009), B.I. Publications Pvt. Limited. Delhi.

PARDASANI, A. G., FELDMAN, S. R. \& CLARK, A. R. (2000): Treatment of psoriasis: an algorithm-based approach for primary care physicians. Am Fam Physician, 61, pp. 725-733, 736.

PATEL, R. V., SHELLING, M. L., PRODANOVICH, S., FEDERMAN, D. G. \& KIRSNER, R. S. (2011): Psoriasis and vascular disease-risk factors and outcomes: a systematic review of the literature. J Gen Intern Med, 26, pp. 1036-1049.

PATHIRANA, D., ORMEROD, A., SAIAG.P, SMITH, C., SPULS.PI, NAST, A., et al. (2009): European S3-Guidelines on the systemic treatment of psoriasis vulgaris. JEADV, 23(Suppl 2), pp. 1-70.

PAUL, C., GOURRAUD, P. A., BRONSARD, V., PREY, S., PUZENAT, E., ARACTINGI, S., et al. (2010): Evidence-based recommendations to assess psoriasis severity: systematic literature review and expert opinion of a panel of dermatologists. J Eur Acad Dermatol Venereol, 24(Suppl 2), pp. 2-9.

PEARCE, D. J., SINGH, S., BALKRISHNAN, R., KULKARNI, A., FLEISCHER, A. B. \& FELDMAN, S. R. (2006): The negative impact of psoriasis on the workplace. J Dermatolog Treat, 17, pp. 24-28.

POLANYI, K. The Great Transformation: The Political and Economic Origins of Our Time. (1944), Beacon Press. Boston.

PopulationPyramid.net: Hungary. (2016a) Available from: https://www.populationpyramid.net/iran-islamic-republic-of/2016/ [Last accessed 22/08/2017].

PopulationPyramid.net: Iran (Islamic Republic of). (2016b) Available from: https://www.populationpyramid.net/iran-islamic-republic-of/2016/ [Last accessed 22/08/2017].

POURAHMAD, J. (2008): History of Medical Sciences in Iran. Iranian Journal of Pharmaceutical Research, 7, pp. 93-99.

POWER, S., GALLAGHER, J. \& MEANEY, S. (2009): Quality of life in health care workers with latex allergy. Occupational Medicine, 60, pp. 62-65.

PUNJABI, N. M. (2008): Patient Versus Proxy Ratings of Quality of Life. In: VERSTER, J. C., PANDI-PERUMAL, S. R. \& STREINER, D. L. (eds.) Sleep and Quality of Life in Clinical Medicine. Humana Press. Totowa, NJ.

PUZENAT, E., BRONSARD, V., PREY, S., GOURRAUD, P. A., ARACTINGI, S., BAGOT, M., et al. (2010): What are the best outcome measures for assessing plaque psoriasis severity? A systematic review of the literature. J Eur Acad Dermatol Venereol, 24(Suppl 2), pp. 10-16. 
RADTKE, M. A. \& AUGUSTIN, M. (2014): Biosimilars in psoriasis: what can we expect? J Dtsch Dermatol Ges, 12, pp. 306-312.

RAHO, G., KOLEVA, D. M., GARATTINI, L. \& NALDI, L. (2012): The burden of moderate to severe psoriasis: an overview. Pharmacoeconomics, 30, pp. 1005-1013.

RANDHEALTH. (2017): 36-Item Short Form Survey (SF-36). Available from: https://www.rand.org/health/surveys_tools/mos/36-item-short-form.html [Last accessed: 22/08/2017].

RATSON, G. A. The Meaning of Health: The Experience of a Lifetime. (2003), Trafford Publishing. Victoria, Canada.

REICH, K. (2009): Approach to managing patients with nail psoriasis. J Eur Acad Dermatol Venereol, 23(Suppl 1), pp. 15-21.

REILLY, M. C., ZBROZEK, A. S. \& DUKES, E. M. (1993): The validity and reproducibility of a work productivity and activity impairment instrument. Pharmacoeconomics, 4, pp. 353-365.

RENCZ, F., KEMENY, L., GAJDACSI, J. Z., OWCZAREK, W., ARENBERGER, P., TIPLICA, G. S., et al. (2015): Use of biologics for psoriasis in Central and Eastern European countries. J Eur Acad Dermatol Venereol, 29, pp. 2222-2230.

BMI REPORT (2016a): Iran Pharmaceuticals \& Healthcare Report Q3

IRAN PHARMACEUTICAL AND HEALTHCARE REPORT (2016b): Iran Pharmaceuticals \& Healthcare Report Q4. Journal.

BMI RESEARCH,. (2016): Iran Pharmaceuticals \& Healthcare Report - Includes 10-Year Forcasts To 2025.

RICE, D. P. (1994): Cost-of-illness studies: fact or fiction? Lancet, 344, pp. 1519-1520.

RYAN, S. (2008): Psoriasis: characteristics, psychosocial effects and treatment options. Br J Nurs, 17, pp. 284-290.

SAAD, A. A., HYRICH, K. L. \& ASHCROFT, D. M. (2011): Drug persistence, effectiveness and safety assessment of anti-TNF therapies in psoriatic arthritis. Expert Opin Drug Saf, 10, pp. 219-226.

SADEGHI, B., ABOLHASSANI, H., NASERI, A., REZAEI, N. \& AGHAMOHAMMADI, A. (2015): Economic burden of common variable immunodeficiency: annual cost of disease. Expert Rev Clin Immunol, 11, pp. 681-688.

SAFDARI, R., SAEEDI, M., VALINEJADI, A., BOURAGHI, H. \& SHAHNAVAZI, H. (2017): Technology Acceptance Model in health care centers of Iran. IJCSNS 17, p. 42.

SAFFARI, M., KARIMI, T., KOENIG, H. G. \& AL-ZABEN, F. (2015): Psychometric evaluation of the Persian version of the Type 2 Diabetes and Health Promotion Scale (T2DHPS): a diabetes-specific measure of lifestyle. Scand J Caring Sci, 29, pp. 603 612.

SAFFARI, M., PAKPOUR, A. H., NADERI, M. K., KOENIG, H. G., BALDACCHINO, D. R. \& PIPER, C. N. (2013): Spiritual coping, religiosity and quality of life: a study on Muslim patients undergoing haemodialysis. Nephrology (Carlton), 18, pp. 269-275.

SAHA, S. \& GERDTHAM, U. G. (2013): Cost of illness studies on reproductive, maternal, newborn, and child health: a systematic literature review. Health Economics Review, 3, pp. 24-24.

SCHÖFFSKI, O., AUGUSTIN, M., PRINZ, J., RAUNER, K., SCHUBERT, E., SOHN, S., et al. (2007): Costs and quality of life in patients with moderate to severe plaque-type 
psoriasis in Germany: A multi-center study. JDDG: Journal der Deutschen Dermatologischen Gesellschaft, 5, pp. 209-218.

SCHRAG, A., SELAI, C., JAHANSHAHI, M. \& QUINN, N. P. (2000): The EQ-5D--a generic quality of life measure-is a useful instrument to measure quality of life in patients with Parkinson's disease. J Neurol Neurosurg Psychiatry, 69, pp. 67-73.

SCHUESSLER, K. F. \& FISHER, G. A. (1985): Quality of Life Research and Sociology. Annual Review of Sociology, 11, pp. 129-149.

SEGEL, J. (2006): Cost of illness studies - A primer: RTI International. RTI-UNC Center of Excellence in Health Promotion Economics, 1, pp. 1-39.

SEYEDIFAR, M., DORKOOSH, F. A., HAMIDIEH, A. A., NADERI, M., KARAMI, H., KARIMI, M., et al. (2016): Health-Related Quality of Life and Health Utility Values in Beta Thalassemia Major Patients Receiving Different Types of Iron Chelators in Iran. Int J Hematol Oncol Stem Cell Res, 10, pp. 224-231.

SHAHRAZ, S., FOROUZANFAR, M. H., SEPANLOU, S. G., DICKER, D., NAGHAVI, P., POURMALEK, F., et al. (2014): Population health and burden of disease profile of Iran among 20 countries in the region: from Afghanistan to Qatar and Lebanon. Arch Iran Med, 17, pp. 336-342.

SHAW, J. W., JOHNSON, J. A. \& COONS, S. J. (2005): US valuation of the EQ-5D health states: development and testing of the D1 valuation model. Med Care, 43, pp. 203 220.

SHERMAN, E. J., PFISTER, D. G., RUCHLIN, H. S., RUBIN, D. M., RADZYNER, M. H., KELLEHER, G. H., et al. (2001): The collection of indirect and nonmedical direct costs (COIN) form. Cancer, 91, pp. 841-853.

SHIRVANI, A., OLYAEEMANESH, A., RABBANIKHAH, F. \& NEJATI, M. (2014): Establishment of Clinical Policy Making in Iran. Patient Saf Qual Improv., 2, pp. 101105.

SHIU, A. T. Y., CHOI, K. C., LEE, D. T. F., YU, D. S. F. \& MAN NG, W. (2014): Application of a health-related quality of life conceptual model in communitydwelling older Chinese people with diabetes to understand the relationships among clinical and psychological outcomes. Journal of Diabetes Investigation, 5, pp. 677686.

SIVAMANI, R. K., GOODARZI, H., GARCIA, M. S., RAYCHAUDHURI, S. P., WEHRLI, L. N., ONO, Y., et al. (2013): Biologic therapies in the treatment of psoriasis: a comprehensive evidence-based basic science and clinical review and a practical guide to tuberculosis monitoring. Clin Rev Allergy Immunol, 44, pp. 121-140.

SMITH, A. An Inquiry Into the Nature and Causes of the Wealth of Nations. (1776), W. Strahan and T. Cadell. London.

SMITH, K. C. (2000): Systemic therapy of psoriasis using methotrexate. Skin Therapy Lett, 6, pp. 1-5.

SMITH, O. \& NGUYEN, S. (2013): Getting better: improving health system outcomes in Europe and Central Asia. World Bank Publications.

Statistical Center for Iran. (2017i) Available from: https://www.amar.org.ir/english/ [Last accessed: 21/08/2017].

STEINKE, S. I. B., PEITSCH, W. K., LUDWIG, A. \& GOEBELER, M. (2013): Cost-ofIllness in Psoriasis: Comparing Inpatient and Outpatient Therapy. PLoS ONE, 8, p. e78152. 
SUKAROVSKA, B. G., LIPOZENCIC, J. \& VRZOGIC, P. (2007): Topical corticosteroids and corticosteroid sparing therapy in psoriasis management. Acta Med Croatica, 61, pp. 375-381.

SULLIVAN, G. M. \& ARTINO, A. R. (2013): Analyzing and Interpreting Data From LikertType Scales. J Grad Med Educ, 5, pp. 541-542.

TAKESHITA, J., GREWAL, S., LANGAN, S. M., MEHTA, N. N., OGDIE, A., VAN VOORHEES, A. S., et al. (2017a): Psoriasis and comorbid diseases: Epidemiology. J Am Acad Dermatol, 76, pp. 377-390.

TAKESHITA, J., GREWAL, S., LANGAN, S. M., MEHTA, N. N., OGDIE, A., VAN VOORHEES, A. S., et al. (2017b): Psoriasis and comorbid diseases: Implications for management. J Am Acad Dermatol, 76, pp. 393-403.

TALLI, S., ETCHETO, A., FAUTREL, B., BALANESCU, A., BRAUN, J., CANETE, J. D., et al. (2016): Patient global assessment in psoriatic arthritis - what does it mean? An analysis of 223 patients from the Psoriatic arthritis impact of disease (PsAID) study. Joint Bone Spine, 83, pp. 335-340.

TANG, M. M., CHANG, C. C., CHAN, L. C. \& HENG, A. (2013): Quality of life and cost of illness in patients with psoriasis in Malaysia: a multicenter study. Int J Dermatol, 52, pp. 314-322.

TARRICONE, R. (2006): Cost-of-illness analysis. Health Policy, 77, pp. 51-63.

TEZEL, N., YILMAZ TASDELEN, O., BODUR, H., GUL, U., KULCU CAKMAK, S., OGUZ, I. D., et al. (2015): Is the health-related quality of life and functional status of patients with psoriatic arthritis worse than that of patients with psoriasis alone? Int J Rheum Dis, 18, pp. 63-69.

The World Health Organization Quality of Life assessment (WHOQOL): position paper from the World Health Organization. (1995).

THE WORLDBANK DataBank, Iran, Islamic Republic. (2015) Available from: http://data.worldbank.org/country/iran-islamic-rep?view=chart [Last accessed: 23/04/2017].

THE WORLDBANK Mortality rate, infant (per 1,000 live births). (2017) Available from: http://data.worldbank.org/indicator/SP.DYN.IMRT.IN [Last accessed: 22/08/2017].

TILL, J. E., OSOBA, D., PATER, J. L. \& YOUNG, J. R. (1994): Research on health-related quality of life: dissemination into practical applications. Qual Life Res, 3, pp. 279283.

TORRANCE, G. W. \& FEENY, D. (1989): Utilities and quality-adjusted life years. Int J Technol Assess Health Care, 5, pp. 559-575.

Iran GDP per capita. (2017) Available from: https://tradingeconomics.com/iran/gdp-percapita [Last accessed: 21/08/2017].

TRISTANI-FIROUZI, P. \& KRUEGER, G. G. (1998): Efficacy and safety of treatment modalities for psoriasis. Cutis, 61, pp. 11-21.

TURAN, Y., DURUOZ, M. T. \& CERRAHOGLU, L. (2009): Relationship between enthesitis, clinical parameters and quality of life in spondyloarthritis. Joint Bone Spine, 76, pp. 642-647.

TUREL ERMERTCAN, A., TEMELTAS, G., DEVECI, A., DINC, G., GULER, H. B. \& OZTURKCAN, S. (2006): Sexual dysfunction in patients with psoriasis. J Dermatol, 33, pp. 772-778. 
Ullbro, C., CROSSNER, C. G., NEDERFORS, T., AlFADLEY, A. \& THESTRUPPEDERSEN, K. (2003): Dermatologic and oral findings in a cohort of 47 patients with Papillon-Lefevre syndrome. J Am Acad Dermatol, 48, pp. 345-351.

VAN VOORHEES, A. S. \& FRIED, R. (2009): Depression and quality of life in psoriasis. Postgrad Med, 121, pp. 154-161.

VELAYATI, A. (1988): An introduction to the history of medicine in Islam and Iran. Med J Islam Repub Iran, 2, pp. 131-136.

WAGSTAFF, A. \& EOZENOU, P.-V. (2016): CATA meets IMPOV: a unified approach to measuring financial protection in health. World Bank Policy Research Working Paper.

WAKKEE, M., THIO, H. B., SPULS, P. I., DE JONG, E. M. \& NIJSTEN, T. (2008): Evaluation of the reimbursement criteria for biological therapies for psoriasis in the Netherlands. Br J Dermatol, 158, pp. 1159-1161.

WARWICK-BOOTH, L., CROSS, R. \& LOWCOCK, D. Contemporary Health Studies: An Introduction. (2012), Polity. Cambridge.

WEINSTEIN, M. C., SIEGEL, J. E., GOLD, M. R., KAMLET, M. S. \& RUSSELL, L. B. (1996): Recommendations of the panel on cost-effectiveness in health and medicine. JAMA, 276, pp. 1253-1258.

WHITEHEAD, S. J. \& SHEHZAD, A. (2010): Health outcomes in economic evaluation: the QALY and utilities. British Medical Bulletin, 96, pp. 5-21.

WHO. The Ottawa Charter for Health Promotion. First International Conference on Health Promotion. (1986): Ottawa.

WHO. Report on the First Inter-Country Meeting on HealthTechnology Assessment (HTA): A tool for evidence informed decision making in health. (2013).

WHO. Iran (Islamic Republic of). (2017a) Available from: http://www.who.int/countries/irn/en/.

WHO. Islamic Republic of Iran - Health care financing. (2017b) Available from: http://www.emro.who.int/irn/programmes/healthfinancinguniversality.html.

WIEBE, S., GUYATT, G., WEAVER, B., MATIJEVIC, S. \& SIDWELL, C. (2003): Comparative responsiveness of generic and specific quality-of-life instruments. J Clin Epidemiol, 56, pp. 52-60.

WILSON, I. B. \& CLEARY, P. D. (1995): Linking clinical variables with health-related quality of life. A conceptual model of patient outcomes. Jama, 273, pp. 59-65.

WU, E. Q., MULANI, P., FARRELL, M. H. \& SLEEP, D. (2007): Mapping FACT-P and EORTC QLQ-C30 to Patient Health Status Measured by EQ-5D in Metastatic Hormone-Refractory Prostate Cancer Patients. Value in Health, 10, pp. 408-414.

YAMAUCHI, K., AKI, H., TOMOTAKE, M., IGA, J., NUMATA, S., MOTOKI, I., et al. (2008): Predictors of subjective and objective quality of life in outpatients with schizophrenia. Psychiatry Clin Neurosci, 62, pp. 404-411.

YANG, Y., BRAZIER, J. \& LONGWORTH, L. (2015): EQ-5D in skin conditions: an assessment of validity and responsiveness. Eur J Health Econ, 16, pp. 927-939.

YAZDANI, S. \& JADIDFARD, M. (2017): Developing a decision support system to link health technology assessment (HTA) reports to the health system policies in Iran. Health Policy Plan, 32, pp. 504-515.

YAZDIZADEH, B., SHAHMORADI, S., MAJDZADEH, R., DOAEE, S., BAZYAR, M., SOURESRAFIL, A., et al. (2016): Stakeholder involvement in health technology 
assessment at national level: a study from Iran. Int J Technol Assess Health Care, 32, pp. 181-189.

YOUSEFI, M., NAJAFI, S., GHAFFARI, S., MAHBOUB-AHARI, A. \& GHADERI, H. (2016): Comparison of SF-6D and EQ-5D Scores in Patients With Breast Cancer. Iran Red Crescent Med J, 18, p. e23556.

YU, A. P., TANG, J., XIE, J., WU, E. Q., GUPTA, S. R., BAO, Y., et al. (2009): Economic burden of psoriasis compared to the general population and stratified by disease severity. Curr Med Res Opin, 25, p. 2429-2438.

YUSEFZADEH, H., REZAPOUR, A., LOTFI, F., EBADIFARD AZAR, F., NABILO, B., ABOLGHASEM GORJI, H., et al. (2015): A Study of Comparative Advantage and Intra-Industry Trade in the Pharmaceutical Industry of Iran. Glob J Health Sci, 7, pp. 295-307.

ZANDI, S., SHAMSI MEYMANDI, S., HASHEMINASAB GORJI, S. \& SABOURI SHAHREBABAK, F. (2011): Evaluation of quality of life in patients with psoriasis. Dermatology and Cosmetic, 2, pp. 166-173.

ZANOLLI, M. (2003): Phototherapy treatment of psoriasis today. J Am Acad Dermatol, 49, pp. S78-86.

ZARE, F., FATTAHI, M. R., SEPEHRIMANESH, M. \& SAFARPOUR, A. R. (2016): Economic Burden of Hepatitis C Virus Infection in Different Stages of Disease: A Report From Southern Iran. Hepat Mon, 16, p. e32654.

ZARE, H., TRUJILLO, A. J., DRIESSEN, J., GHASEMI, M. \& GALLEGO, G. (2014): Health inequalities and development plans in Iran; an analysis of the past three decades (1984-2010). Int J Equity Health, 13, p. 42.

ZARGARAN, M., NIKFAR, S. \& CHERAGHALI, A. M. (2016): Evaluation of prescriptions of medicines not included in Iran medicine list: A cross-sectional study. J Res Pharm Pract, 5, pp. 234-237.

ZENG, J., LUO, S., HUANG, Y. \& LU, Q. (2017): Critical role of environmental factors in the pathogenesis of psoriasis. J Dermatol March 2017 [Ebub ahead of print] DOI: 10.1111/1346-8138.13806

ZGHAL, A., ZEGLAOUI, F., KALLEL, L., KARMOUS, R., BEN AMMAR, H., LABBANE, R., et al. (2003): [Quality of life in dermatology: Tunisian version of the Skindex-29]. Tunis Med, 81, pp. 34-37.

ZUG, K. A., LITTENBERG, B., BAUGHMAN, R. D., KNEELAND, T., NEASE, R. F., SUMNER, W., et al. (1995): Assessing the preferences of patients with psoriasis. A quantitative, utility approach. Arch Dermatol, 131, pp. 561-568. 


\section{APPENDICES}

\subsection{Appendix 1- Questionnaire}

In your opinion what factors contribute the most to the health of a person in general?

Degree of Importance in respect of health in general:

0: Most Irrelevant, 1: Irrelevant, 2: Not at all Relevant, 3: Neutral, 4: Less Relevant, 5: Relevant, 6: Most Relevant

Please do not answer if you do not understand the term.

\begin{tabular}{|l|l|l|l|l|l|l|l|l|}
\hline & Aspects & \multicolumn{6}{|c|}{ Degree of Importance } \\
\hline & & $\mathbf{0}$ & $\mathbf{1}$ & $\mathbf{2}$ & $\mathbf{3}$ & $\mathbf{4}$ & $\mathbf{5}$ & $\mathbf{6}$ \\
\hline $\mathbf{1}$ & Self-reproduction & & & & & & & \\
\hline $\mathbf{2}$ & Reproduction of society & & & & & & & \\
\hline 3 & Sociability & & & & & & & \\
\hline 4 & Well-balanced & & & & & & & \\
\hline 5 & Machine-like & & & & & & & \\
\hline 6 & Flow & & & & & & & \\
\hline 7 & Constructive Programs of Personality & & & & & & & \\
\hline 8 & Normal Genes & & & & & & & \\
\hline 9 & Identity or Rooted in one's Culture & & & & & & & \\
\hline 10 & Creativity & & & & & & & \\
\hline 11 & Longevity & & & & & & & \\
\hline 12 & Beauty & & & & & & & \\
\hline 13 & Attractiveness & & & & & & & \\
\hline 14 & Fitness & & & & & & & \\
\hline 15 & Workability & & & & & & & \\
\hline 16 & Ability to Relax & & & & & & & \\
\hline 17 & Sport & & & & & \\
\hline
\end{tabular}




\begin{tabular}{|l|l|l|l|l|l|l|l|l|}
\hline 18 & Goals, Harmony & & & & & & & \\
\hline 19 & Religiousness and Belief & & & & & & & \\
\hline 20 & Optimism & & & & & & & \\
\hline 21 & Realism & & & & & & & \\
\hline 22 & Maturity & & & & & & & \\
\hline 23 & Playfulness & & & & & & & \\
\hline 24 & Discipline & & & & & & & \\
\hline 25 & Lack of Illness & & & & & & & \\
\hline 26 & Engagement & & & & & & & \\
\hline 27 & Inner Freedom & & & & & & & \\
\hline 28 & Productivity & & & & & & & \\
\hline 29 & Innovativeness & & & & & & & \\
\hline 30 & Positive Emotional Feeling & & & & & & & \\
\hline 31 & Constructive Hobby & & & & & & & \\
\hline 32 & Morality & & & & & & & \\
\hline 33 & Love & Responsibility & & & & & & \\
\hline 34 &
\end{tabular}

Please write the names of any factor(s), which you think is/are important in the overall well-being of a person. 


\title{
10.2 Appendix 2 - Dermatology life quality index
}

\author{
DERMATOLOGY LIFE QUALITY INDEX (DLQI) \\ Hospital No: \\ Date: \\ Name: \\ Score: \\ Address: \\ Diagnosis:
}

The aim of this questionnaire is to measure how much your skin problem has affected your life OVER THE LAST WEEK. Please tick $(\checkmark)$ one box for each question.

1. Over the last week, how itchy, sore, painful or stinging has your skin been?

\begin{tabular}{|c|c|c|}
\hline $\begin{array}{l}\text { Very much } \\
\text { A lot } \\
\text { A little } \\
\text { Not at all }\end{array}$ & $\begin{array}{l}\square \\
\square \\
\square \\
\square\end{array}$ & \\
\hline $\begin{array}{l}\text { Very much } \\
\text { A lot } \\
\text { A little } \\
\text { Not at all }\end{array}$ & $\begin{array}{l}\square \\
\square \\
\square \\
\square\end{array}$ & \\
\hline $\begin{array}{l}\text { Very much } \\
\text { A lot } \\
\text { A little } \\
\text { Not at all }\end{array}$ & $\begin{array}{l}\square \\
\square \\
\square \\
\square\end{array}$ & Not relevant \\
\hline $\begin{array}{l}\text { Very much } \\
\text { A lot } \\
\text { A little } \\
\text { Not at all }\end{array}$ & $\begin{array}{l}\square \\
\square \\
\square \\
\square\end{array}$ & Not relevant \\
\hline $\begin{array}{l}\text { Very much } \\
\text { A lot } \\
\text { A little } \\
\text { Not at all }\end{array}$ & $\begin{array}{l}\square \\
\square \\
\square \\
\square\end{array}$ & Not relevant \\
\hline $\begin{array}{l}\text { Very much } \\
\text { A lot } \\
\text { A little } \\
\text { Not at all }\end{array}$ & $\begin{array}{l}\square \\
\square \\
\square \\
\square\end{array}$ & Not relevant \\
\hline $\begin{array}{l}\text { Yes } \\
\text { No }\end{array}$ & $\begin{array}{l}\square \\
\square\end{array}$ & Not relevant \\
\hline $\begin{array}{l}\text { A lot } \\
\text { A little } \\
\text { Not at all }\end{array}$ & $\begin{array}{l}\square \\
\square \\
\square\end{array}$ & \\
\hline $\begin{array}{l}\text { Very much } \\
\text { A lot } \\
\text { A little } \\
\text { Not at all }\end{array}$ & $\begin{array}{l}\square \\
\square \\
\square \\
\square\end{array}$ & Not relevant \\
\hline $\begin{array}{l}\text { Very much } \\
\text { A lot } \\
\text { A little } \\
\text { Not at all }\end{array}$ & $\begin{array}{l}\square \\
\square \\
\square \\
\square\end{array}$ & Not relevant \\
\hline $\begin{array}{l}\text { Very much } \\
\text { A lot } \\
\text { A little } \\
\text { Not at all }\end{array}$ & $\begin{array}{l}\square \\
\square \\
\square \\
\square\end{array}$ & Not relevant \\
\hline
\end{tabular}

Please check you have answered EVERY question. Thank you.

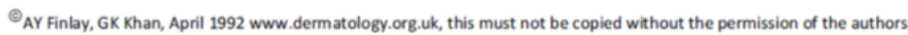




\subsection{Appendix 3- EQ-5D-3L}

By placing a tick in one box in each group below, please indicate which statements best describe your own health state today.

\section{Mobility}

I have no problems in walking about

I have some problems in walking about

I am confined to bed

\section{Self-Care}

I have no problems with self-care

I have some problems washing or dressing myself

I am unable to wash or dress myself

Usual Activities (e.g. work, study, housework, family or

leisure activities)

I have no problems with performing my usual activities

I have some problems with performing my usual activities

I am unable to perform my usual activities

\section{Pain/Discomfort}

I have no pain or discomfort

I have moderate pain or discomfort

I have extreme pain or discomfort

\section{Anxiety/Depression}

I am not anxious or depressed

I am moderately anxious or depressed

I am extremely anxious or depressed 
To help people say how good or bad a health state is, we have drawn a scale (rather like a thermometer) on which the best state you can imagine is marked 100 and the worst state you can imagine is marked 0 .

We would like you to indicate on this scale how good or bad your own health is today, in your opinion. Please do this by drawing a line from the box below to whichever point on the scale indicates how good or bad your health state is today.

\section{Your own health state \\ today}

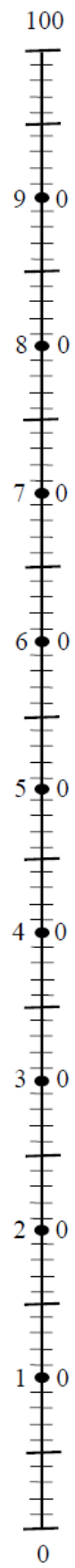

Worst imaginable health state 